\title{
Structural change in the link between oil and the European stock market: implications for risk management
}

https://doi.org/10.1515/demo-2019-0004

Received October 18, 2018; accepted March 29, 2019

\begin{abstract}
The relationship between the European stock market and the crude oil depends on the significance of the different industries in the European economy. The literature points to a structural change after the 2008 crisis without getting into details of which sectors lead this regime switch. The co-movement between oil prices and stock market is known to exhibit (1) non-linearity, (2) asymmetric tail dependence and (3) variation over time. I combine a copula approach with Switching Markov models to capture this complex linkage while the CoVaR measure translates the consequences of the tail dependence into potential losses. The results indicate a change in the lower tail dependence from negative to positive association between oil and Eurostoxx, meaning a shift in the exposure of our stock portfolio to commodity risk. There is a structural change in dependence after the 2008 financial crisis led by energy-intensive sector, e.g. basic materials and consumer goods. The economic cycle and its implications for profit margin and oil demand might explain this switch. Healthcare sector responds to oil shocks in an opposite way than Eurostoxx, displaying useful features to reduce the exposure of the stock portfolio to oil spillovers.
\end{abstract}

Keywords: conditional measures, oil prices, european industries, spillover, switching Markov regime, copula, stress test

AMS: 91G50, 91G60, 91B30, 91B84, 62M05

\section{Introduction}

The relationship between stock market and oil prices is a key topic extensively studied in the literature, given the several transmission channels that connect both markets. A large number of industries employ oil and petroleum products, such as kerosene or plastic materials, as input factors, so that higher input costs will generally affect firms' returns and sales price, triggering inflationary processes. The effects of oil shocks go beyond inflation and declines in corporate profits. A shock in oil prices may also show up in aggregate measures of output and employment ([36], [53], [40]). On the other hand, stock market returns are a high-frequency proxy of economic growth, so that analysing the stock market exposure to oil movements allows us to evaluate short-term effects of oil shocks on the economy.

The oil-stock link may well be sector specific, and it would then not be convenient to try to characterise it at the level of the stock market index. [12] show that the diversification opportunities to reduce the exposure

\footnotetext{
*Corresponding Author: Javier Ojea Ferreiro: Complutense University of Madrid and European Central Bank. Directorate Macroprudential Policy and Financial Stability, European Central Bank, Sonnemannstrasse 20, 60322 Frankfurt, Germany. Tel: +49691344 3336. Emails: jojea@ucm.es/Javier.Ojea_Ferreiro@ecb.europa.eu.

All errors are my own. The views expressed are those of the author and do not necessarily reflect those of the ECB.
} 
to oil prices arise across industries more than across countries. [62] and [60] realize that oil exposure depends on the role of the country as an oil provider or consumer. [48] point out that the domestic stock market index can dress up the impact of oil shocks on the economy depending on the sectoral diversification of each country. Hence, the discrepancies between countries might be due to a difference in their industrial production more than to a geographical issue. [10] suggest industry-specific factors within each region to explain differences in the same sectors across regions, such as the degree of oil consumption or the concentration in the industry. [11] also find high variability in oil exposure across sectors. The sensitivity to changes in oil prices is higher on oil-related industries ([54], [70], [17]). [48] indicate that energy-intensive sectors, like transportation or chemical industrials, have a great exposure to oil shocks in G7 economies. [55] obtain the same conclusions for the transport sector in developed countries.

The literature identifies several issues to be considered in the econometric analysis to avoid drawing misleading conclusions: non-linearities, structural breaks, asymmetric behaviour and tail dependence. Non-linearity shows up as a difference in correlation on average than on extreme scenarios. [23] points out that overlooking this feature may lead to deny any impact from oil on stock markets ([9], [21] and [41]). [64] highlights this characteristic in his analysis, finding structural breaks that explain a change in the dependence between oil and the stock market. A change in monetary policy, e.g. the introduction of the Euro ([54], [73]) or an economic crisis, e.g. the 2008 financial crisis ([68], [77]) may imply a structural break in the linkage between oil and stock markets. An asymmetric pattern, i.e. the different joint behaviour in a low-quantile than in a high-quantile scenario, must also be considered when analysing extreme co-movements in the stock market and oil prices. [6] provide evidence of an increase in the co-movement between both markets during acute periods of financial stress. Tail dependence, i.e. the probability of having very extreme realizations for stock market returns given very extreme realizations for oil returns, plays a key role in understanding the linkage under severe scenarios especially in the lower joint tail ([6], [56], [75]). Investors' herd behaviour during the contraction phase in the business cycle might also explain this feature.

Methodologically, the copula approach enables us to capture the asymmetric pattern exhibited by financial data. The greater flexibility of this state-of-the-art technique explains the increasing attention that has received in the latest years to carry out the analysis of spillovers between oil and stock markets ([73], [56], [75], [68], [51]). This approach allows for gathering more information about the distribution, which motivates its use in this study. To find possible structural changes in that linkage, the copula structure evolves according to Switching Markov specification. The Switching Markov approach is more robust to misspecification than other models employed to incorporate time-varying characteristics as [61]. ${ }^{1}$ This sophisticated technique identifies endogenously different regimes over time having a clear economic interpretation. Switching Markov models are ideal to capture regime switch episodes between oil shocks and economic variables, such as changes in output growth ([63], [24], [39], [25]), sector employment ([28]) or stock markets ([14], [64], [5]). To my knowledge no study has yet considered jointly the copula methodology with Switching Markov dynamics to analyse the link between oil and the European stock market. This methodological perspective allows for disclosing some hidden patterns inside the data, while shedding light on possible changes in joint tail dependence.

Unlike other articles that use a similar methodology ([69], [37]), this study does not use a SWARCH model to fit marginal behaviour for two reasons ${ }^{2}$. The first reason is related to the model parsimony whilst the second one concerns economic interpretation. Assuming a SWARCH model would lead to a significant increase in the number of parameters. To overcome this drawback, [69] and [37] assume an originating variable in the contagion process, so the switch in dependence will be dependent on the switch in variance

\footnotetext{
1 For a comparison between different specification for the evolution of dependence using copulas see for instance [50]. 2 There is an additional reason to reject a $S W-G A R C H$ model ([33], [15]): the computational complexity consequence of the path-dependence in the process.
} 
of one variable. Economically, we can not justify that oil or stock returns originate the change in the co-movement, because this swift may have diverse sources outside this bivariate relationship. Thinking about an implicit variable that leads the switch in the dependence between equity and oil returns has more sense. [26] find a common factor among different set of commodities that we could identify as a proxy of the external demand and international trade stability. Hence, it has sense to model the relationship depending on an endogenous probability that is not directly linked to the evolution of the marginal distributions.

I compute the impact of extreme movements in oil prices on the European stock market and its sectors, bearing in mind the non-linearity of that relationship, the possible structural changes and the asymmetric features exhibited by the co-movement between oil and stock markets. The focus on European industries plays a key role to understand the diversification advantages available during periods of great oscillations in oil prices. The aim of this article is to check the existence of a structural break in the relationship between oil prices and Eurostoxx, identifying the sectors leading such change as well as those that are useful to reduce the contagion from oil to a European stock portfolio. The study also deals with the challenge of translating the impact of oil spillover on stock markets into a quantitative measure convenient for risk management purposes. The change in the Value-at-Risk $(\mathrm{VaR})$ of the stock market when oil prices move abruptly measures the effect of tail dependence on the extreme quantiles of the stock market returns. The Conditional Value at Risk ( $\mathrm{CoVaR}$ ) provides a simple way to summarize complex information, such as the portfolio exposure to a commodity risk. It is therefore a perfect tool to understand the consequence of risk as potential losses.

The input data employed for our empirical analysis goes from the beginning of 2000 to the end of 2015 including several periods of crisis and potential structural breaks, e.g. the dot-com crisis, the 2008 financial crisis, the European debt crisis or the 2014 oil glut period. Our results are in line with the literature, finding a structural change after the financial crisis ([68]) and a high sensitivity to oil shocks of oil-related sectors and industries with high-energy requirements ([54], [48], [55]). Our findings indicates that the relationship between oil prices and the European stock market experienced a structural change after 2008 led by sectors with high consumption of oil. The relationship between the stock market and oil returns presents a strong asymmetric tail dependence. They had an asymmetric negative association before 2008 , with low quantiles of oil returns and high quantiles of stock returns having stronger dependence than high quantiles of oil returns and low quantiles of stock returns. The relationship became positive in the aftermath of the 2008 financial crisis, with lower tail dependence. The economic cycle and its implications for profit margin, oil demand and herd behaviour may explain the change in dependence. During the expansion phase of the business cycle a decrease in the price of a key production input as oil would increase the profit margin between sales price and the unit cost of production. On the other side, increases in oil prices entail a general rise in production costs which would be translated to sales prices. At the outset of the crisis firms ran into losses, the unemployment rate increased sharply and a substitution effect occurred between oil and employment ([28]) leading to a decrease in the oil demand as an input factor. In contrast to [68], which do not find dependence before 2008, our results point out to a negative association between variables. [68] use copulas that only allow for positive association, which might overlook the change in the relationship between oil and the stock market. This potentially misleading conclusion has serious implications for risk management because both sectors may then be assumed to be independent when actually, the stock portfolio is exposed to sharp changes in oil prices. The study presents the change in the Value-at-Risk at $5 \%$ and 95\% when oil prices experience a severe downward movement, i.e. bearish CoVaR, or an acute upward swing, i.e. bullish CoVaR. The differences between CoVaR and VaR values are found statistically significant using Kolgomorov-Smirnov (KS) bootstrapping test, specially after the 2008 financial crisis. The four-month period ahead forecast exercise using out-of-sample data from 2015 to 2018 indicates that adding the healthcare sector to the stock portfolio reduces the oil exposure.

This research has implications for investors and portfolio managers, who need risk management strategies to protect stock portfolio against extreme movements in oil prices; for market authorities, who have to supervise stock firms' quotes, measuring the exposure and impact of oil swings on the stock market; 
and for policy makers, who are concerned on a sector analysis regarding the effect of extreme changes in oil prices on the markets due to its consequences on growth, employment and household income. Financial institutions also need information concerning how the exposure to oil prices could affect firm's returns directly, for instance via positions in oil derivatives, and also indirectly through investment of financial firms in stock market.

The article is laid out as follows: Section 2 presents the CoVaR measure and the copula methodology using a Switching Markov model to produce time-varying copulas. Section 3 introduces the data and performs a descriptive analysis. Section 4 presents the results and section 5 concludes.

\section{Methodology}

This section is structured in three parts. The first part presents the CoVaR measure, in which the main results of the article are based on. Subsection 2.2 introduces the copula methodology and how to measure CoVaR using this approach. Finally subsection 2.3 highlights some features concerning the marginal and joint distribution model with particular attention to the time-varying specification for the dependence between variables, i.e. Switching Markov model.

\subsection{Conditional Value at Risk}

The Conditional Value at Risk (CoVaR) measure ([4], [32]) indicates in this study a quantile of the stock market returns given an sharp change in oil prices. CoVaR gives a conditional view of $V a R$ measure, which is widely employed for risk management purposes and capital buffer requirements in the financial sector. CoVaR translates spillovers from oil to stock market into potential losses in the stock market portfolio. The comparison between $\mathrm{CoVaR}$ and the unconditional $\mathrm{VaR}$ can give us an idea of the change in the risk measure when extreme oil scenarios occurs as an indicator of dependence. This way of looking at the link between oil and stock market is very convenient for investors, who get aware of the negative consequences of oil unhedging, and policy makers and market authorities, which need a quantitative estimate of the effects of swings in oil prices on stock markets.

CoVaR focuses on the tail of the distribution where non-linearities and asymmetries appear and where the effects of spillovers are more harmful. I compute four assessment of $\mathrm{CoVaR}$ depending on the oil-related scenario and the tail of the stock markets. The variable $r_{o}$ in the hereinafter notation refers to the conditioning variable, i.e. oil returns, and $r_{m}$ represents the conditioned variable, i.e. stock market returns. The subscript $t$ indicating the time is left out for notational convenience. I distinguish two types of scenarios for the oil returns: a bearish scenario where oil returns are below its $\alpha 100$ - th quantile, i.e. $P\left(r_{o}<\operatorname{VaR}(\alpha)\right)=\alpha$, and a bullish scenario where oil returns are above its highest $\alpha-$ th quantile, i.e. $P\left(r_{o}>\operatorname{VaR} R_{o}(1-\alpha)\right)=\alpha$. The bearish and bullish $\operatorname{CoVaR}_{m \mid o}(\alpha, \beta)$ are computed at a confidence level $\beta 100 \%$ for the stock market. Hence, setting the $\beta$ close to one and close to zero allows for analysing the effects of oil spillovers on the right and left tails of the distribution of stock market returns. The asymmetries in tail dependence and its changes over time justify the assessment of CoVaR for different scenarios and confidence levels.

The CoVaR measure comes from the Bayes' theorem and the copula representation of the joint distribution. Next subsection presents the copula methodology and shows how we can employ it to compute CoVaR. 


\subsection{CoVaR in terms of copulas}

Copulas functions provide a straightforward decomposition of the joint distribution. This property gives us higher flexibility to model complex joint distribution capturing diverse features as asymmetric dependence or strong joint tail behaviour. Sklar's theorem ([72]) states that a multivariate cumulative distribution function can be expressed as a combination of marginal cumulative distribution functions and a copula, i.e.

$$
F\left(r_{o}, r_{m}\right)=C\left(F_{o}\left(r_{o}\right), F_{m}\left(r_{m}\right)\right),
$$

where $F_{k}$ is the cumulative distribution function of variable $k=o, m$ and $C(\ldots)$ is the copula function. Bayes' theorem allows for expressing a conditional probability as the ratio of the joint probability of seeing both scenarios to the probability of observing the conditioning scenario. Copulas and rotated copulas provide us the expression for the joint probability. After solving the conditional probability equation, the CoVaR value is the result of using the inverse distribution function of the conditioned variable.

For instance, the bearish $\operatorname{CoVaR}_{m \mid o}(\alpha, \beta)$ of the market returns $m$ would be obtained implicitly from

$$
\begin{aligned}
P\left(r_{m}<\operatorname{CoVaR}_{m \mid o} \mid r_{o}<\operatorname{VaR}_{o}(\alpha)\right) & =\frac{P\left(r_{m}<\operatorname{CoVaR} R_{m}, r_{o}<\operatorname{VaR}_{o}(\alpha)\right)}{P\left(r_{o}<\operatorname{VaR}_{o}(\alpha)\right)} \\
& =\beta,
\end{aligned}
$$

where $P\left(r_{o}<\operatorname{VaR}_{o}(\alpha)\right)=\alpha$ and $P\left(r_{m}<\operatorname{CoVaR} R_{m \mid o}, r_{o}<\operatorname{VaR}_{o}(\alpha)\right)$ can be expressed as

$$
C\left(F_{m}\left(\operatorname{CoVaR}_{m \mid o}\right), \alpha\right) \text {. }
$$

The quantile $F_{m}\left(\operatorname{CoVaR}_{m \mid o}\right)$ is obtained by numerical optimization. ${ }^{3}$ Assessing CoVaR through copulas is faster and less time consuming than other approaches that imply integration methods. Then, the CoVaR value arises as the result of employing the inverse cumulative distribution function of the conditioned variable, i.e $F_{m}^{-1}\left(F_{m}\left(\operatorname{CoVaR}_{m \mid o}\right)\right)=\operatorname{CoVaR}_{m \mid o}$.

The bullish $\operatorname{CoVaR}_{m \mid o}(\alpha, \beta)$ of the stock market returns is obtained from

$$
\begin{aligned}
P\left(r_{m}<\operatorname{CoVaR}_{m \mid o} \mid r_{o}>\operatorname{VaR}_{o}(1-\alpha)\right) & =\frac{P\left(r_{m}<\operatorname{CoVaR}_{m \mid o}, r_{o}>\operatorname{VaR}_{o}(1-\alpha)\right)}{P\left(r_{o}>\operatorname{VaR}_{o}(1-\alpha)\right)} \\
& =\beta,
\end{aligned}
$$

where $P\left(r_{o}>\operatorname{VaR}_{o}(1-\alpha)\right)=\alpha$ and $P\left(r_{m}<\operatorname{CoVaR} R_{m \mid o}, r_{o}>\operatorname{Va} R_{o}(1-\alpha)\right)$ can be expressed as

$$
F_{m}\left(\operatorname{CoVaR}_{m \mid o}\right)-C\left(F_{m}\left(\operatorname{CoVaR}_{m \mid o}\right), 1-\alpha\right) \text {. }
$$

The CoVaR presents the same drawbacks than $\operatorname{VaR}$ as a risk measure, i.e. it is not sub-additive. The CoES overcomes the shortcomings of the CoVaR, i.e. it is a coherent risk measure ([3], [42]), which complements the information provided by the CoVaR. The Conditional Expected Shortfall (CoES) is the mean value of the variable beyond the CoVaR. We would focus on the mean returns below this threshold when the interest lies in the left tail of the conditional distribution, i.e.

$$
\operatorname{CoES}_{m \mid o}(\alpha, \beta)=\frac{1}{\beta} \int_{0}^{\beta} \operatorname{CoVaR}_{m \mid o}(\alpha, q) d q .
$$

whilst if the interest is on the right tail of the conditional distribution would be

$$
\operatorname{CoES}_{m \mid o}(\alpha, \beta)=\frac{1}{1-\beta} \int_{\beta}^{1} \operatorname{CoVaR}_{m \mid o}(\alpha, q) d q .
$$

3 Using MATLAB software and for certain values of $\alpha$ and $\beta$, the function fzero is employed to get $u^{\star}=F_{m}\left(\operatorname{CoVaR}_{m \mid o}\right)$. Note that only in case of independence between both markets $F_{m}\left(\operatorname{CoVaR} R_{m \mid o}\right)=\beta$. 


\subsection{Marginal distribution and joint dependence structure}

This subsection introduces the model for the marginal distribution and the copula functions that make up the joint distribution.

\subsubsection{Marginal model}

We characterise the marginal densities of the stock market $(m)$ and oil $(o)$ returns by an AR(p) model, i.e.

$$
r_{k, t}=\underbrace{\phi_{k, 0}+\sum_{j=1}^{p} \phi_{k, j} r_{k, t-j}}_{\mu_{k, t}}+\epsilon_{k, t}, \quad k=m, o
$$

where $p$ is a non-negative integer, $\phi_{k, j}$ are the autoregressive (AR) parameters with $j=0, \ldots, p$ and $\epsilon_{k, t}=$ $\sigma_{k, t} z_{k, t}$. The dynamic of the variance of $\epsilon_{k, t}$ follows a GJR - GARCH(1,1) specification, which allows for leverage effects, i.e.

$$
\sigma_{k, t}^{2}=\omega_{k}+\beta_{k} \sigma_{k, t-1}^{2}+\left(\alpha_{k}+\gamma_{k} \mathbb{1}_{k, t-1<0}\right) \epsilon_{k, t-1}^{2}, \quad k=m, o
$$

where $\omega_{k}, \beta_{k}$ and $\alpha_{k}$ are the GARCH parameters and $\mathbb{1}_{\epsilon_{k, t-1}<0}$ is an indicator function that values 1 if $\epsilon_{k, t-1}<0$ and zero otherwise. $\gamma_{k}$ captures leverage effects, i.e. negative shocks have more impact on variance than positive ones. When $\gamma_{k}=0$ we have the GARCH model. Furthermore, $z_{k, t}$ is a i.i.d. random variable with zero mean and unit variance that follows a [38]'s skewed-t distribution which allows us to capture higher moments, i.e. skewness and kurtosis.

The density of [38]'s skewed-t distribution is

$$
h\left(z_{k, t} \mid \eta_{k}, \lambda_{k}\right)=\left\{\begin{array}{ll}
b c\left(1+\frac{1}{\eta_{k}-2}\left(\frac{b z_{k, t}+a}{1-\lambda_{k}}\right)^{2}\right)^{-\left(\eta_{k}+1\right) / 2} & z_{k, t}<-a / b \\
b c\left(1+\frac{1}{\eta_{k}-2}\left(\frac{b z_{k, t}+a}{1+\lambda_{k}}\right)^{2}\right)^{-\left(\eta_{k}+1\right) / 2} & z_{k, t} \geq-a / b
\end{array},\right.
$$

where $2<\eta_{k}<\infty$ and $-1<\lambda_{k}<1$. The constants $a, b$ and $c$ are given by

$$
a=4 c \lambda_{k}\left(\frac{\eta_{k}-2}{\eta_{k}-1}\right), b=\sqrt{1+3 \lambda_{k}^{2}-a^{2}}, c=\frac{\Gamma\left(\frac{\eta_{k}+1}{2}\right)}{\sqrt{\pi\left(\eta_{k}-2\right)} \Gamma\left(\frac{\eta_{k}}{2}\right)} .
$$

Note that when $\lambda_{k}=0$ Equation (6) reduces to the standard Gaussian distribution as $\eta_{k} \rightarrow \infty$. When $\lambda_{k}=0$ and $\eta_{k}$ finite, we obtain the standardized symmetric-t distribution.

\subsubsection{Copula specification and time-varying features}

\subsubsection{Set of copulas}

I initially choose five types of copulas as potential dependence functions to fit the data because of their tail dependence features, i.e. Gaussian, Student t, Clayton, Gumbel, BB1. Gaussian and Student copulas allow for positive and negative association, while Gaussian copula has no tail dependence, Student $t$ copula has symmetric tail dependence. Gumbel and Clayton copulas allow only for positive asymmetric association, while Clayton copula has lower tail dependence, Gumbel copula has upper tail dependence. BB1 copula, also known as Clayton-Gumbel copula, allows only positive association, but it can be asymmetric. It has two parameters that model upper and lower tail dependence (See Table 1). Later on, the set of copulas is enhanced by rotating the Archimedean copulas, i.e. Gumbel, Clayton and BB1 copulas, to enable negative co-movement with implications for tail dependence. Appendix A provides further details about these copulas and their properties. 
Table 1: Main tail dependence features for each copula

\begin{tabular}{|c|c|c|}
\hline Family & $\tau_{L}$ & $\tau_{U}$ \\
\hline Gaussian & $-\quad($ if $\rho=1$ then 1$)$ & $-\quad($ if $\rho=1$ then 1$)$ \\
\hline Student t & $2 t_{\eta+1}\left(-\sqrt{\frac{(\eta+1)(1-\rho)}{1+\rho}}\right)$ & $2 t_{\eta+1}\left(-\sqrt{\frac{(\eta+1)(1-\rho)}{1+\rho}}\right)$ \\
\hline Clayton & $2^{-1 / \theta}$ & - \\
\hline Gumbel & - & $2-2^{1 / \theta}$ \\
\hline BB1 (Clayton-Gumbel) ${ }^{a}$ & $2^{-\frac{1}{\theta \delta}}$ & $2-2^{1 / \delta}$ \\
\hline
\end{tabular}

Note:

- - represents no tail dependence.

Source: [8, p. 22], [44], [46], [29] and [45, p. 193-204].

Let $u_{1}$ and $u_{2}$ denote two uniform-distributed variables across $(0,1)$.

- The lower tail dependence, $\tau_{L}$, is defined as $\tau_{L}=\lim _{q \rightarrow 0} P\left(u_{2}<q \mid u_{1}<q\right)$.

- The upper tail dependence, $\tau_{U}$ is defined as $\tau_{U}=\lim _{q \rightarrow 1} P\left(u_{2}>q \mid u_{1}>q\right)$.

\subsubsection{Model selection.}

An inaccurate copula choice can have serious consequences in the joint dependence construction, leading to mistaken interpretation of the relationship between variables. To avoid choosing a wrong copula, I use analytical and graphical tools to propose a set of copulas that fit the empirical evidence as potential dependence structures. In addition to that, I consider potential variations over time in the copula parameters and in the copula itself following a Switching Markov model.

I use graphical tools as contour plots, lambda functions and Tail Concentration Functions (TCF) and analytical tools as the Akaike Information Criterion Corrected for small-sample bias (AICC) to choose a suitable copula that fits the true data dependence. AICC is the principal indicator for copula selection ([18], [66], [67], [68], [69], [65]). The results are also analysed by looking at the confidence interval for the risk measure using bootstraping techniques.

\subsubsection{Switching Markov specification and estimation process}

The link between oil and stock market returns has been claimed to exhibit a structural change after the 2008 financial crisis according to recent literature, e.g. [68], [77]. Hence, I consider a two-regime Switching Markov model to replicate the evolution over time of the dependence structure, i.e. the changes in tail dependence across regimes. The switch can be limited to a change in the copula parameter or a change also in the copula itself depending on the empirical evidence provided by analytical and graphical tools. Each regime has an economic interpretation depending on the type of dependence observed within each state. The regimes are not directly observable but they can be identified from the estimation process.

The joint distribution is decompose following Equation (1) assuming that the copula function depends on a latent variable $s_{t}$ that reflects the kind of relationship in the co-movement between oil prices and the stock market, i.e.

$$
\left.F\left(r_{o, t}, r_{m, t}\right)=C\left(F_{o, t}\left(r_{o, t} ; \mu_{o, t}, \sigma_{o, t}, \eta_{o}, \lambda_{o}\right), F_{m, t}\left(r_{m, t} ; \mu_{m, t}, \sigma_{m, t}, \eta_{m}, \lambda_{m}\right)\right) ; \theta_{s_{t}}, s_{t}\right)
$$

where $\mu_{k, t}$ is given by Equation (4), $\sigma_{k, t}$ follows the dynamic in Equation (5) and $\eta_{k}, \lambda_{k}$ are the parameters from the innovation process in Equation (6) with $k=o, m . C\left(\ldots ; \theta_{s_{t}}, s_{t}\right)$ is the copula under the state $s_{t}$ with parameter $\theta_{s_{t}}$. To begin with, I constrain the copula switch to a simple change in its parameter $\theta_{s_{t}}$ on the assumption that the type of copula remains unchanged throughout the entire sample. Later on, this constraint is relaxed to allow for different copulas across regimes. In other words, the Switching Markov approach models the dependence between oil returns and stock markets returns as a copula mixture where the weights are given by the forecasting probabilities, i.e. $P\left(s_{t} \mid I_{t-1}\right)$ where $I_{t-1}$ indicates the information set at $t-1$. 
The copula of the conditional process depends on a regime, $s_{t}$, which is assumed to be stochastic and unobservable. The probability of being at each time $t$ in each state $s_{t}$ depends only on the state at $t-1$, i.e. the regime generating process follows a first order Markov chain defined by its transition probabilities

$$
p_{i j}=P\left(s_{t}=j \mid s_{t-1}=i\right)
$$

such that $\sum_{j=1}^{2} p_{i j}=1$ for $i=1,2$.

The transition matrix defined by the Markov Chain is

$$
P=\left[\begin{array}{cc}
p_{11} & 1-p_{22} \\
1-p_{11} & p_{22}
\end{array}\right],
$$

where $1-p_{11}=p_{12}$ and $1-p_{22}=p_{21}$ refer to the probability of changing between states and $p_{11}$ and $p_{22}$ are the probabilities of staying in the same state. For the sake of brevity the reader can find further details about the Switching Markov methodology in Appendix B.

The parameters are estimated using the full maximum likelihood method. The copula is assumed to be regime dependent, i.e. it moves according to a two-state Markov Chain $\left(s_{t}=1\right.$ and $\left.s_{t}=2\right)$. This assumption keeps the model tractable for estimation purposes but, at the same time, gives a great flexibility to identify changes in the linkage. At each time $t$ the likelihood for each observation can be written as

$$
L_{t}\left(r_{o, t}, r_{m, t} ; I_{t-1}, \Theta_{t}\right)=f\left(r_{o, t}, r_{m, t} \mid \Theta_{s_{t}=1}, I_{t-1}\right) P\left(s_{t}=1 \mid I_{t-1}\right)+f\left(r_{o, t}, r_{m, t} \mid \Theta_{s_{t}=2}, I_{t-1}\right) P\left(s_{t}=2 \mid I_{t-1}\right),
$$

where $\Theta_{t}$ stands for the set of parameters of the joint distribution at each state. This is a mixture of two joint distribution where the weights are given by the likelihood of being at each state. Deriving from Equation (1) we can rewrite $f\left(r_{o, t}, r_{m, t} \mid \Theta_{s_{t}=i}\right)$ as

$$
f_{o, t}\left(r_{o, t} ; \mu_{o, t}, \sigma_{o, t}, \eta_{o}, \lambda_{o}\right) f_{m, t}\left(r_{m, t} ; \mu_{m, t}, \sigma_{m, t}, \eta_{m}, \lambda_{m}\right) c\left(u_{o, t}, u_{m, t} ; \theta_{s_{t}=i}, s_{t}=i\right)
$$

where $u_{o, t}=F_{o, t}\left(r_{o, t} ; \mu_{o, t}, \sigma_{o, t}, \eta_{o}, \lambda_{o}\right), u_{m, t}=F_{m, t}\left(r_{m, t} ; \mu_{m, t}, \sigma_{m, t}, \eta_{m}, \lambda_{m}\right)$ and $c\left(\ldots ; \theta_{s_{t}=i}, s_{t}=i\right)$ is the copula density under the state $s_{t}=i$ with parameter $\theta_{s_{t}=i}$ with $i=1$, 2. It is worth noting that the loglikelihood function, i.e. $\sum_{t} \log \left(L_{t}\left(r_{o, t}, r_{m, t} ; I_{t-1}, \Theta_{t}\right)\right)$ has to be maximized using a non-linear method because this function depends in a non-linear way on the set of parameters. ${ }^{4}$

\section{Data}

I employ weekly data on stock market, exchange rate and commodity prices from 7 January 2000 to 23 October 2015. The length of the time series includes several crises where the oil prices have experienced great oscillations.

Concerning commodity prices, I use the spot prices of Europe Brent crude oil sourced from the US Energy Information Agency (http://www.eia.doe.gov). This is the main benchmark to settle the price of light crudes and it is a better proxy for oil price series than OPEC oil quote ([73]). Brent crude oil is denominated in dollars per barrel, so it is transformed into Euros to perform the empirical exercise. The EUR/USD exchange rate is obtained from the European Central Bank Statistical Data Warehouse (https://sdw.ecb.europa.eu).

Regarding the European stock market variables, I employ the EUROSTOXX index and its ten-industry decomposition based on the Industry Classification Benchmark (ICB) nomenclature obtained from Datastream (oil \&

4 The fminsearch function in MATLAB software provides good estimates while some transformation of the parameters are performed to keep them in a feasible region. For instance instead of looking for values of $p_{11}$ and $p_{22}$, I obtain the optimal estimate for a parameter $x$ and $y$ such that $1 /(1+\exp (-x))=p_{11}$ and $1 /(1+\exp (-y))=p_{22}$. [35] employ this kind of transformations to estimate the parameters of its $S W A R C H$ model. 
gas, basic materials, industrials, consumer goods, healthcare, consumer services, telecommunications, utilities, financials, technology). This set of variables makes possible to measure not only the joint effect of large swings in oil prices on the European economy as a whole but also on the different productive industries.

Table 2 reports the main statistics for the stock market returns and the oil returns denominated in Euros. It considers the full sample and two subsamples where 15 September 2008 is established as a breakpoint after the fall of Lehman Brothers and the consequent onset of the financial crisis. The post-crisis subsample shows higher kurtosis and standard deviation. It also shows a more negative skewness and mean than the pre-crisis subsample. The p-value of Jarque Bera indicates the importance of higher moments in the distribution, supporting the choice of [38]'s skewed t distribution for the marginals. The correlation between stock market returns and oil returns increases after the financial crisis. In some cases, as in the health care sector, the correlation moves from negative values to positive ones after the 2008 crisis. Figure 1 shows the time varying correlation between oil and Eurostoxx (blue line), oil and basic materials (red line) and oil and heath care sector (yellow line). We get the time-varying correlation using a rolling windows approach on the weekly returns with a five-year windows length. Two main conclusions are inferred from this figure. First, the health care sector presents lower correlation throughout the entire sample than basic materials or Eurostoxx. Second, around 2008-2009 the correlation between these stock returns and oil returns experiences a sharp upward movement which might be an indication of regime switch. This evidence is also shown in the empirical joint distribution of Figure 2.

Figure 2 shows an approximation to the joint distribution of Eurostoxx returns and oil returns. Axis shows the empirical cumulative distribution function, i.e. $\tilde{F}\left(r_{i, t}\right)=\frac{\sum_{t=1}^{T} \mathbb{1}_{r_{i, t}} r_{i, j}}{T+1}$. The probability space is divided into 25 areas where each area indicates a interquintile range for each variable. The colour of each area depends on the probability mass observed, the darker colours indicate a higher clustering of data. For instance a darker colour in the bottom left corner of the graph indicates the higher density of pairwise observations when both returns are in their lowest quintile, i.e. there is a higher dependence in the lower tail.

Figure 3 shows the empirical joint distribution between the oil and the different sectors of the stock market. Left set of subfigures refer to the full period while center and right set of subfigures consider respectively the observations in the pre-crisis and post-crisis sample. The relationship between oil and basic materials or health care sectors seems to change from a negative dependence in the pre-crisis period to a positive tail dependence in the post-crisis phase. This change in linkage is ignored if we look at the full sample. There are evidences concerning a structural change during the analysed period justifying the Switching Markov choice.

\section{Results}

This section is divided in two parts. The first subsection focuses in estimation results. It identifies structural changes in the co-movement between oil and stock market, paying special attention to the swing in tail dependence, and its impact on model risk. The second subsection studies the implications of this change on the joint behaviour for risk measures. I employ the CoVaR measure to quantify the effects of extreme movements in oil prices on the VaR estimates of the stock market. To close this section, I perform an out-of-sample forecast exercise building a stock portfolio without tail dependence with oil returns.

\subsection{Estimation results}

This subsection shows three set of results where the constraints and assumptions are gradually relaxed.

First, I present the results of the estimates with constant dependence parameters for the considered set of copulas. I study a possible change in dependence after the 2008 financial crisis using different graphical tools as lambda functions and Tail Concentration Functions (TCF).

Second, I relax the constraint regarding the fixed dependence over time while assuming an unchanged type 


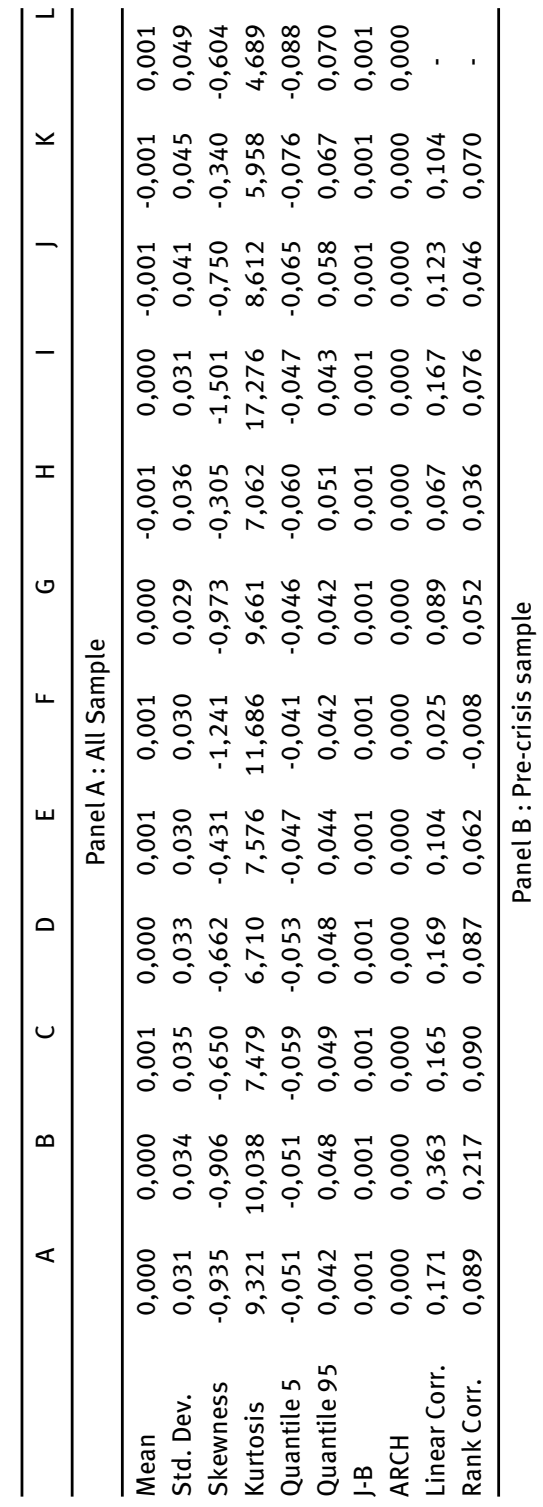

$$
\text { 웅 }
$$

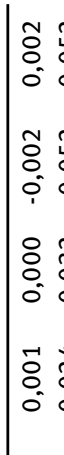

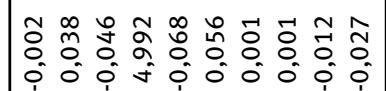

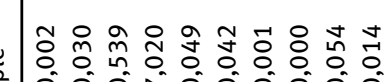
空

(8)

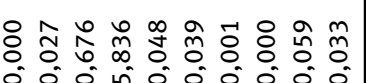

8.

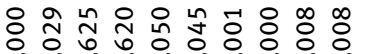

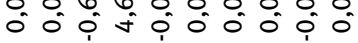

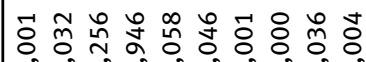

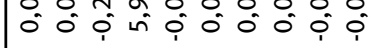

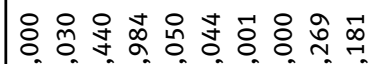

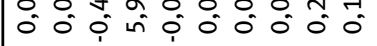

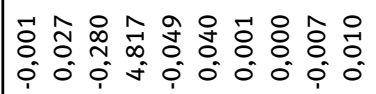

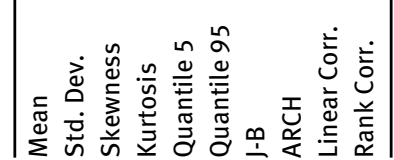

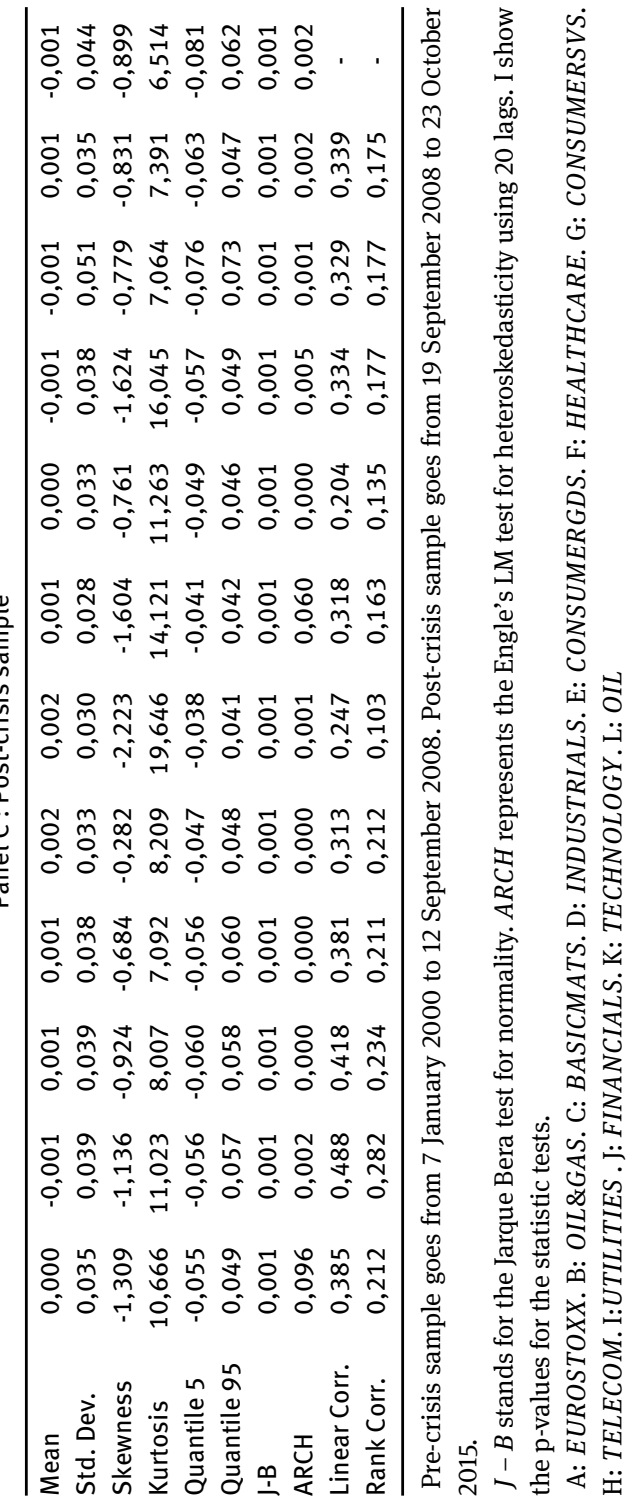


Figure 1: Time-varying correlation between stock returns and oil returns.

This figures shows the evolution of the correlation between oil and Eurostoxx (blue line), basic materials (red line) and health care (yellow line). The correlation evolves over time using a rolling window on weekly returns with a five-year window length, i.e. at each time $t \mathrm{I}$ assess the correlation of the weekly returns between $t-260$ and $t$. The figures depict two evidences. First, the lower correlation between health care and oil than other stock returns. Second, the shift in the correlation after 2008-2009, which might indicate the presence of a regime switch.

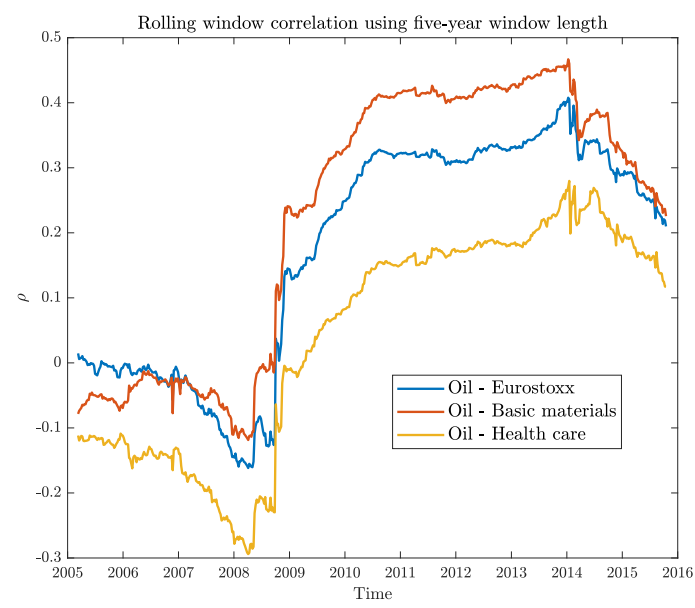

Figure 2: Empirical joint distribution for returns of EUROSTOXX and Brent oil denominated in Euros.

Top figure shows the empirical joint distribution function for all the sample, middle graphs represents the pre-crisis subsample and the bottom one the post-crisis subsample. Darker colours indicate a higher data clustering on certain part of the distribution. Looking at the entire sample and assessing a constant copula parameter may overlook the complex dependence evolution within the data.
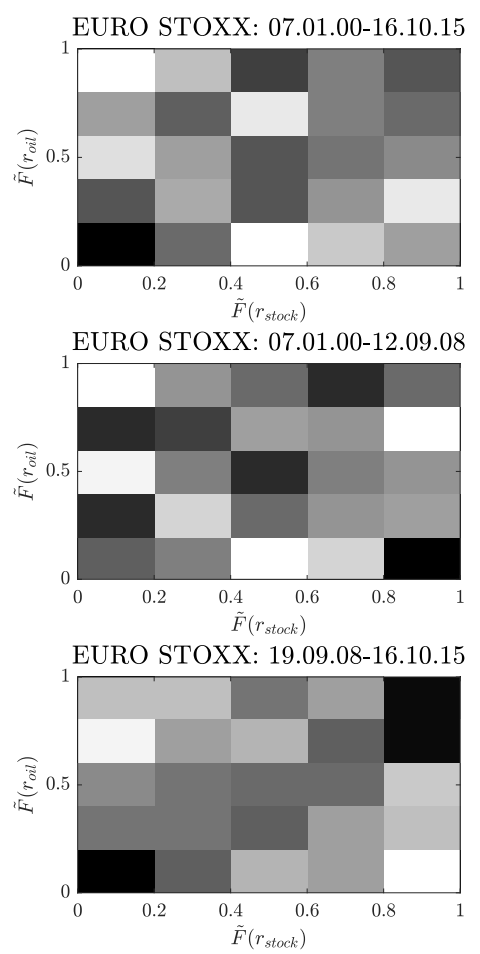
Figure 3: Empirical joint distribution for returns of EUROSTOXX sector portfolios and Brent oil denominated in Euros. Left set of subfigures show the empirical joint distribution function for all the sample, centre set of graphs represents the precrisis subsample and the right one the post-crisis subsample. Darker colours indicate a higher data clustering on certain part of the distribution. Looking at the entire sample and assessing a constant copula parameter may overlook the complex dependence evolution within the data.

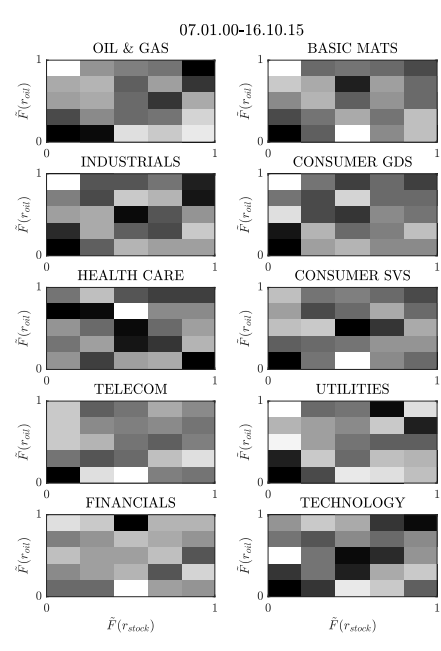

(a) All sample

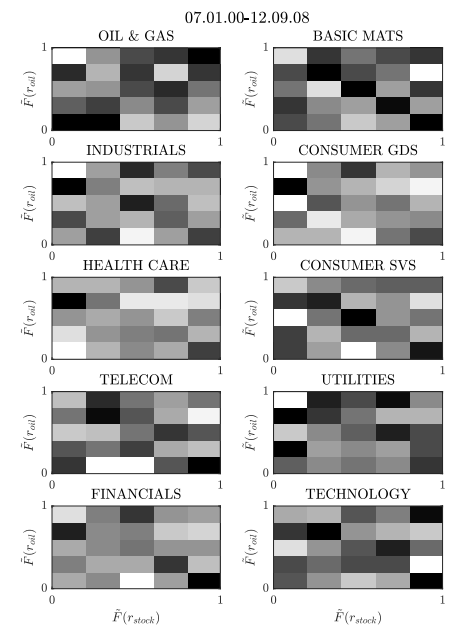

(b) Pre-crisis

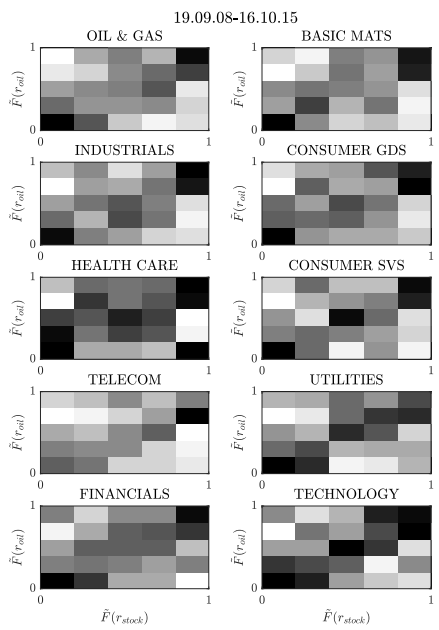

(c) Post-crisis

of copula. This change is justified by the results of the likelihood ratio test, which indicate a change in the dependence with oil returns for most of the stock market industries.

Finally, the previous constraint is also removed, allowing for a change in the copula over time. I select the set of potential copulas for the structural break given the information contained in the data analysis from Section 3. Apart from the likelihood ratio test results, which indicates the better fit of time-varying dependence against constant dependence, I indicate the difference in CoVaR under both models measuring the implicit model risk in the constant specification.

\subsubsection{Estimates assuming constant dependence parameters}

Tables 3a and 3b present the results of the joint models for the best copula fit. The hypothesis of lack of autocorrelation and homocedasticity in the residuals given by an AR(1)-GJR-GARCH(1,1) model are not rejected, supporting the choice done for the marginal model. The hypothesis that the residuals come from a [38]'s skewed $t$ distribution cannot be rejected either. The marginal distribution is well-specified according to the results of the joint distribution with constant dependence. Table 4 shows the AICC values of the stock-oil model using the initial set of copulas. The Clayton copula depicts the best fit for most of the sectors followed by the BB1 and Student t copula. Clayton copula implies lower tail dependence while BB1 and Student t copula imply upper and lower tail dependence. Oil \& gas, industrial and technology sectors obtain a better fit under the BB1 copula, which has asymmetric tail dependence, i.e. the joint behaviour with oil returns is different at low quantiles than at high quantiles. The Student t explains better the relationship between healthcare and oil. To motivate the need of time-varying parameters for dependence I present the results of two graphical tools, i.e. lambda function and Tail Concentration Functions (TCF), employed to describe co-movement and tail dependence.

The lambda function ([30], [1], [18], [71]) is a useful graphical tool that comes from the difference between the quantile $q$ and the Kendall function $K(q, \theta)$, i.e.

$$
\lambda(q, \theta)=q-K(q, \theta)
$$




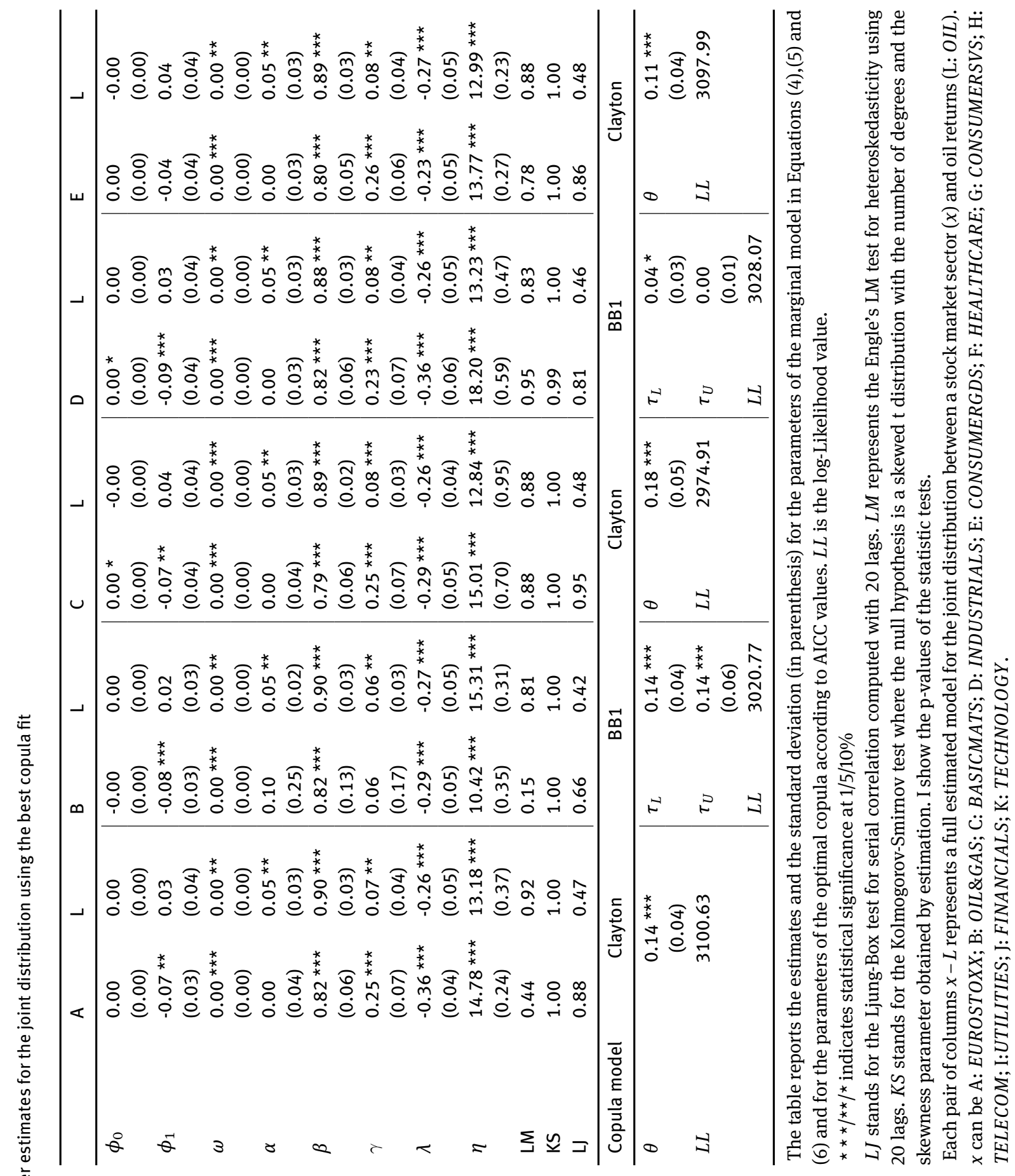




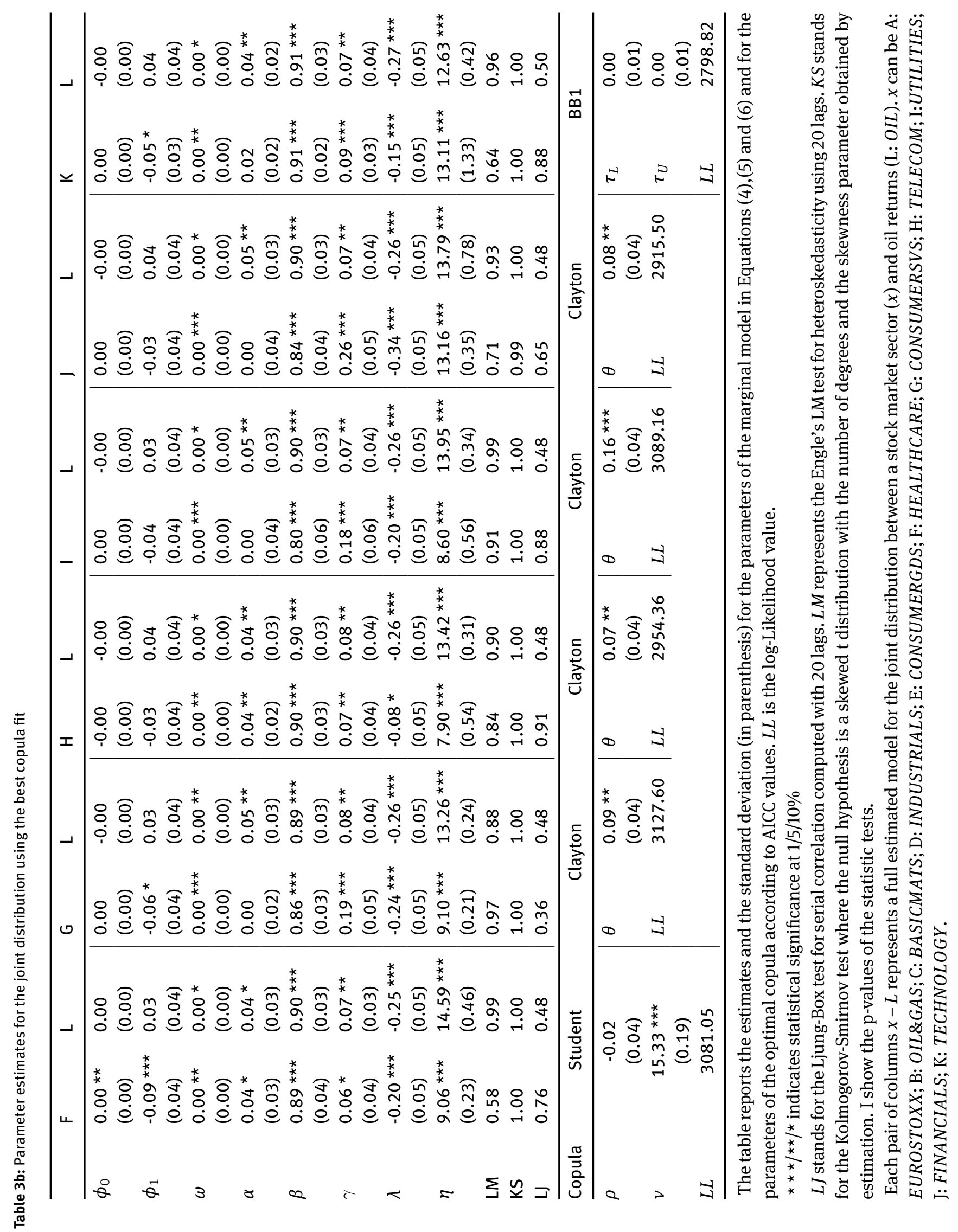


Table 4: AICC values for the models with constant copula parameter

\begin{tabular}{|c|c|c|c|c|c|c|c|c|c|c|c|}
\hline AICC & A & B & C & D & $\mathrm{E}$ & $\mathrm{F}$ & G & $\mathrm{H}$ & I & $J$ & K \\
\hline & 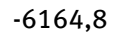 & $-5995,9$ & 1 & $f$ & & & & -5 & 5,6 & $-5792,4$ & 3,7 \\
\hline tudent & $-6163,7$ & $-5998,6$ & $-5911,2$ & $-6017,8$ & $-6159,0$ & $-6125,2$ & $-6216,3$ & $-5868,3$ & $-6136,5$ & $-5792,8$ & $-5558,4$ \\
\hline ayton & $-6166,5$ & $-5988,3$ & $-5915,0$ & $-6018,8$ & $-6161,2$ & $-6124,7$ & $-6220,4$ & $-5873,9$ & $-6143,5$ & $-5796,2$ & $-5554,2$ \\
\hline umbel & $-6160,4$ & $-5993,4$ & $-5903,3$ & $-6015,1$ & $-6156,5$ & $-6123,3$ & $-6215,0$ & $-5868,8$ & $-6130,8$ & $-5791,7$ & $-5555,0$ \\
\hline 3B1 & $-6165,6$ & $-6004,6$ & $-5913,0$ & $-6019,2$ & $-6159,1$ & $-6122,6$ & $-6218,3$ & $-5871,8$ & $-6141,5$ & $-5794,1$ & $-5560,8$ \\
\hline
\end{tabular}

This table shows the values of the Akaike Information Criterion corrected for small sample bias (AICC) ([43]).

$A I C C=2 k \frac{T}{T-k-1}-2 \log (\hat{L})$, where $T$ is the sample size, $k$ is the number of estimated parameters and $\hat{L}$ is the Log-likelihood value. Minimum $A I C C$ value in bold letters indicates the best copula fit.

A: EUROSTOXX; B: OIL\&GAS; C: BASICMATS; D: INDUSTRIALS; E: CONSUMERGDS; F: HEALTHCARE; G: CONSUMERSVS; H: TELECOM; I:UTILITIES; J: FINANCIALS; K: TECHNOLOGY.

where $K(q, \theta)$ is the Kendall function, which represent the probability associated to the joint distribution, i.e. $K(q, \theta)=P\left(C\left(u_{1}, u_{2} ; \theta\right) \leq q\right) .^{5}$ The top subfigure in Figure 4 presents the lambda function for the estimated copula function in the solid cyan line, while the grey area depicts the $90 \%$ confidence interval obtained by bootstrapping. The red line shows the empirical lambda function for the full sample using the residuals from the marginal models. The dotted black lines are the bands of the lambda function for perfect positive dependence (flat line) and independence (curve line). The solid green and the dashed blue lines are the pre-crisis and post-crisis empirical lambda functions. The pre-crisis empirical lambda is close to the independence case while the post-crisis empirical lambda shows a lower curvature, which indicates an increase in dependence.

The Tail Concentration Function (TCF) is proposed by [59] to quantify tail dependence features at a finite scale, where the weight for each tail depends on the selected quantile, i.e.

$$
T C F(q)=\frac{C(q, q)}{q} \mathbb{1}_{q \leq 0.5}+\frac{1-2 q+C(q, q)}{1-q} \mathbb{1}_{q>0.5},
$$

where $q$ represents a certain quantile, $C(q, q)$ is the copula function and $\mathbb{1}$ is the indicator function.

The bottom subfigure in Figure 4 shows the TCF between the stock market returns and the oil returns. The cyan line is the TCF for the estimated copula while the grey area represents its $90 \%$ confidence interval obtained by bootstrapping. Red line is the empirical TCF for the full sample while the solid green line and the dashed blue line are the empirical TCF for the pre-crisis and post-crisis samples. These results show an increase in the lower tail dependence after the 2008 financial crisis, which is translated into higher TCF values for $q \leq 0.5$. Therefore, there are grounds for believing that the tail dependence between oil and stock market changed after the 2008 financial crisis. Figure 4 focuses on the Eurostoxx. The figures for the productive sectors are provided in Appendix D.

The next subsection relaxes the assumption of constant dependence over time identifying changes in the degree of dependence between stock market and oil returns.

\subsubsection{Estimates allowing for time-varying dependence parameters while keeping unchanged the type of copula}

This section introduces the estimate results of the joint distribution function presented in Equation (7). The model assumes that the optimal copula according to Table 4 keeps unchanged but its parameters can vary

5 Further details about the Kendall function can be found in [22, p. 8-11,25-26]. 

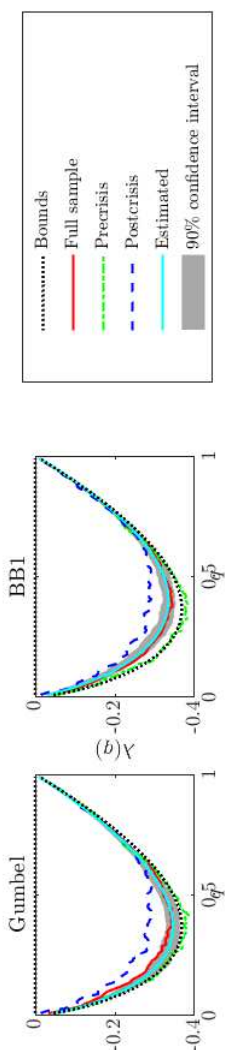

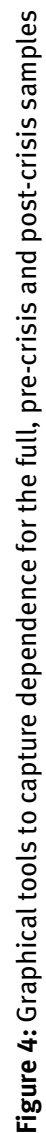

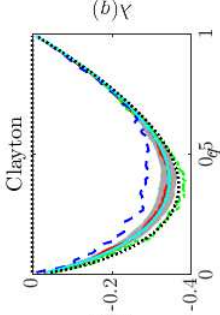

(b) $Y$

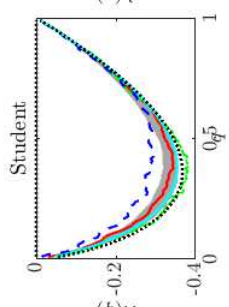

$(b) Y$

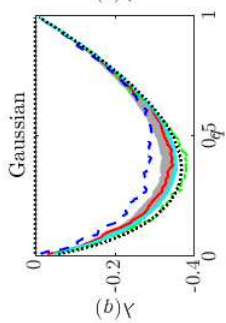

xxolsoyกA
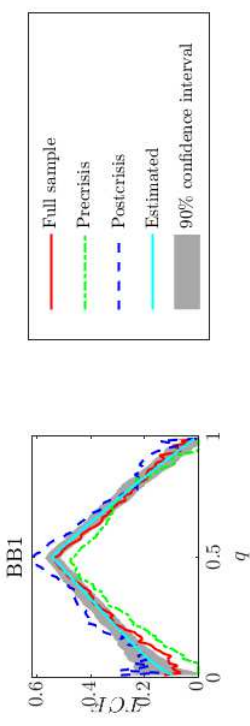

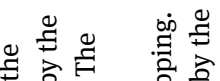

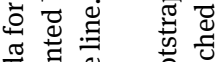

卷苋

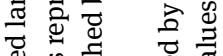

过罂

छे छ

禺莕

灵芯递焉

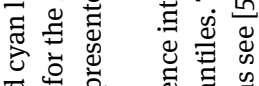

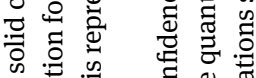

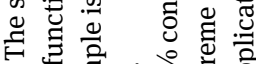

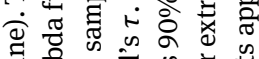

要

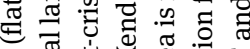

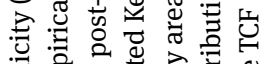

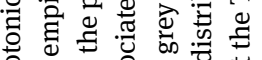

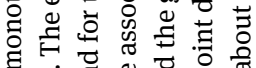

의

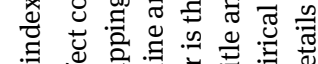

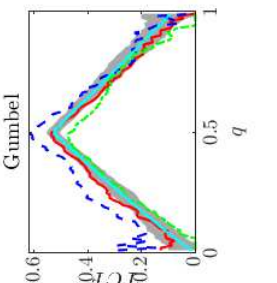

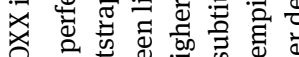

च ठ

ช

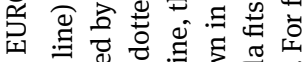

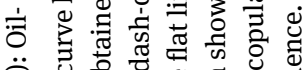

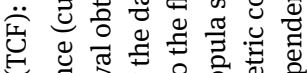

过

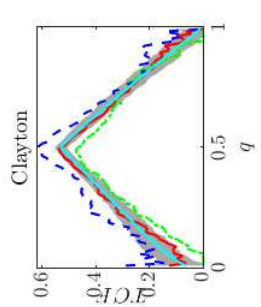

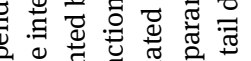

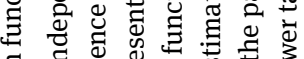

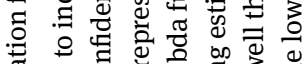

क्ष

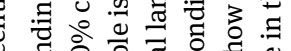

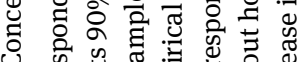

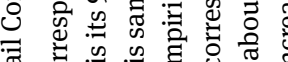

สี

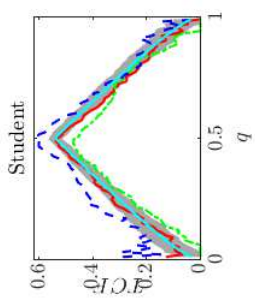

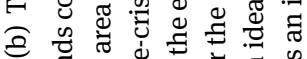

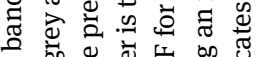

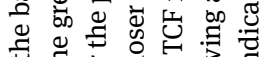

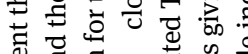

๙

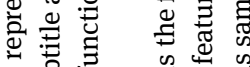

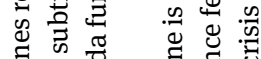

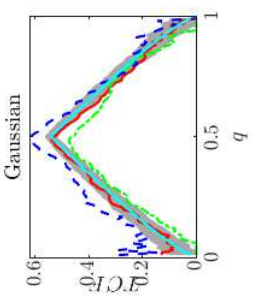

记

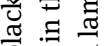

등

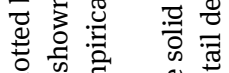

के ज्ञ

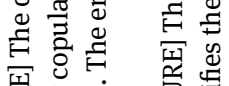

武品品哥

总砉专焉

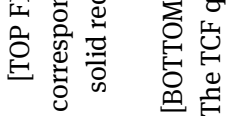


across regimes.

Tables $5 \mathrm{a}$ and $5 \mathrm{~b}$ present the estimates of the joint distribution and their standard deviations where the copula parameter evolves according to a two-regime Markov Chain. Figures 5a shows the smoothed probabilities using [47]'s algorithm. The scope of these probabilities is to determine if and when regime switch occurs. Figure 5a points to a structural change in the dependence between oil returns and Eurostoxx index after the 2008 financial crisis in line with recent results in the literature like [68]. The sectors that lead the switch in the co-movement between the Eurostoxx index and the oil returns are basic materials, consumer goods, consumer services, telecommunications, utilities and technology. All of them present a similar change in dependence around 2008 following the same copula specification, i.e. Clayton copula. There seems to be an increase in dependence after 2008 between these sector returns and oil returns. Although the financial sector has the same copula specification and presents a rise in dependence after 2008, it seems a transitory change. Actually, the expected duration for the high dependence regime in the financial sector is around two years and for the low dependence regime is four years. The expected duration of the regimes in the Eurostoxx is four years longer than in the financial sector. The healthcare sector exhibits an increase in the correlation but a decrease in tail dependence across regimes. Actually, the great increase in the number of degrees of freedom might indicate that the dependence between oil and healthcare sector is better explained by a Student $\mathrm{t}$-Gaussian mixture. The dependence in basic materials or technology with oil returns might arise from a mixture between Clayton copula and a copula that allows negative co-movement, due to the pattern inferred from the pre-crisis sample in Figure 3 and Table 2.

The following section discloses the hidden patterns in the type of dependence between oil and stock market according to a two-state Switching Markov specification, where the type of copula can change across states.

\subsubsection{Estimates allowing for changes in the type of copula}

The empirical joint density function in Figures 1, 2 and 3 point out a change in the link from negative to positive association for Eurostoxx and most of its sectors. Assuming an unchanged type of copula over time is a strong constraint given the fact that some copulas only enable positive association. In fact, Clayton, Gumbel and BB1 copulas only allow for positive tail dependence. These copulas cannot detect potential changes in the sign of the relationship. This entails significant problems for risk management because might claim that hedging against extreme movements in oil prices is not required when a dependence between oil and stock market returns exists.

Hence, I compare the results from previous section, where the copula choice was assumed constant over time, with the estimation of a model where not only the copula parameter but the copula itself can change across regimes.

The set of copula combinations considered in Table 6 depends on the results from the previous subsection and the descriptive analysis from Section 3. For instance, the Clayton copula is combined with the independence copula, i.e. the product of the marginal distributions, for the sectors that have presented lower tail dependence. This combination allow us to check if the low-dependence regime means that before 2008 oil returns and those sectors were independent. The limitations of the model to detect negative dependence might lead to misinterpretations of the low-dependence regime. The Clayton copula is, consequently, combined with copulas that express a negative relationship without tail dependence (Gaussian), symmetric tail dependence (Student), lower tail dependence $\left(90^{\circ}\right.$ rotated Clayton), upper tail dependence $\left(90^{\circ}\right.$ rotated Gumbel) or asymmetric tail dependence $\left(90^{\circ}\right.$ rotated BB1). Further details about the use of rotated copulas are provided in Appendix A. For these sectors Table 6 shows a change from a negative to positive lower tail dependence, i.e. R90Clayton-Clayton, with the exception of consumer services which does not seem to have tail dependence before 2008 but it also presents a negative behaviour. These results are in line with the intuition behind Figure 2. Utilities is the only sector where the low-dependence regime from previous subsection is identified with the independent copula. Table 7 displays the $p$-values of the one-sample 
Figure 5a: Smoothed probabilities assuming same copula type but different copula parameter across regimes

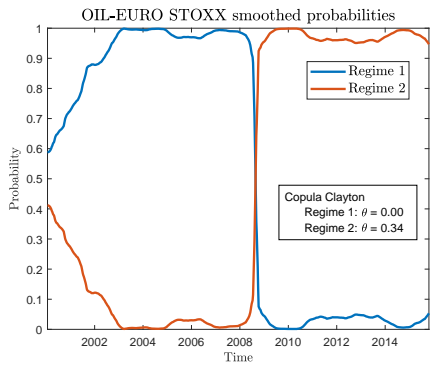

(a) Oil- EUROSTOXX index

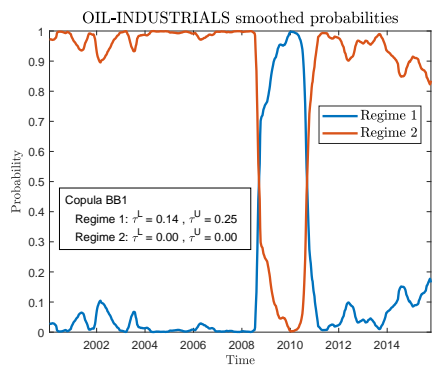

(d) Oil - INDUSTRIALS sector

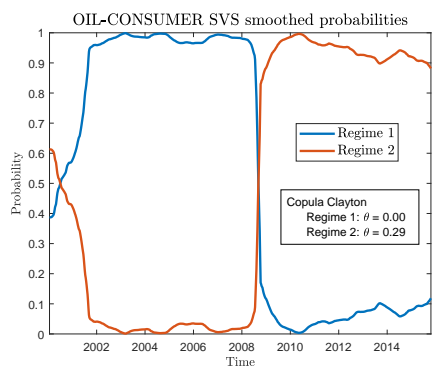

(g) Oil- CONSUMER SVS sector

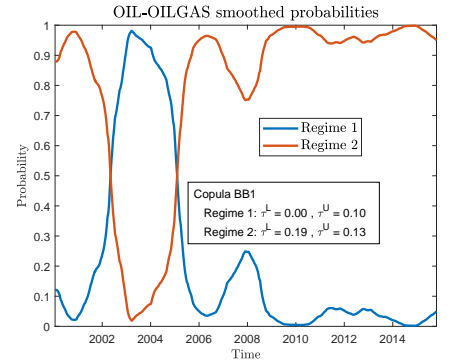

(b) Oil - OIL \& GAS sector

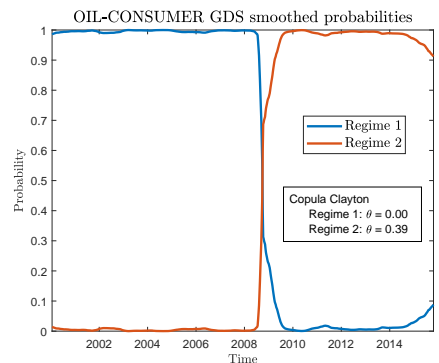

(e) Oil - CONSUMER GDS sector

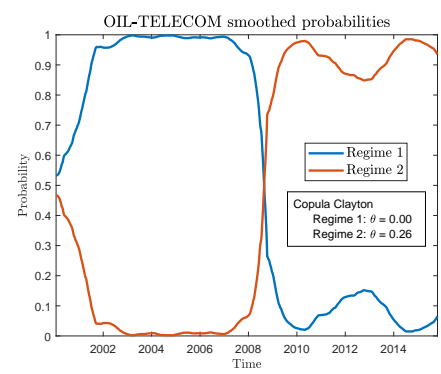

(h) Oil - TELECOM sector

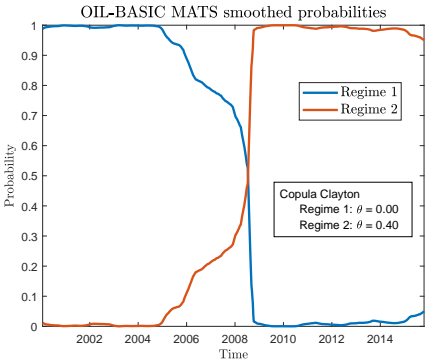

(c) Oil - BASIC MATS sector

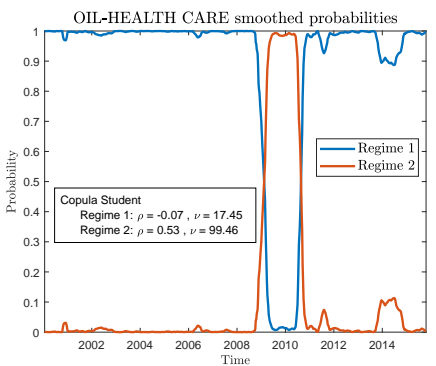

(f) Oil - HEALTH CARE sector

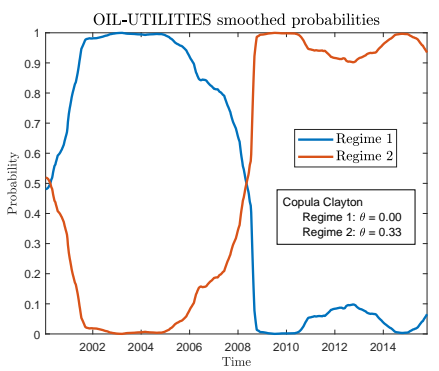

(i) Oil - UTILITIES sector

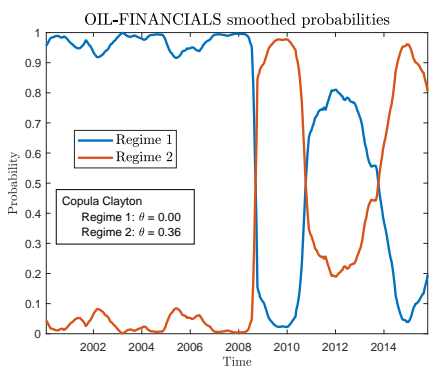

(j) Oil - FINANCIALS sector

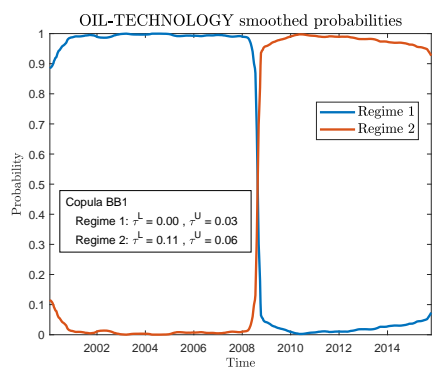

(k) Oil - TECHNOLOGY sector

Smoothed probabilities are obtained using [47]'s algorithm. Further information about this algorithm is provided in Appendix B. The text box indicates the chosen copula according to Table 4 and the optimal parameters depending on the regime. Across regimes the copula parameter changes but the type of copula is assumed to be constant over time. 


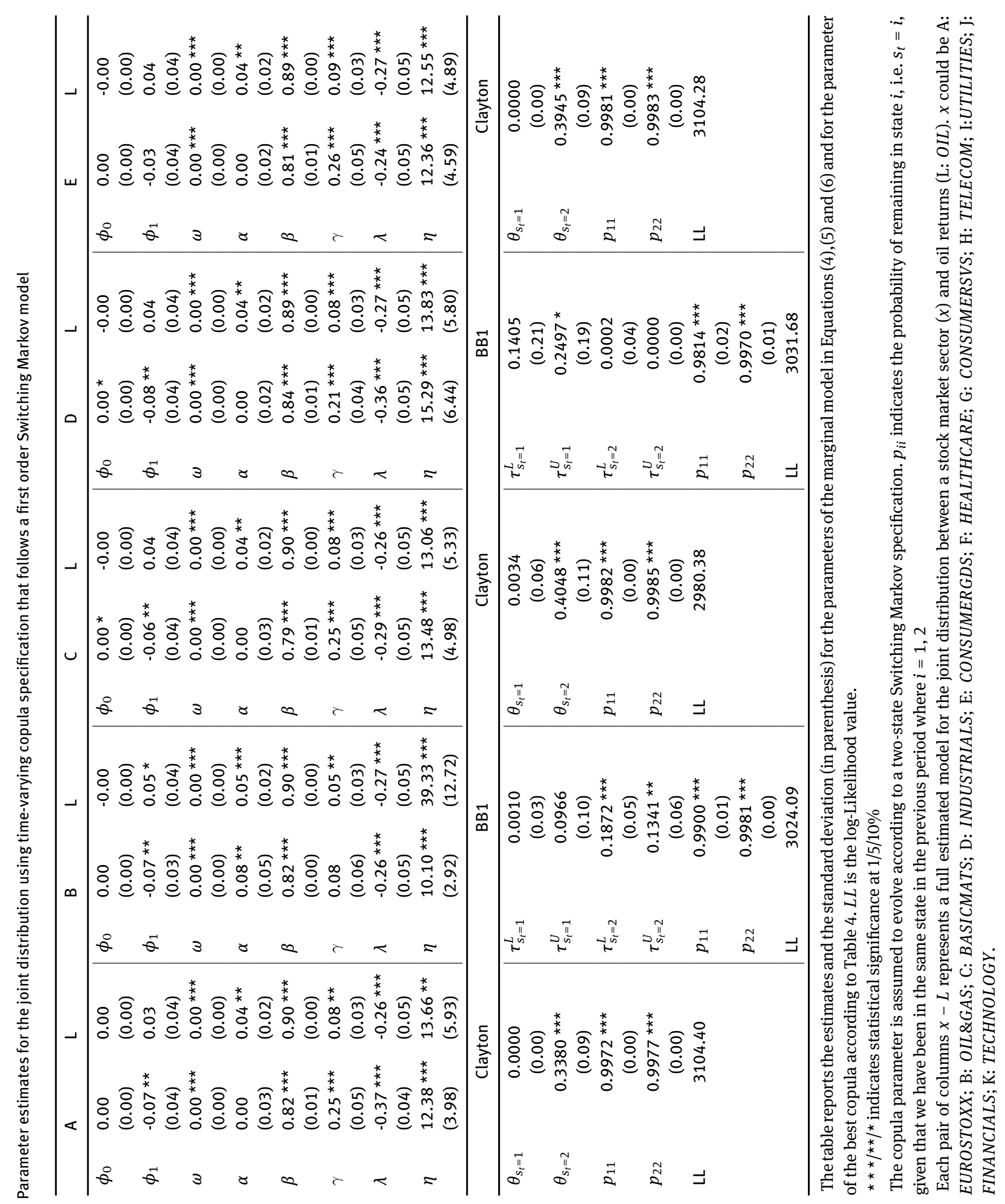




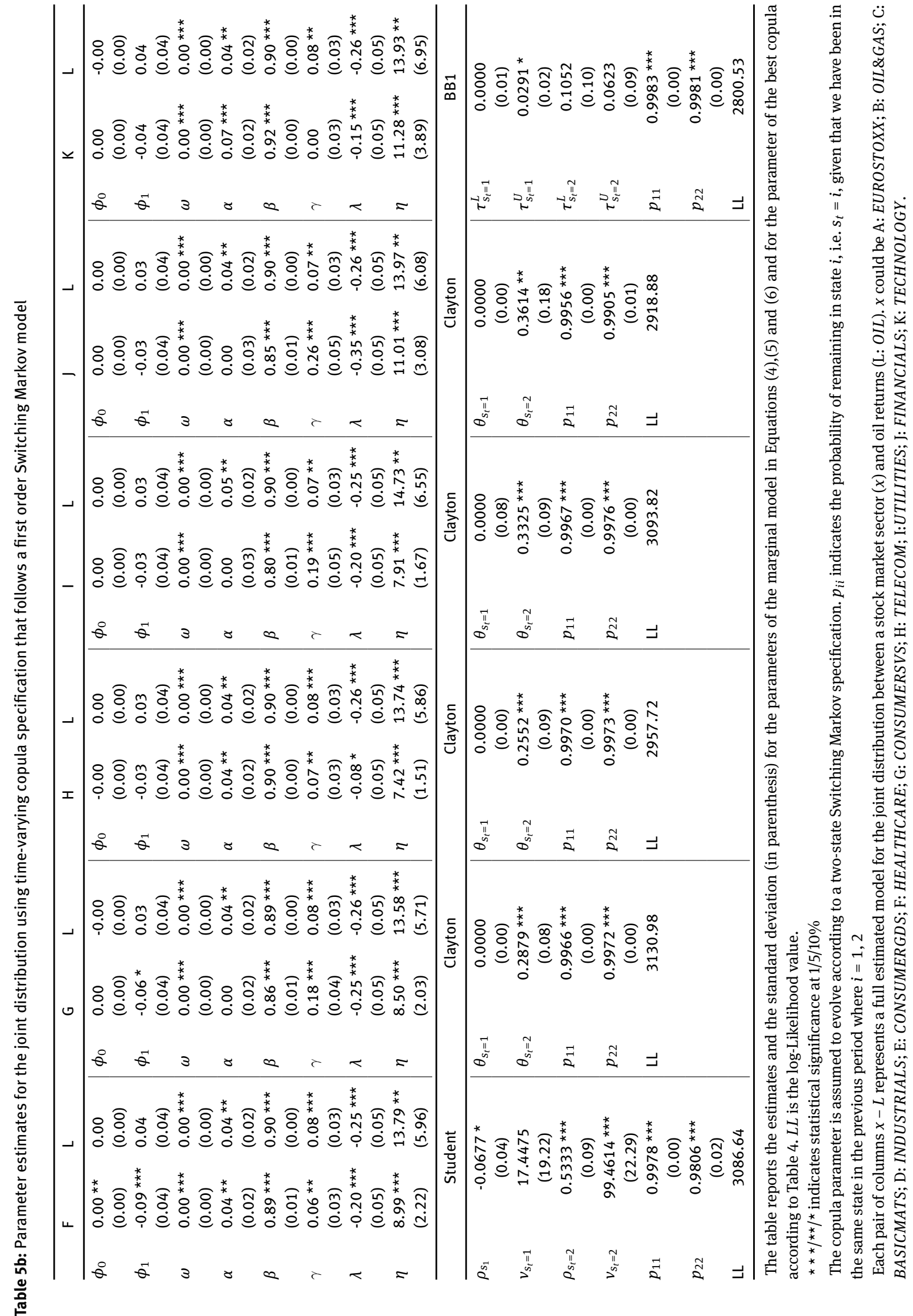


Table 6: AICC values for the models with different copula

\begin{tabular}{|c|c|c|c|c|c|c|c|}
\hline & EUROSTOXX & BASICMATS & CONSUMERGDS & CONSUMERSVS & TELECOM & UTILITIES & FINANCIALS \\
\hline Clayton-Clayton & $-6163,5$ & $-5915,4$ & $-6163,2$ & $-6216,6$ & $-5870,1$ & $-6142,3$ & $-5792,4$ \\
\hline Ind -Clayton & $-6165,6$ & $-5917,5$ & $-6165,3$ & $-6218,8$ & $-5872,2$ & $-6144,4$ & $-5794,6$ \\
\hline Gaussian-Clayton & $-6165,0$ & $-5915,5$ & $-6164,1$ & $-6226,8$ & $-5875,9$ & $-6142,4$ & $-5799,1$ \\
\hline Student-Clayton & $-6162,7$ & $-5913,9$ & $-6161,6$ & $-6224,5$ & $-5873,4$ & $-6140,0$ & $-5796,7$ \\
\hline R90Gumbel-Clayton & $-6163,5$ & $-5915,4$ & $-6163,2$ & $-6218,5$ & $-5870,2$ & $-6142,3$ & $-5794,2$ \\
\hline R90Clayton-Clayton & $-6169,6$ & $-5919,6$ & $-6166,2$ & $-6224,9$ & $-5879,7$ & $-6143,1$ & $-5803,0$ \\
\hline \multirow[t]{2}{*}{ R90BB1-Clayton } & $-6167,5$ & $-5917,5$ & $-6165,5$ & $-6222,8$ & $-5877,6$ & $-6141,0$ & $-5800,9$ \\
\hline & OILGAS & & INDUSTRIALS & & HEALTHCARE & & TECHNOLOGY \\
\hline BB1-BB1 & $-5998,6$ & BB1-BB1 & $-6013,8$ & Student-Student & $-6123,7$ & BB1-BB1 & $-5551,5$ \\
\hline Ind-BB1 & $-6012,2$ & BB1-Ind & $-6018,1$ & Ind-Gaussian & $-6124,4$ & Ind-BB1 & $-5554,8$ \\
\hline Gaussian-BB1 & $-6001,1$ & BB1-Gaussian & $-6017,9$ & Student-Gaussian & $-6125,0$ & Gaussian-BB1 & $-5566,9$ \\
\hline Gumbel-BB1 & $-5997,1$ & BB1-R90Gumbel & $-6016,0$ & & & Student-BB1 & $-5561,4$ \\
\hline \multirow[t]{3}{*}{ Clayton-BB1 } & $-6011,0$ & & & & & Gumbel-BB1 & $-5559,8$ \\
\hline & & & & & & R90Clayton-BB1 & $-5563,3$ \\
\hline & & & & & & R90Gumbel-BB1 & $-5568,3$ \\
\hline
\end{tabular}

This table shows the values of the Akaike Information Criterion corrected for small sample bias (AICC) ([43]).

$A I C C=2 k \frac{T}{T-k-1}-2 \log (\hat{L})$, where $T$ is the sample size, $k$ is the number of estimated parameters and $\hat{L}$ is the Log-likelihood value. Minimum AICC value in bold letters indicates the best copula fit. The second and the third best copulas are shown in italic letters.

Table 7: Kolgomorov Smirnov one sample test against the uniform distribution

\begin{tabular}{lllllllllllll}
\hline & A & B & C & D & E & F & G & H & I & J & K \\
\hline$C\left(u_{\text {oil }} \mid u_{\text {stock }}\right)$ & 0,9897 & 0,6849 & 0,9500 & 0,9709 & 0,9715 & 0,9966 & 0,9896 & 0,9805 & 0,9888 & 0,9735 & 0,9958 \\
$C\left(u_{\text {stock }} \mid u_{\text {oil }}\right)$ & 0,8220 & 0,9562 & 0,9816 & 0,2642 & 0,6991 & 0,6096 & 0,7387 & 0,6401 & 0,5957 & 0,3388 & 0,4302 \\
\hline
\end{tabular}

This table shows the p-values of the Kolgomorov Smirnov test comparing the conditional copula distribution from the best model according to Table 6 with the uniform distribution.

A: EUROSTOXX; B: OIL\&GAS; C: BASICMATS; D: INDUSTRIALS; E: CONSUMERGDS; F: HEALTHCARE; G: CONSUMERSVS; H: TELECOM; I:UTILITIES; J: FINANCIALS; K: TECHNOLOGY. 
Kolgomorov-Smirnov test of the conditional copula against the uniform distribution where no indication of misleading copula is found. The conditional copula comes from the derivation of the copula function from one input variable, e.g. $C\left(u_{2} \mid u_{1}\right)=\partial C\left(u_{1}, u_{2}\right) / \partial u_{1} . C\left(u_{2} \mid u_{1}\right)$ indicates the distribution of $u_{2}$ given the realization of $u_{1}$. If the copula gathers properly the dependence between variables, the conditional probability of $u_{2}$ must be uniformly distributed (see [69]).

Figure 6a sheds light on the possible structural break in the joint dependence. Besides the smoothed probabilities under the best copula fit according to Table 6 , the figure shows the $90 \%$ confidence interval (grey area) obtained in a bootstrapping procedure. 500 paths of length 2000 are simulated following the algorithm in Appendix C, which I employ to re-estimate the parameters of the model. The set of new estimates are employed to generate a confidence interval regarding the point estimates. The point estimates using the original data are not always within the grey area due to the procedure employed. According to the smoothed probabilities, the periods associated with the regime of negative or null dependence are between 2003 and 2008. The wider confidence intervals before 2008 also indicates a higher uncertainty for some sectors. The estimates and the standard deviation for the new models are presented in Tables 8a, 8b and 8c.

Health care sector presents a regime with strong negative tail dependence while the other regime has positive but small correlation. This feature indicates that adding the healthcare to a stock portfolio can decrease the exposure to oil spillovers at extreme quantiles.

A likelihood ratio test is performed to test if the model with time-varying dependence is statistically better than the model with constant dependence. The model with constant dependence represents the restricted model, while the model with time-varying copula represents the unrestricted model. The likelihood ratio is distributed as

$$
-2\left(\log \left(\text { Likel }_{R}\right)-\log \left(\text { Likel }_{U R}\right)\right) \sim X_{k_{U R}-k_{R}}
$$

where $k$ refers to the number of parameters for the model while $R$ is the restricted (constant) model and $U R$ is the (time-varying) unrestricted model.

Note that the constant model is nested in the time-varying model. However the transition probabilities of the Markov process are not identified under the null hypothesis, so regularity conditions justifying the $\chi^{2}$ approximation to the likelihood ratio test are not held. Following [19], I replicate 500 series of returns with a sample length of 1000 under the constant model using Monte Carlo simulations. Then, the Switching Markov model is fitted for each generated series. Finally, I calculate the likelihood ratio statistic of each Monte Carlo simulation getting the distribution of the likelihood ratio statistic under the null hypothesis, which I use to obtain the p-value.

The results in Table 9 indicate that the null hypothesis is not rejected for oil \& gas, industrial and technology sector when the unrestricted model only allows for a change in the parameter of the copula. Nevertheless, the probability of each state gives useful information concerning a potential change. Allowing for a change not only in the parameter but also in the copula itself improves the model, rejecting the null hypothesis that constant and time-varying models are equivalent.

The fitting improvement using the model with time-varying dependence can be quantify in terms of the estimation of a percentile for Eurostoxx depending on the scenario for oil prices. Figure 7 shows the difference between the estimation of the same percentile under the same oil-related scenario over the analysed period for the Eurostoxx using the time-varying copula (minuend) and the constant dependence model (subtrahend). The model risk of assuming a constant dependence across assets implies an overestimation by $8 \%$ and a underestimation by $4 \%$ of the same risk measure depending on the period, scenario and chosen percentile. Appendix D provides the same type of figures for the stock sectors. They indicate a higher model risk in the estimation of low quantiles of stock returns than high percentiles, in particular under scenarios where oil prices experience a downward movement. 
Figure 6a: Smoothed probabilities assuming different copula type across regimes

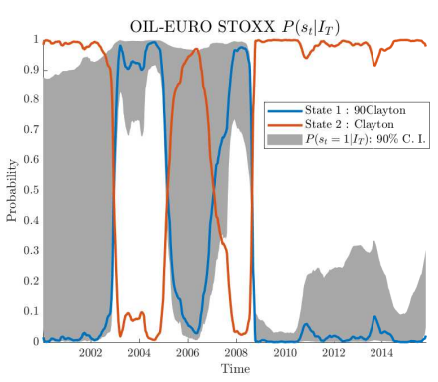

(a) Oil- EUROSTOXX index

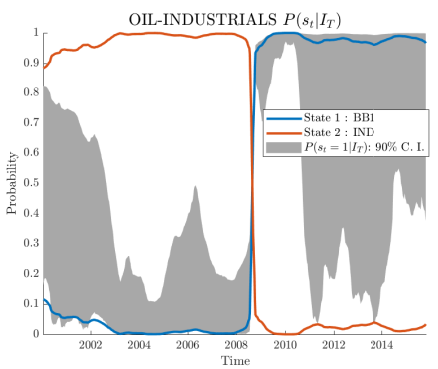

(d) Oil - INDUSTRIALS sector

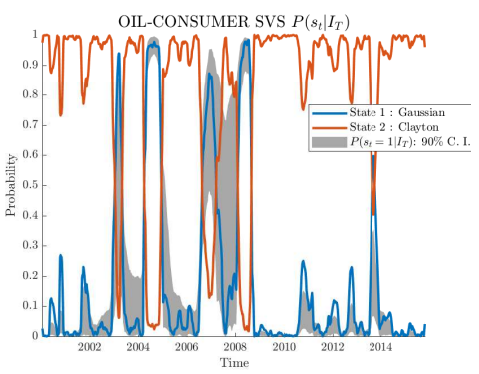

(g) Oil- CONSUMER SVS sector

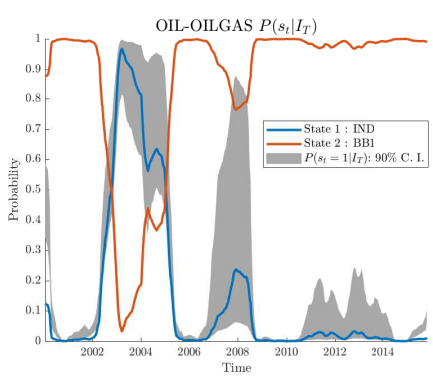

(b) Oil - OIL \& GAS sector

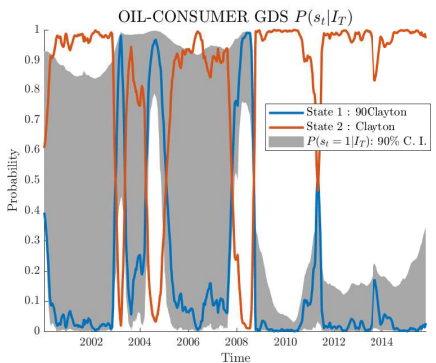

(e) Oil - CONSUMER GDS sector

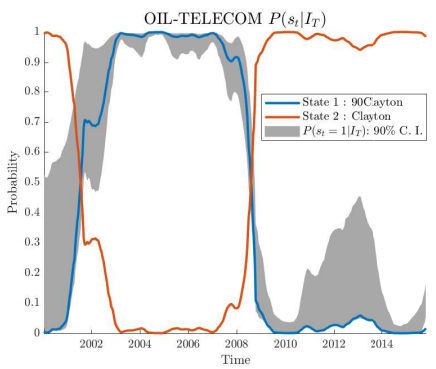

(h) Oil - TELECOM sector

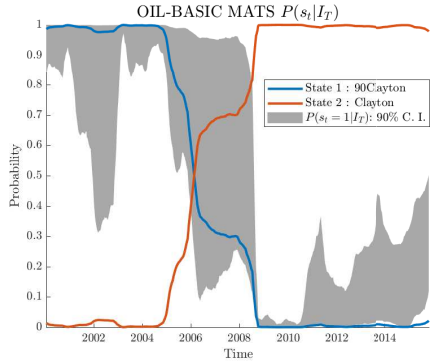

(c) Oil - BASIC MATS sector

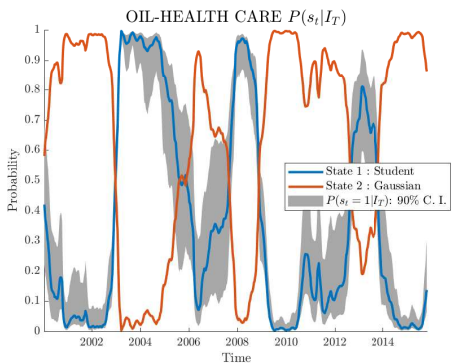

(f) Oil - HEALTH CARE sector

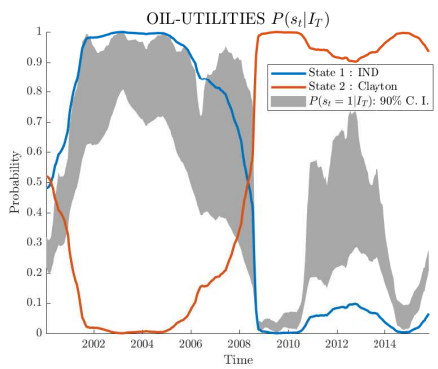

(i) Oil - UTILITIES sector

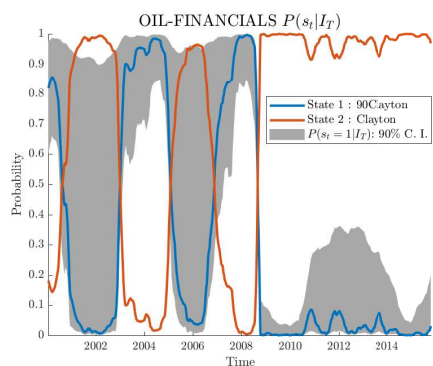

(j) Oil - FINANCIALS sector

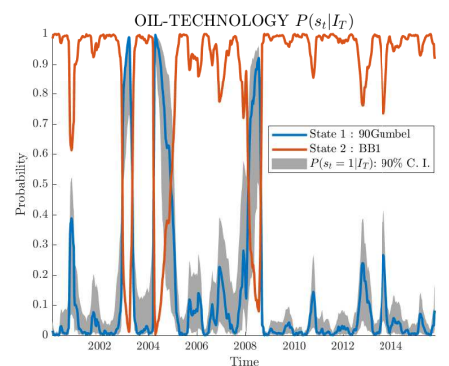

(k) Oil - TECHNOLOGY sector

Smoothed probabilities are obtained using [47]'s algorithm. Further information about this algorithm is provided in Appendix B. The legend box indicates the chosen copula according to Table 6 . Solid lines indicate the states under the best mixture of copulas. Grey area indicates the $90 \%$ confidence interval of the smoothed probability of state 1 following a Monte Carlo technique explained in Appendix C. Generally speaking there is a clear regime after 2008 that implies positive tail dependence between oil and stock market while in the period 2003-2008 predominates a regime that implies negative tail dependence, although with higher uncertainty. 
Table 8a: Parameter estimates for the joint distribution using a mixture of copulas where the weights are given by the forecast probability of each state

\begin{tabular}{|c|c|c|c|c|c|c|c|c|}
\hline & $A$ & $\mathrm{~L}$ & B & $\mathrm{L}$ & $C$ & $\mathrm{~L}$ & $\mathrm{D}$ & $\mathrm{L}$ \\
\hline$\overline{\phi_{0}}$ & $\begin{array}{l}0.00 \\
(0.00)\end{array}$ & $\begin{array}{l}-0.00 \\
(0.00)\end{array}$ & $\begin{array}{l}0.00 \\
(0.00)\end{array}$ & $\begin{array}{l}0.00 \\
(0.00)\end{array}$ & $\begin{array}{l}0.00 \text { * } \\
(0.00)\end{array}$ & $\begin{array}{l}-0.00 \\
(0.00)\end{array}$ & $\begin{array}{l}0.00 \text { * } \\
(0.00)\end{array}$ & $\begin{array}{l}-0.00 \\
(0.00)\end{array}$ \\
\hline$\phi_{1}$ & $\begin{array}{l}-0.07^{\star *} \\
(0.04)\end{array}$ & $\begin{array}{l}0.03 \\
(0.04)\end{array}$ & $\begin{array}{l}-0.05 \text { * } \\
(0.03)\end{array}$ & $\begin{array}{l}0.05 \text { * } \\
(0.04)\end{array}$ & $\begin{array}{l}-0.06^{\star \star} \\
(0.04)\end{array}$ & $\begin{array}{l}0.03 \\
(0.04)\end{array}$ & $\begin{array}{l}-0.08 \text { ** } \\
(0.04)\end{array}$ & $\begin{array}{l}0.04 \\
(0.04)\end{array}$ \\
\hline$\omega$ & $\begin{array}{l}0.00 \text { ** } \\
(0.00)\end{array}$ & $\begin{array}{l}0.00 \text { * } \\
(0.00)\end{array}$ & $\begin{array}{l}0.00 \text { *** } \\
(0.00)\end{array}$ & $\begin{array}{l}0.00 \text { ** } \\
(0.00)\end{array}$ & $\begin{array}{l}0.00 * * \star \\
(0.00)\end{array}$ & $\begin{array}{l}0.00 \text { ** } \\
(0.00)\end{array}$ & $\begin{array}{l}0.00 \text { ** } \\
(0.00)\end{array}$ & $\begin{array}{l}0.00 \text { ** } \\
(0.00)\end{array}$ \\
\hline$\alpha$ & $\begin{array}{l}0.00 \\
(0.04)\end{array}$ & $\begin{array}{l}0.05 \text { ** } \\
(0.03)\end{array}$ & $\begin{array}{l}0.03 \\
(0.07)\end{array}$ & $\begin{array}{l}0.04 \text { ** } \\
(0.02)\end{array}$ & $\begin{array}{l}0.00 \\
(0.04)\end{array}$ & $\begin{array}{l}0.04 \text { ** } \\
(0.02)\end{array}$ & $\begin{array}{l}0.00 \\
(0.03)\end{array}$ & $\begin{array}{l}0.04 \text { * } \\
(0.03)\end{array}$ \\
\hline$\beta$ & $\begin{array}{l}0.84 \text { *** } \\
(0.07)\end{array}$ & $\begin{array}{l}0.90 * \star * \\
(0.03)\end{array}$ & $\begin{array}{l}0.80 \text { *** } \\
(0.07)\end{array}$ & $\begin{array}{l}0.91 \text { *** } \\
(0.03)\end{array}$ & $\begin{array}{l}0.80 * \star * \\
(0.08)\end{array}$ & $\begin{array}{l}0.90 * * * \\
(0.03)\end{array}$ & $\begin{array}{l}0.83 * * * \\
(0.07)\end{array}$ & $\begin{array}{l}0.89 * * * \\
(0.03)\end{array}$ \\
\hline$\gamma$ & $\begin{array}{l}0.22 \text { *** } \\
(0.07)\end{array}$ & $\begin{array}{l}0.08 \text { ** } \\
(0.04)\end{array}$ & $\begin{array}{l}0.17^{\star \star \star *} \\
(0.07)\end{array}$ & $\begin{array}{l}0.06 \text { ** } \\
(0.03)\end{array}$ & $\begin{array}{l}0.23 * \star \star \\
(0.07)\end{array}$ & $\begin{array}{l}0.07 \text { ** } \\
(0.04)\end{array}$ & $\begin{array}{l}0.22 \text { *** } \\
(0.08)\end{array}$ & $\begin{array}{l}0.09 * * \\
(0.04)\end{array}$ \\
\hline$\lambda$ & $\begin{array}{l}-0.37^{* * *} \\
(0.04)\end{array}$ & $\begin{array}{l}-0.27^{\star * \star} \\
(0.05)\end{array}$ & $\begin{array}{l}-0.28^{* * \star} \\
(0.05)\end{array}$ & $\begin{array}{l}-0.25^{\star \star \star} \\
(0.05)\end{array}$ & $\begin{array}{l}-0.30 \text { ***} \\
(0.05)\end{array}$ & $\begin{array}{l}-0.26^{\star \star \star} \\
(0.05)\end{array}$ & $\begin{array}{l}-0.36^{* \star \star} \\
(0.05)\end{array}$ & $\begin{array}{l}-0.26^{* \star *} \\
(0.05)\end{array}$ \\
\hline$\eta$ & $\begin{array}{l}12.13^{\text {***}} \\
(0.46)\end{array}$ & $\begin{array}{l}11.99 \text { *** } \\
(0.89)\end{array}$ & $\begin{array}{l}9.70 \text { *** } \\
(0.57)\end{array}$ & $\begin{array}{l}15.38^{* \star *} \\
(0.47)\end{array}$ & $\begin{array}{l}14.03^{\text {***}} \\
(0.47)\end{array}$ & $\begin{array}{l}14.01 \text { *** } \\
(0.61)\end{array}$ & $\begin{array}{l}16.38^{\star \star \star *} \\
(0.52)\end{array}$ & $\begin{array}{l}13.98^{* \star \star} \\
(0.47)\end{array}$ \\
\hline & \multicolumn{2}{|c|}{ (a) } & \multicolumn{2}{|c|}{ (b) } & \multicolumn{2}{|c|}{ (a) } & \multicolumn{2}{|c|}{ (c) } \\
\hline$\overline{\theta_{s_{t}=1}}$ & \multicolumn{2}{|c|}{$\begin{array}{c}0.3877^{\star \star \star} \\
(0.16)\end{array}$} & $\tau^{L}$ & $\begin{array}{l}0.1477 \text { ** } \\
(0.07)\end{array}$ & $\theta_{s_{t}=1}$ & $\begin{array}{l}0.1139 \text { ** } \\
(0.07)\end{array}$ & $\tau^{L}$ & $\begin{array}{l}0.1055 \text { * } \\
(0.07)\end{array}$ \\
\hline$\theta_{s_{t}=2}$ & \multicolumn{2}{|c|}{$\begin{array}{c}0.2742 * * * \\
(0.06)\end{array}$} & $\tau^{U}$ & $\begin{array}{l}0.1636 * \star \star \\
(0.05)\end{array}$ & $\theta_{s_{t}=2}$ & $\begin{array}{l}0.3577 \text { *** } \\
(0.09)\end{array}$ & $\tau^{U}$ & $\begin{array}{l}0.0783 \text { * } \\
(0.05)\end{array}$ \\
\hline$p_{11}$ & \multicolumn{2}{|c|}{$\begin{array}{c}0.9838 * * * \\
(0.01)\end{array}$} & $p_{11}$ & $\begin{array}{l}0.9866 \text { *** } \\
(0.01)\end{array}$ & $p_{11}$ & $\begin{array}{l}0.9979 * * * \\
(0.00)\end{array}$ & $p_{11}$ & $\begin{array}{l}0.9982 \text { *** } \\
(0.00)\end{array}$ \\
\hline$p_{22}$ & \multicolumn{2}{|c|}{$\begin{array}{c}0.9956 * \star \star \\
(0.00)\end{array}$} & $p_{22}$ & $\begin{array}{l}0.9978 * \star \star \\
(0.00)\end{array}$ & $p_{22}$ & $\begin{array}{l}0.9986 * * * \\
(0.00)\end{array}$ & $p_{22}$ & $\begin{array}{l}0.9979 * \star * \\
(0.00)\end{array}$ \\
\hline LL & \multicolumn{2}{|c|}{3104.40} & LL & 3024.09 & $\mathrm{LL}$ & 2980.38 & LL & 3031.68 \\
\hline
\end{tabular}

The table reports the estimates and the standard deviation (in parenthesis) for the parameters of the marginal model in Equations (4),(5) and (6) and for the best copula mixture according to Table 6. $L L$ is the log-Likelihood value.

$\star \star \star / \star \star / \star$ indicates statistical significance at $1 / 5 / 10 \%$

The copula parameter is assumed to evolve according to a two-state Switching Markov specification. $p_{i i}$ indicates the probability of remaining in state $i$, i.e. $s_{t}=i$, given that we have been in the same state in the previous period where $i=1,2$

Each pair of columns $x-L$ represents a full estimated model for the joint distribution between a stock market sector $(x)$ and oil returns (L: OIL). $x$ could be A: EUROSTOXX; B: OIL\&GAS; C: BASICMATS; D: INDUSTRIALS; E: CONSUMERGDS; F: HEALTHCARE; G: CONSUMERSVS; H: TELECOM; I:UTILITIES; J: FINANCIALS; K: TECHNOLOGY.

Copula mixtures: (a) 90R Clayton- Clayton; (b) Independence- BB1; (c) BB1- Independence; (d) StudentGaussian; (e) Gaussian-Clayton; (f) Independence- Clayton; (g) R90 Gumbel-BB1. 
Table 8b: Parameter estimates for the joint distribution using a mixture of copulas where the weights are given by the forecast probability of each state

\begin{tabular}{|c|c|c|c|c|c|c|c|c|}
\hline & $E$ & $\mathrm{~L}$ & $\mathrm{~F}$ & $\mathrm{~L}$ & G & $\mathrm{L}$ & $\mathrm{H}$ & $\mathrm{L}$ \\
\hline$\phi_{0}$ & $\begin{array}{l}0.00 \\
(0.00)\end{array}$ & $\begin{array}{l}-0.00 \\
(0.00)\end{array}$ & $\begin{array}{l}0.00 \text { ** } \\
(0.00)\end{array}$ & $\begin{array}{l}0.00 \\
(0.00)\end{array}$ & $\begin{array}{l}0.00 \\
(0.00)\end{array}$ & $\begin{array}{l}0.00 \\
(0.00)\end{array}$ & $\begin{array}{l}-0.00 \\
(0.00)\end{array}$ & $\begin{array}{l}0.00 \\
(0.00)\end{array}$ \\
\hline$\phi_{1}$ & $\begin{array}{l}-0.04 \\
(0.04)\end{array}$ & $\begin{array}{l}0.03 \\
(0.04)\end{array}$ & $\begin{array}{l}-0.10 * \star \star \\
(0.04)\end{array}$ & $\begin{array}{l}0.04 \\
(0.04)\end{array}$ & $\begin{array}{l}-0.06 * \star \\
(0.04)\end{array}$ & $\begin{array}{l}0.03 \\
(0.04)\end{array}$ & $\begin{array}{l}-0.03 \\
(0.04)\end{array}$ & $\begin{array}{l}0.02 \\
(0.04)\end{array}$ \\
\hline$\omega$ & $\begin{array}{l}0.00 \star \star \star \\
(0.00)\end{array}$ & $\begin{array}{l}0.00 \text { * } \\
(0.00)\end{array}$ & $\begin{array}{l}0.00 \\
(0.00)\end{array}$ & $\begin{array}{l}0.00 \text { * } \\
(0.00)\end{array}$ & $\begin{array}{l}0.00 \text { ** } \\
(0.00)\end{array}$ & $\begin{array}{l}0.00 \text { * } \\
(0.00)\end{array}$ & $\begin{array}{l}0.00 \text { * } \\
(0.00)\end{array}$ & $\begin{array}{l}0.00 \text { * } \\
(0.00)\end{array}$ \\
\hline$\alpha$ & $\begin{array}{l}0.00 \\
(0.03)\end{array}$ & $\begin{array}{l}0.05 * * \\
(0.03)\end{array}$ & $\begin{array}{l}0.04 \text { * } \\
(0.03)\end{array}$ & $\begin{array}{l}0.04 \text { ** } \\
(0.03)\end{array}$ & $\begin{array}{l}0.00 \\
(0.02)\end{array}$ & $\begin{array}{l}0.04 \text { * } \\
(0.03)\end{array}$ & $\begin{array}{l}0.04 \text { ** } \\
(0.02)\end{array}$ & $\begin{array}{l}0.04 \text { ** } \\
(0.03)\end{array}$ \\
\hline$\beta$ & $\begin{array}{l}0.82 \text { *** } \\
(0.05)\end{array}$ & $\begin{array}{l}0.90 * * * \\
(0.03)\end{array}$ & $\begin{array}{l}0.88^{* \star \star} \\
(0.07)\end{array}$ & $\begin{array}{l}0.90 * * * \\
(0.03)\end{array}$ & $\begin{array}{l}0.87^{\star \star \star *} \\
(0.04)\end{array}$ & $\begin{array}{l}0.90 * * * \\
(0.03)\end{array}$ & $\begin{array}{l}0.91 \text { *** } \\
(0.03)\end{array}$ & $\begin{array}{l}0.90 * \star \star \\
(0.03)\end{array}$ \\
\hline$\gamma$ & $\begin{array}{l}0.22 \star \star \star \\
(0.07)\end{array}$ & $\begin{array}{l}0.08^{\star \star \star} \\
(0.04)\end{array}$ & $\begin{array}{l}0.06 \\
(0.05)\end{array}$ & $\begin{array}{l}0.07 \text { ** } \\
(0.04)\end{array}$ & $\begin{array}{l}0.17^{\star \star \star} \\
(0.05)\end{array}$ & $\begin{array}{l}0.09 \text { ** } \\
(0.04)\end{array}$ & $\begin{array}{l}0.06^{\star \star} \\
(0.04)\end{array}$ & $\begin{array}{l}0.07^{\star \star} \\
(0.04)\end{array}$ \\
\hline$\lambda$ & $\begin{array}{l}-0.25^{\star \star \star} \\
(0.05)\end{array}$ & $\begin{array}{l}-0.28 * \star \star \\
(0.05)\end{array}$ & 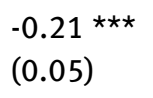 & $\begin{array}{l}-0.23 * \star \star \\
(0.05)\end{array}$ & $\begin{array}{l}-0.25 * \star * \\
(0.05)\end{array}$ & $\begin{array}{l}-0.26 \star \star \star \star \\
(0.05)\end{array}$ & $\begin{array}{l}-0.08 * \\
(0.05)\end{array}$ & $\begin{array}{l}-0.27^{* \star *} \\
(0.05)\end{array}$ \\
\hline$\eta$ & $\begin{array}{l}11.90^{\star \star \star} \\
(0.88)\end{array}$ & $\begin{array}{l}11.12^{\star \star \star} \\
(1.43)\end{array}$ & $\begin{array}{l}8.77^{\star \star \star} \\
(0.86)\end{array}$ & $\begin{array}{l}13.98^{\star \star \star} \\
(0.89)\end{array}$ & $\begin{array}{l}8.02 * \star \star \\
(0.57)\end{array}$ & $\begin{array}{l}11.50^{\star * *} \\
(1.45)\end{array}$ & $\begin{array}{l}7.26 * \star \star \\
(0.53)\end{array}$ & $\begin{array}{l}12.84^{\star \star \star} \\
(0.72)\end{array}$ \\
\hline & (a) & & (d) & & (e) & & (a) & \\
\hline$\theta_{s_{t}=1}$ & $\begin{array}{l}0.6372 \text { ** } \\
(0.28)\end{array}$ & & $\bar{\rho}$ & $\begin{array}{l}-0.2788 \text { *** } \\
(0.09)\end{array}$ & $\rho$ & $\begin{array}{l}-0.4848 * \star \star \\
(0.10)\end{array}$ & $\theta_{s_{t}=1}$ & $\begin{array}{l}0.2465 \text { *** } \\
(0.09)\end{array}$ \\
\hline$\theta_{s_{t}=2}$ & $\begin{array}{l}0.2397^{\star \star \star \star} \\
(0.06)\end{array}$ & & $v$ & $\begin{array}{l}6.7021 * \star \star \\
(1.54)\end{array}$ & $\theta$ & $\begin{array}{l}0.2382 \text { *** } \\
(0.07)\end{array}$ & $\theta_{s_{t}=2}$ & $\begin{array}{l}0.2314^{* \star *} \\
(0.07)\end{array}$ \\
\hline$p_{11}$ & $\begin{array}{l}0.9523 \text { *** } \\
(0.03)\end{array}$ & & $\rho$ & $\begin{array}{l}0.1279 \text { ** } \\
(0.06)\end{array}$ & $p_{11}$ & $\begin{array}{l}0.9343^{* * *} \\
(0.03)\end{array}$ & $p_{11}$ & $\begin{array}{l}0.9952^{* * *} \\
(0.00)\end{array}$ \\
\hline$p_{22}$ & $\begin{array}{l}0.9903^{\text {*** }} \\
(0.01)\end{array}$ & & $p_{11}$ & $\begin{array}{l}0.9793 \text { *** } \\
(0.01)\end{array}$ & $p_{22}$ & $\begin{array}{l}0.9862 \text { *** } \\
(0.01)\end{array}$ & $p_{22}$ & $\begin{array}{l}0.9977^{* * *} \\
(0.00)\end{array}$ \\
\hline LL & 3104.28 & & $\begin{array}{l}p_{22} \\
\mathrm{LL}\end{array}$ & $\begin{array}{l}0.9890 * \star \star \\
(0.01) \\
3086.64\end{array}$ & LL & -3130.98 & LL & 2957.72 \\
\hline
\end{tabular}

The table reports the estimates and the standard deviation (in parenthesis) for the parameters of the marginal model in Equations (4),(5) and (6) and for the best copula mixture according to Table 6. $L L$ is the log-Likelihood value.

$\star \star \star / \star \star / \star$ indicates statistical significance at $1 / 5 / 10 \%$

The copula parameter is assumed to evolve according to a two-state Switching Markov specification. $p_{i i}$ indicates the probability of remaining in state $i$, i.e. $s_{i}$, given that we have been in the same state in the previous period where $i=1,2$

Each pair of columns $x-L$ represents a full estimated model for the joint distribution between a stock market sector $(x)$ and oil returns (L: OIL). $x$ could be A: EUROSTOXX; B: OIL\&GAS; C: BASICMATS; D: INDUSTRIALS; E: CONSUMERGDS; F: HEALTHCARE; G: CONSUMERSVS; H: TELECOM; I:UTILITIES; J: FINANCIALS; K: TECHNOLOGY.

Copula mixtures: (a) 90R Clayton- Clayton; (b) Independence- BB1; (c) BB1- Independence; (d) StudentGaussian; (e) Gaussian-Clayton; (f) Independence- Clayton; (g) R90 Gumbel-BB1.

Next subsection computes the effects of extreme changes in oil prices on the Value-at-Risk for Eurostoxx and for the different European industrial subsectors at 5\% and 95\% confidence level. 
Table 8c: Parameter estimates for the joint distribution using a mixture of copulas where the weights are given by the forecast probability of each state

\begin{tabular}{|c|c|c|c|c|c|c|}
\hline & 1 & $\mathrm{~L}$ & J & $\mathrm{L}$ & $\mathrm{K}$ & $\mathrm{L}$ \\
\hline$\phi_{0}$ & $\begin{array}{l}0.00 \\
(0.00)\end{array}$ & $\begin{array}{l}0.00 \\
(0.00)\end{array}$ & $\begin{array}{l}0.00 \\
(0.00)\end{array}$ & $\begin{array}{l}-0.00 \\
(0.00)\end{array}$ & $\begin{array}{l}0.00 \\
(0.00)\end{array}$ & $\begin{array}{l}-0.00 \\
(0.00)\end{array}$ \\
\hline$\phi_{1}$ & $\begin{array}{l}-0.03 \\
(0.04)\end{array}$ & $\begin{array}{l}0.03 \\
(0.04)\end{array}$ & $\begin{array}{l}-0.03 \\
(0.04)\end{array}$ & $\begin{array}{l}0.03 \\
(0.04)\end{array}$ & $\begin{array}{l}-0.05^{*} \\
(0.04)\end{array}$ & $\begin{array}{l}0.06 \text { * } \\
(0.04)\end{array}$ \\
\hline$\omega$ & $\begin{array}{l}0.00 \text { ** } \\
(0.00)\end{array}$ & $\begin{array}{l}0.00 \text { * } \\
(0.00)\end{array}$ & $\begin{array}{l}0.00 * * \star \\
(0.00)\end{array}$ & $\begin{array}{l}0.00 \text { * } \\
(0.00)\end{array}$ & $\begin{array}{l}0.00 \text { ** } \\
(0.00)\end{array}$ & $\begin{array}{l}0.00 \text { ** } \\
(0.00)\end{array}$ \\
\hline$\alpha$ & $\begin{array}{l}0.00 \\
(0.04)\end{array}$ & $\begin{array}{l}0.05 \text { ** } \\
(0.03)\end{array}$ & $\begin{array}{l}0.00 \\
(0.04)\end{array}$ & $\begin{array}{l}0.05 \text { ** } \\
(0.03)\end{array}$ & $\begin{array}{l}0.03 \\
(0.02)\end{array}$ & $\begin{array}{l}0.02 \\
(0.02)\end{array}$ \\
\hline$\beta$ & $\begin{array}{l}0.80 \text { *** } \\
(0.08)\end{array}$ & $\begin{array}{l}0.90 * * * \\
(0.03)\end{array}$ & $\begin{array}{l}0.85 * \star * \\
(0.04)\end{array}$ & $\begin{array}{l}0.90^{* * *} \\
(0.03)\end{array}$ & $\begin{array}{l}0.92 * * * \\
(0.02)\end{array}$ & $\begin{array}{l}0.90 * \star \star \\
(0.03)\end{array}$ \\
\hline$\gamma$ & $\begin{array}{l}0.19 * * * \\
(0.07)\end{array}$ & $\begin{array}{l}0.07^{\star *} \\
(0.04)\end{array}$ & $\begin{array}{l}0.24 * * * \\
(0.05)\end{array}$ & $\begin{array}{l}0.07^{* *} \\
(0.04)\end{array}$ & $\begin{array}{l}0.07^{* *} \\
(0.03)\end{array}$ & $\begin{array}{l}0.11 \text { *** } \\
(0.04)\end{array}$ \\
\hline$\lambda$ & $\begin{array}{l}-0.20 \star \star \star \star \\
(0.05)\end{array}$ & $\begin{array}{l}-0.25 * \star \star \\
(0.05)\end{array}$ & $\begin{array}{l}-0.34 \text { *** } \\
(0.05)\end{array}$ & $\begin{array}{l}-0.27^{\star \star \star *} \\
(0.05)\end{array}$ & $\begin{array}{l}-0.17^{\star \star \star *} \\
(0.05)\end{array}$ & $\begin{array}{l}-0.26 * \star * \\
(0.04)\end{array}$ \\
\hline$\eta$ & $\begin{array}{l}7.91 * * * \\
(0.66)\end{array}$ & $\begin{array}{l}14.73^{\star \star \star} \\
(0.56)\end{array}$ & $\begin{array}{l}11.23^{\star * \star} \\
(0.51)\end{array}$ & $\begin{array}{l}11.80 * * \star \\
(0.68)\end{array}$ & $\begin{array}{l}11.32 \text { *** } \\
(0.43)\end{array}$ & $\begin{array}{l}13.83^{* \star \star} \\
(4.91)\end{array}$ \\
\hline & (f) & & (a) & & (g) & \\
\hline$\theta$ & 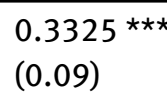 & & $\theta_{s_{t}=1}$ & $\begin{array}{l}0.4767^{\star \star \star} \\
(0.15)\end{array}$ & $\theta$ & $\begin{array}{l}1.4572 \text { *** } \\
(0.20)\end{array}$ \\
\hline$p_{11}$ & $\begin{array}{l}0.9967^{\star \star \star} \\
(0.00)\end{array}$ & & $\theta_{s_{t}=2}$ & $\begin{array}{l}0.2089 * \star \star \\
(0.06)\end{array}$ & $\tau^{L}$ & $\begin{array}{l}0.0137 \\
(0.03)\end{array}$ \\
\hline$p_{22}$ & $\begin{array}{l}0.9976^{\star \star \star} \\
(0.00)\end{array}$ & & $p_{11}$ & $\begin{array}{l}0.9848 \text { *** } \\
(0.01)\end{array}$ & $\tau^{U}$ & $\begin{array}{l}0.0840 \text { ** } \\
(0.04)\end{array}$ \\
\hline LL & -3093.82 & & $\begin{array}{l}p_{22} \\
\mathrm{LL}\end{array}$ & $\begin{array}{l}0.9936 \text { *** } \\
(0.00) \\
2918.88\end{array}$ & $\begin{array}{l}p_{11} \\
p_{22} \\
\mathrm{LL}\end{array}$ & 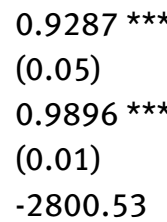 \\
\hline
\end{tabular}

The table reports the estimates and the standard deviation (in parenthesis) for the parameters of the marginal model in Equations (4),(5) and (6) and for the best copula mixture according to Table 6. $L L$ is the log-Likelihood value.

$\star \star \star / \star \star / \star$ indicates statistical significance at $1 / 5 / 10 \%$

The copula parameter is assumed to evolve according to a two-state Switching Markov specification. $p_{i i}$ indicates the probability of remaining in state $i$, i.e. $s_{t}=i$, given that we have been in the same state in the previous period where $i=1,2$ Each pair of columns $x-L$ represents a full estimated model for the joint distribution between a stock market sector $(x)$ and oil returns (L: OIL). $x$ could be A: EUROSTOXX; B: OIL\&GAS; C: BASICMATS; D: INDUSTRIALS; E: CONSUMERGDS; F: HEALTHCARE; G: CONSUMERSVS; H: TELECOM; I:UTILITIES; J: FINANCIALS; K: TECHNOLOGY.

Copula mixtures: (a) 90R Clayton- Clayton; (b) Independence- BB1; (c) BB1Independence; (d) Student-Gaussian; (e) Gaussian-Clayton; (f) IndependenceClayton; (g) R90 Gumbel-BB1. 
Table 9: Likelihood ratio test between the constant and the time-varying model

\begin{tabular}{lrrrrrrrrrrr}
\hline & A & B & \multicolumn{1}{l}{ C } & D & \multicolumn{1}{l}{ E } & \multicolumn{1}{l}{ F } & G & H & I & J & \multicolumn{1}{l}{ K } \\
\hline LR - (a) & 7,523 & 6,637 & 10,932 & 7,219 & 12,581 & 11,188 & 6,765 & 6,704 & 9,326 & 6,770 & 3,413 \\
p-value - (a) & 0,056 & 0,160 & 0,040 & 0,120 & 0,006 & 0,026 & 0,064 & 0,088 & 0,050 & 0,074 & 0,466 \\
\hline LR - (b) & 13,703 & 15,966 & 15,139 & 7,270 & 15,571 & 10,342 & 16,946 & 16,288 & 9,326 & 17,338 & 18,088 \\
p-value - (b) & 0,002 & 0,000 & 0,000 & 0,016 & 0,002 & 0,018 & 0,000 & 0,004 & 0,012 & 0,008 & 0,000 \\
\hline
\end{tabular}

This tables shows in the top row the likelihood ratio, i.e. $L R=-2\left(\log \left(\operatorname{Likelihood}_{R}\right)-\log \left(\operatorname{Likelihood}_{U R}\right)\right)$, where the distribution under the null hypothesis is obtained by a Monte Carlo simulation.

The two first rows (a) indicate the likelihood ratio test where the restricted model is the constant model and the unrestricted model is the model that only allow for changes in the copula parameter. The last two rows (b) indicate the likelihood ratio test where the restricted model is the constant model and the unrestricted model is the model that allow for a change in the copula itself. The copulas employed is the best one according AICC in tables 4 and 6.

$L R$ shows the statistic of the likelihood ratio.

The $p$-value indicates the $\mathrm{p}$-value for the Likelihood test where the null hypothesis indicates that the restricted model (constant) and the unrestricted model (time-varying model) are not statistically different between them, while the alternative hypothesis is the unrestricted model is statistically better than the restricted model.

Note that for some cases where we can not reject under the case (a) we can do it under case (b) due to a better fitting and a lower number of parameters, e.g. for the cases where the copula is combined with the independence case.

A: EUROSTOXX; B: OIL\&GAS; C: BASICMATS; D: INDUSTRIALS; E: CONSUMERGDS; F: HEALTHCARE; G: CONSUMERSVS; H: TELECOM; I:UTILITIES; J: FINANCIALS; K: TECHNOLOGY.

Figure 7: Model risk assessment when we assume a constant dependence compared to the time-varying model.
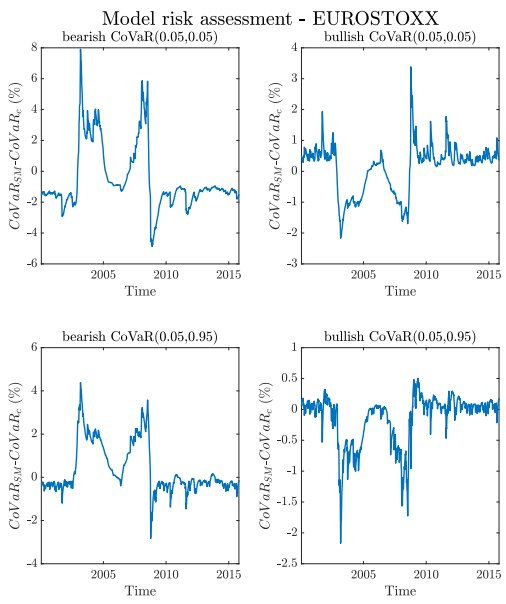

These figures show the difference between the estimation of the same percentile of Eurostoxx returns under the same oil-related scenario using the Switching Markov model that allows for changes in the copula against the constant model. Top figures focuses on a low quantile $(\beta=5 \%)$ whilst bottom graphs estimate the high quantile $(\beta=95 \%)$. Left figures show a percentile of stock returns under a bearish scenario for oil returns, i.e. oil returns below its percentile $5 \%$, and right figures show a percentile of stock returns under a bullish scenario for oil returns, i.e. oil returns above its percentile $95 \%$. These charts indicate the higher model risk in the lower tail than in the upper tail when assuming a constant dependence across markets. 


\subsection{Implications of structural changes in joint tail dependence for risk management}

This section presents first the results of the $\operatorname{CoVaR}(0.05,0.05)$ and $\operatorname{Co} \operatorname{VaR}(0.05,0.95)$ for each stock sector conditioned to a bearish or bullish scenario for oil returns. Second, a table summarizes different quantiles of the change in the $V a R$ measure once considered the oil scenario before and after the financial crisis. Third, a Kolgomorov-Smirnov bootstrap test is performed to check that the risk of overlooking the oil scenario is statistically significant. Fourth, I build a portfolio using Eurostoxx and healthcare to minimize (in absolute terms) the mean Conditional Value-at-Risk at 5\% confidence level. I rebalance the portfolio every four months from 23 October 2015, the last day of the in-sample period, to 27 July 2018.

Figures 8 and 9 plot on the right axis the $V a R$ estimates, which is depicted by the dash-dotted black line. These figures present on the right axis the difference CoVaR - VaR for the best copula (solid blue line) according to AICC values from Table 6 and its 90\% confidence interval computed by Monte Carlo simulations (see Appendix C).

Figure 8 shows a bearish oil scenario for the $\operatorname{CoVaR}_{m \mid o, t}(0.05,0.05)$. The oil \& gas sector has always a $\operatorname{CoVaR}_{m \mid o, t}(0.05,0.05)$ more negative than $\operatorname{VaR}_{m, t}$ although this difference is smaller during the period 2003-2005. During period 2003-2005 the difference $\operatorname{CoVaR}_{m \mid o, t}(0.05,0.05)-V a R_{m, t}$ is positive for most of the sectors (Eurostoxx, financial, healthcare, basic materials, utilities, telecommunications, consumer goods, consumer services). There is no change in the $V a R_{m, t}$ for the industrial sector before 2008. The period 20072008 also presents $\operatorname{CoVaR}_{m \mid o, t}(0.05,0.05)$ less negative than $\operatorname{VaR}_{m, t}$. The healthcare sector looks quite insensitive in its lower tail to negative shocks on the oil price with a maximum negative difference between $2 \%$ and $7 \%$ depending on the copula choice while for most of the sectors the difference reaches two-digit numbers.

Figure 9 shows a bullish oil scenario for $\operatorname{CoVaR}_{m \mid o, t}(0.05,0.05)$, where the unconditional $\operatorname{VaR}_{m, t}$ seems to be overestimating the losses. The healthcare sector is one exception where the $\operatorname{CoVaR}_{m \mid o, t}(0.05,0.05)$ has higher losses than the $\operatorname{VaR}_{m, t}(0.05)$ during the period 2003-2008. Moreover, healthcare sector shows this pattern after the 2008 financial crisis, during 2012-2014, moving in the opposite direction of Eurostoxx or oil \& gas sector given extreme upward movements in oil prices. This feature makes it a potential good asset to reduce the tail dependence of a stock portfolio with the oil returns.

Figure for the upper tail of the stock market sectors, i.e. $\operatorname{VaR}_{m, t}(0.95)$, and $\operatorname{CoVaR}_{m, t}(0.05,0.95)-$ $\operatorname{VaR}_{m, t}(0.95)$ show a much lower change than in the lower tail, where two-digit values are reached. Figures for the upper tail along with the CoES charts are provided in Appendix D. CoES figures provide a robustness check and give information the quantile of the CoVaR. The CoES plots support the main conclusions shown by the CoVaR.

Table 10 displays the p-values of the Kolgomorov-Smirnov (KS) bootstrap test for the cumulative distribution function of $\operatorname{CoVaR}$ and $V a R$ in the pre-crisis and post-crisis sample. ${ }^{6}$ Within the pre-crisis sample, the null hypothesis of equal cumulative distribution function of $\operatorname{CoVaR}$ and $V a R$ can not be rejected for the industrial sector, but within the post-crisis period it is rejected for all the oil scenarios and confidence levels. The KS null hypothesis can not be rejected either for the consumer services under a bullish oil scenario for $\operatorname{CoVaR}_{m \mid o, t}(0.05,0.05)$ in the pre-crisis sample, but it is rejected in the post-crisis period. The utilities sector presents the same results under a bullish oil scenario for $\operatorname{CoVaR} R_{m \mid o, t}(0.05,0.95)$.

Table 11 shows the 75 - th, 50 - th and 25 - th quantiles for the difference $\operatorname{CoVaR}_{m \mid o, t}(0.05,0.05)-$ $\operatorname{VaR}_{m, t}(0.05)$ and $\operatorname{CoVaR}_{m \mid o, t}(0.05,0.95)-\operatorname{VaR}_{m, t}(9.05)$ given a upward or downward movement in oil prices for the pre-crisis and post-crisis sample. The red cells indicates an underestimation of the VaR measure given a certain scenario higher than $2 \%$ while the green cells represents an overestimation of the

6 The main reason to build bootstrap tests in estimated measures is due to the introduction of a nuisance parameter in the sample distribution. The distribution under the null hypothesis might be different because of the estimated parameters, affecting to the confidence interval and the p-values. See [2], [16] and [58] for further details about Kolgomorov-Smirnov bootstrap test. 
Figure 8: $\operatorname{CoVaR}_{m \mid o, t}(0.05,0.05)$ for a certain sector given a bearish scenario for oil prices

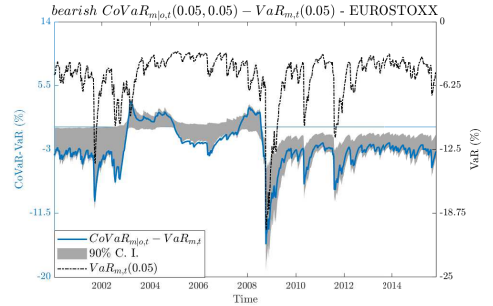

(a) Oil- EUROSTOXX index

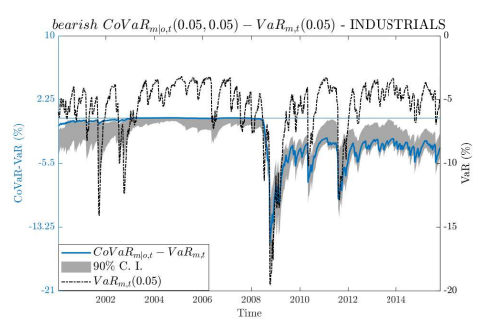

(d) Oil - INDUSTRIALS sector

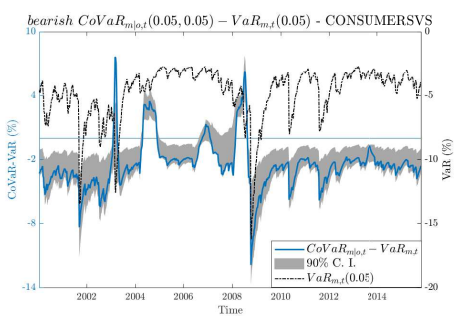

(g) Oil- CONSUMER SVS sector

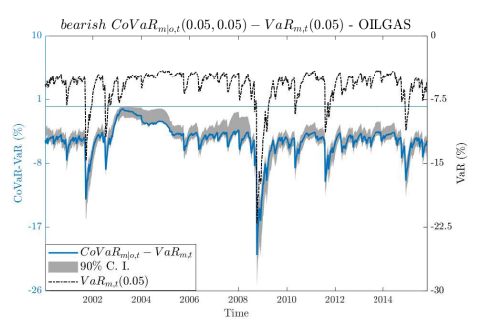

(b) Oil - OIL \& GAS sector

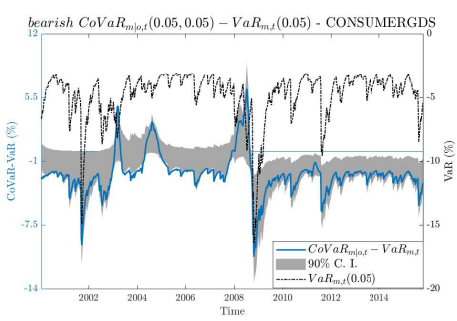

(e) Oil - CONSUMER GDS sector

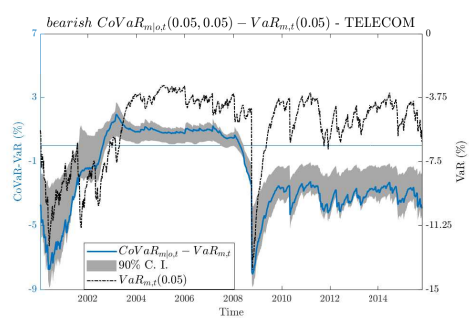

(h) Oil - TELECOM sector

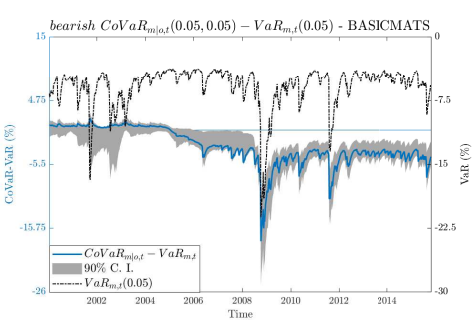

(c) Oil - BASIC MATS sector

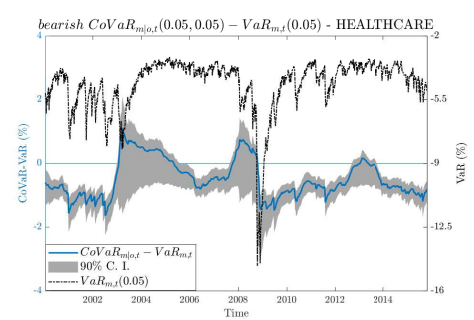

(f) Oil - HEALTH CARE sector

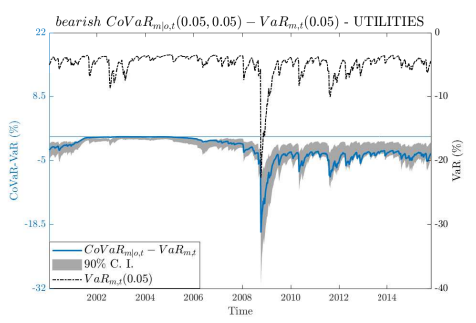

(i) Oil - UTILITIES sector

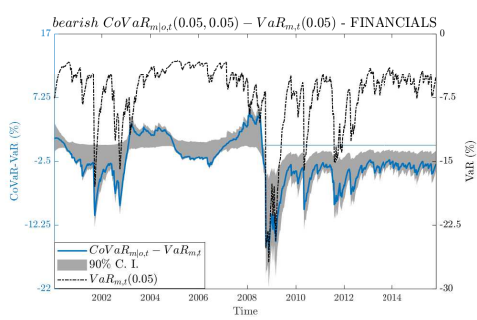

(j) Oil - FINANCIALS sector

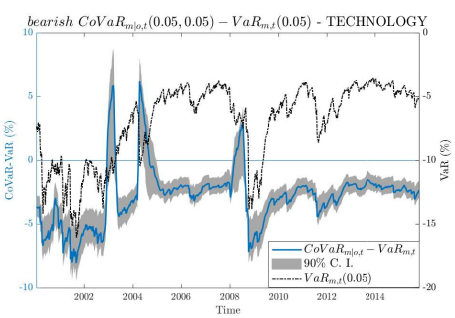

(k) Oil - TECHNOLOGY sector

Left axis shows the difference in percentage between the $\operatorname{CoVaR}_{m, t}(0.05)$ of the returns for a certain sector under a extreme downward movement in oil price, i.e. below its 5-th quantile, and its unconditional $\operatorname{VaR}_{m, t}(0.05)$. Solid blue line shows this difference given the best copula mixture according to table 6 . Grey area indicates the $90 \%$ confidence interval of the difference between $\mathrm{CoVaR}_{m \mid o, t}(0.05,0.05)$ and $\mathrm{VaR}_{m, t}(0.05)$ following a Monte Carlo technique explained in Appendix C. The right axes shows the value of the $\operatorname{VaR}_{m, t}(0.05)$ in percentage. The dash-dotted black line indicate the $V a R$ level over time. 
Figure 9: $\operatorname{CoVaR}_{m \mid o, t}(0.05,0.05)$ for a certain sector given a bullish scenario for oil prices

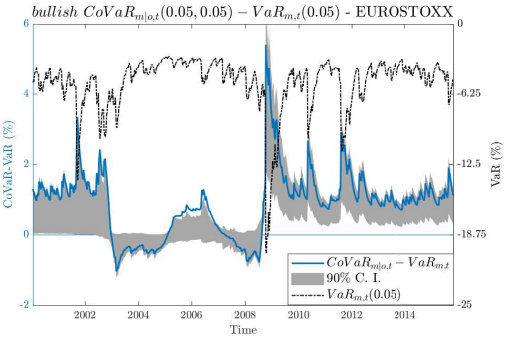

(a) Oil- EUROSTOXX index

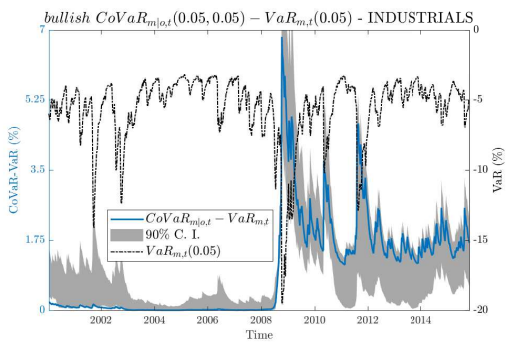

(d) Oil - INDUSTRIALS sector

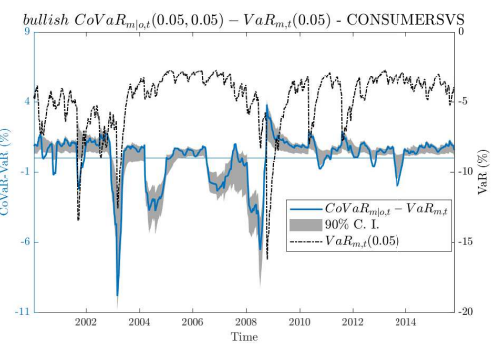

(g) Oil- CONSUMER SVS sector

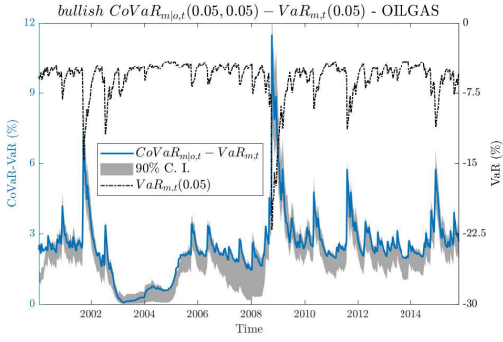

(b) Oil - OIL \& GAS sector

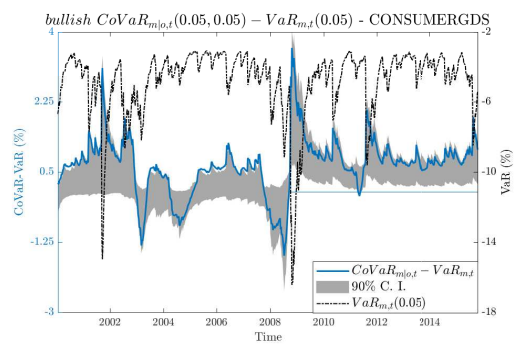

(e) Oil - CONSUMER GDS sector

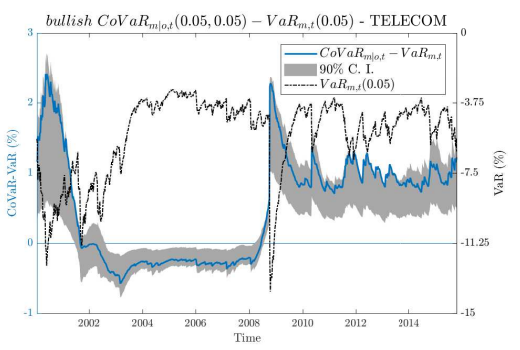

(h) Oil - TELECOM sector

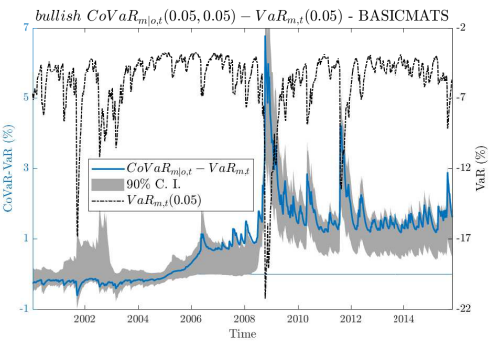

(c) Oil - BASIC MATS sector

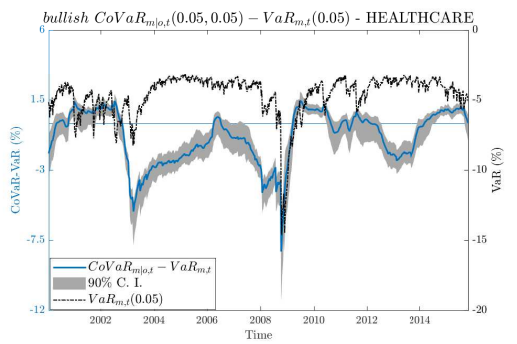

(f) Oil - HEALTH CARE sector

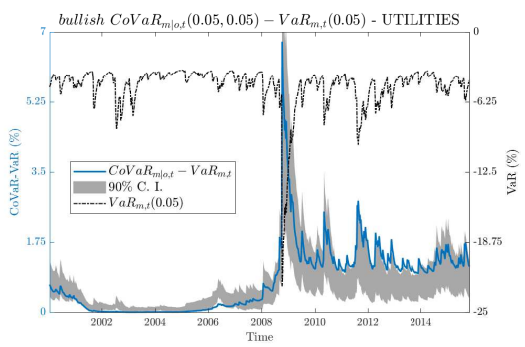

(i) Oil - UTILITIES sector

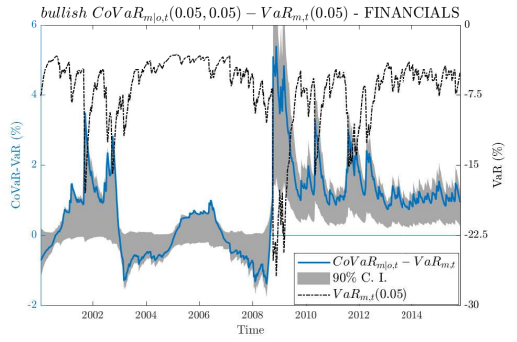

(j) Oil - FINANCIALS sector

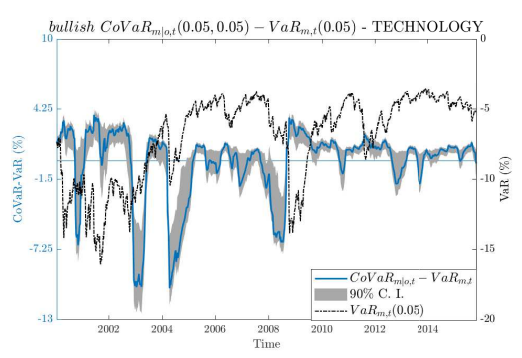

(k) Oil - TECHNOLOGY sector

Left axis shows the difference in percentage between the $\operatorname{CoVaR}_{m \mid o, t}(0.05,0.05)$ of the returns for a certain sector under a extreme upward movement in oil prices, i.e. above its 95-th quantile, and its unconditional $\operatorname{VaR} m, t(0.05,0.05)$. Solid blue line shows this difference given the best copula mixture according to table 6 . Grey area indicates the $90 \%$ confidence interval of the difference between $\mathrm{CoVaR}_{m \mid o, t}(0.05)$ and $\mathrm{VaR}_{m, t}(0.05)$ following a Monte Carlo technique explained in Appendix C. The right axes shows the value of the $\operatorname{VaR}_{m, t}(0.05)$ in percentage. The dash-dotted black line indicate the VaR level over time. 
Table 10: Kolgomorov-Smirnov bootstrap p-values

\begin{tabular}{|c|c|c|c|c|c|c|c|c|c|c|c|c|}
\hline & & A & B & C & D & $E$ & $\mathrm{~F}$ & G & $\mathrm{H}$ & I & J & $\mathrm{K}$ \\
\hline \multirow[t]{2}{*}{ BE05 } & $\begin{array}{l}\text { Pre- } \\
\text { crisis }\end{array}$ & 0,000 & 0,000 & 0,000 & 0,255 & 0,000 & 0,001 & 0,000 & 0,000 & 0,000 & 0,000 & 0,000 \\
\hline & $\begin{array}{l}\text { Post- } \\
\text { crisis }\end{array}$ & 0,000 & 0,000 & 0,000 & 0,000 & 0,000 & 0,000 & 0,000 & 0,000 & 0,000 & 0,000 & 0,000 \\
\hline \multirow[t]{2}{*}{ BU05 } & $\begin{array}{l}\text { Pre- } \\
\text { crisis }\end{array}$ & 0,000 & 0,000 & 0,000 & 1,000 & 0,000 & 0,000 & 0,109 & 0,000 & 0,009 & 0,000 & 0,001 \\
\hline & $\begin{array}{l}\text { Post- } \\
\text { crisis }\end{array}$ & 0,000 & 0,000 & 0,000 & 0,000 & 0,000 & 0,001 & 0,000 & 0,000 & 0,000 & 0,000 & 0,000 \\
\hline \multirow[t]{2}{*}{ BE95 } & $\begin{array}{l}\text { Pre- } \\
\text { crisis }\end{array}$ & 0,000 & 0,000 & 0,000 & 0,991 & 0,000 & 0,000 & 0,015 & 0,001 & 0,000 & 0,009 & 0,001 \\
\hline & $\begin{array}{l}\text { Post- } \\
\text { crisis }\end{array}$ & 0,000 & 0,000 & 0,000 & 0,000 & 0,000 & 0,001 & 0,000 & 0,000 & 0,000 & 0,000 & 0,000 \\
\hline \multirow[t]{2}{*}{ BU95 } & $\begin{array}{l}\text { Pre- } \\
\text { crisis }\end{array}$ & 0,000 & 0,000 & 0,071 & 0,986 & 0,041 & 0,007 & 0,000 & 0,000 & 0,678 & 0,000 & 0,000 \\
\hline & $\begin{array}{l}\text { Post- } \\
\text { crisis }\end{array}$ & 0,004 & 0,000 & 0,000 & 0,000 & 0,058 & 0,000 & 0,030 & 0,000 & 0,000 & 0,078 & 0,000 \\
\hline
\end{tabular}

This table shows the p-values of the Kolgomorov-Smirnov bootstrap test using 2000 simulations to compare the distribution of $\mathrm{CoVaR}$ with the values of $\mathrm{VaR}$ before and after the 2008 financial crisis. For more information about the Kolmogorov Smirnov bootstrap test see for instance [2], [16], [58].

A: EUROSTOXX; B: OIL\&GAS; C: BASICMATS; D: INDUSTRIALS; E: CONSUMERGDS; F: HEALTHCARE; G: CONSUMERSVS; H: TELECOM; I:UTILITIES; J: FINANCIALS; K: TECHNOLOGY.

BE05: bearish $\operatorname{CoVaR}_{m \mid 0, t}(0.05,0.05)$, BU05: bullish $\operatorname{CoVaR}_{m \mid o, t}(0.05,0.05)$, BE95: bearish $\operatorname{CoVaR}_{m \mid 0, t}(0.05,0.95)$, BU95: bullish $\operatorname{CoVaR}_{S^{U}, o^{U}}(0.05,0.95)$. BE05 and BU05 are compared with the $\operatorname{VaR}_{m, t}(0.05)$ while BE95 and BU95 are compared with $\operatorname{VaR}_{m, t}(0.95)$.

Pre-crisis subsample goes from January $7^{\text {th }}, 2000$ to September $12^{\text {th }}, 2008$. Post-crisis subsample goes from $19^{\text {th }}$ September 2008 to $23^{\text {rd }}$ October 2015. 
Table 11: Quantiles of the CoVaR - VaR distribution before and after the 2008 financial crisis.

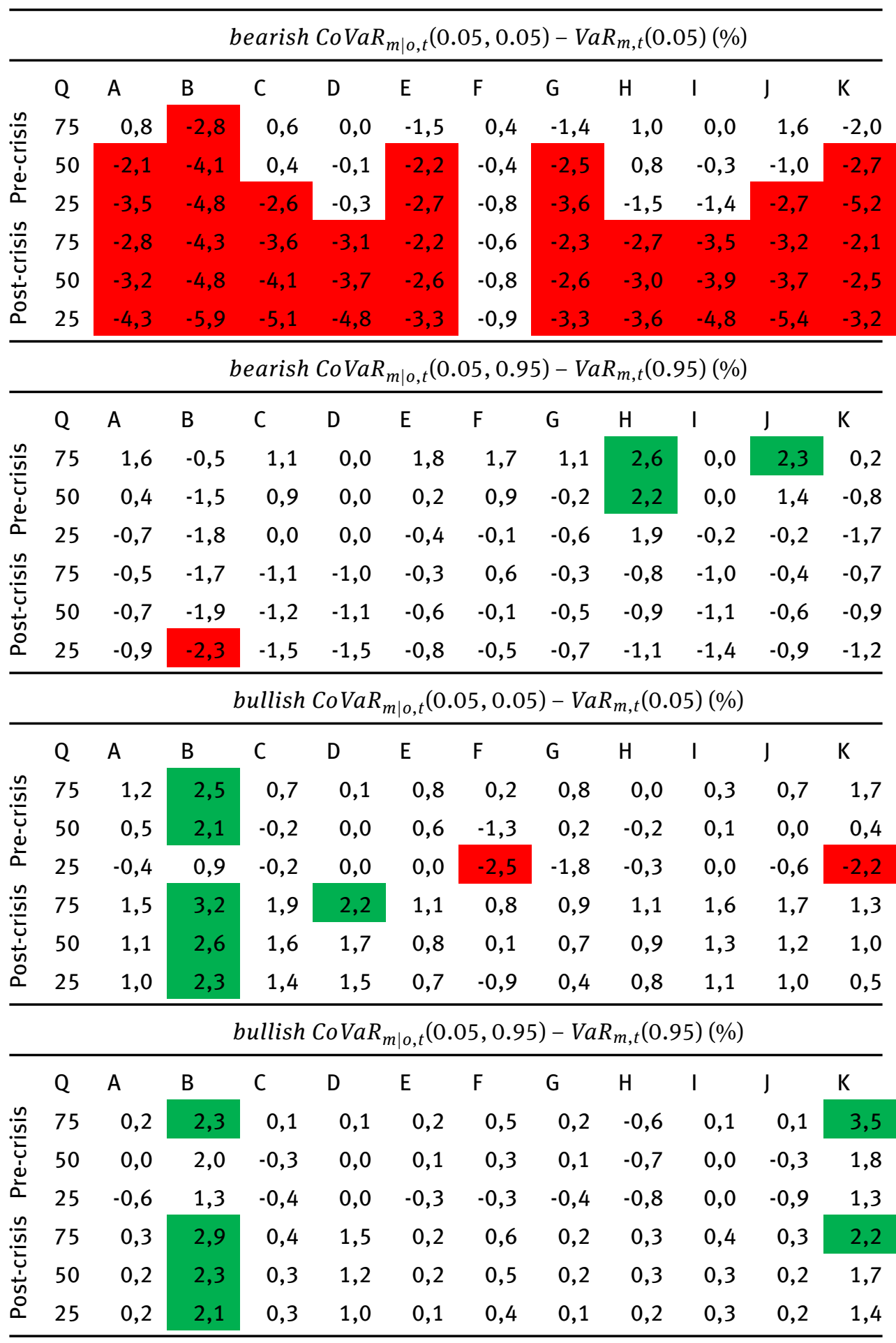

The table shows different quantiles (75-th, the median and the 25-th) of the CoVaR - VaR distribution in the pre-crisis and post-crisis samples. Values that implies an underestimation (overestimation) of the $V a R$ higher than $2 \%$ are in red (green).

A: EUROSTOXX; B: OIL\&GAS; C: BASICMATS; D: INDUSTRIALS; E: CONSUMERGDS; F: HEALTHCARE; G: CONSUMERSVS; H: TELECOM; I:UTILITIES; J: FINANCIALS; K: TECHNOLOGY. 
$V a R$ measure when a certain oil-related scenario occurs higher than $2 \%$. The change in $\operatorname{VaR}_{m, t}(0.05)$ occurs in more sectors than in the $V a R_{m, t}(0.95)$ given a bearish oil scenario. This change also increases after the financial crisis getting even in the highest 25 -th quantile an excess of losses greater than $2 \%$ for all sectors with the exception of the healthcare.

The following subsection performs a forecast exercise to test the healthcare sector's features as a hedging asset against extreme oil movement.

\subsection{Portfolio exercise using an out-of-sample period}

Results in previous sections suggest that the healthcare sector may have useful features to reduce the exposure of the stock portfolio to extreme movements in oil prices. To test the hedging possibilities, I build a portfolio given the information available up to the end of the in-sample period, i.e. 23 October 2015. The portfolio is rebalanced every four months until 27 July 2018. It consists of long positions in a benchmark stock market index, the Eurostoxx, and the healthcare sector. I use Monte Carlo simulations to obtain the weekly returns of Eurostoxx and healthcare sector four months ahead ${ }^{7}$. The same seed is used for all the simulations of the oil quantile to be sure that the paths for Eurostoxx and healthcare returns are consistent, i.e. obtained under the same oil scenario. Then, I compute the VaR, the bullish CoVaR and the bearish CoVaR for different weights of the portfolio. The top subgraph from Figure 10 presents the forecast for the nine rebalancing periods of $\operatorname{VaR}$ in the brown line, the bearish $\operatorname{CoVaR}(0.05,0.05)$ in the red line and the bullish $\operatorname{CoV} \operatorname{VaR}(0.05,0.05)$ in the blue line. Eurostoxx returns have lower bearish $\operatorname{CoVaR}(0.05,0.05)$ than healthcare sector but higher bullish $\operatorname{CoVaR}(0.05,0.05)$ for most of the forecast periods. To weight equally the extreme downward and upward movements in oil prices I assess the mean $\operatorname{CoVaR}(0.05,0.05)$ as the mean between the bearish and bullish $\operatorname{CoVaR}(0.05,0.05)$ in the black line. Not surprisingly, the optimal weight to minimize VaR (vertical dash-dotted brown line) and the optimal weights to minimize mean $\operatorname{CoVaR}(0.05,0.05)$ (vertical dash-dotted black line) coincide for most of the periods. Due to the simulation procedure, Eurostoxx and healthcare returns are conditionally independent, i.e. they are dependent only through the common exposure to oil returns. Hence, decreasing the exposure of the portfolio to extreme movements in oil prices implies a reduction in the degree of dependence between both assets. The lower subgraph from Figure 10 presents a performance measure where expected return is weighted by its risk, defined by its $5 \%$ lowest return in absolute value. The higher this ratio is, the lower is the risk to be faced by the investor for the same expected return. Note that the relationship between this ratio and the weights of the portfolio is not linear, and its sign depends on the oil scenario. This result indicates potential advantages introducing healthcare into the stock portfolio. Finally, I show the joint distribution of oil, Eurostoxx, healthcare sector and our optimal portfolio in Figure 11 for the out-of-sample period. The scatter plot combines with the histograms of the marginal distribution in the axes, smoothed by a kernel function. The x-axis shows the marginal distribution of the oil returns. The yellowish area indicates the scenario where oil prices experience a bullish period (top subplot) or a bearish period (bottom subplot). The y-axis indicates the conditional distribution histogram (smoothed by a kernel function), where the portfolio behaviour is closer to the distribution of the returns of the Eurostoxx or healthcare sector depending on the oil scenario. This features gives to our portfolio a better performance in terms of $\mathrm{CoVaR}^{8}$.

7 Detailed information about the simulation process is provided in Appendix C

8 The CoVaR is employed taking the $10 \%$ lowest returns of the equity portfolios given that the oil returns is above its $10 \%$ best case scenario or below its $10 \%$ worst case scenario 
Figure 10: Forecast exercise : building a portfolio without tail dependence using Eurostoxx and health sector assets

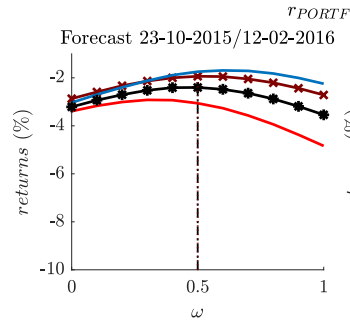

Forecast 23-09-2016/13-01-2017

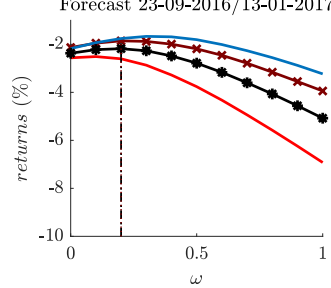

Forecast 25-08-2017/15-12-2017

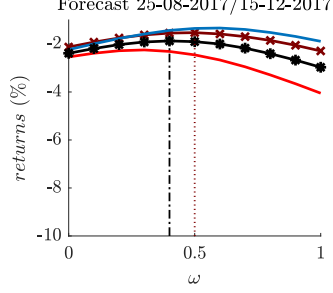

PORTFOLIO,$t=\omega r_{E U R O S T O X X, t}+(1-\omega) r_{H E A L T H C A R E, t}$

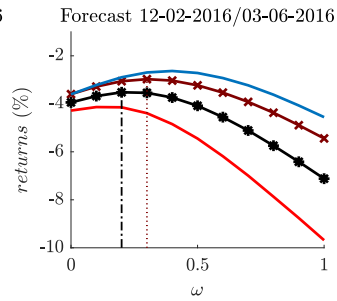

Forecast 13-01-2017/05-05-2017
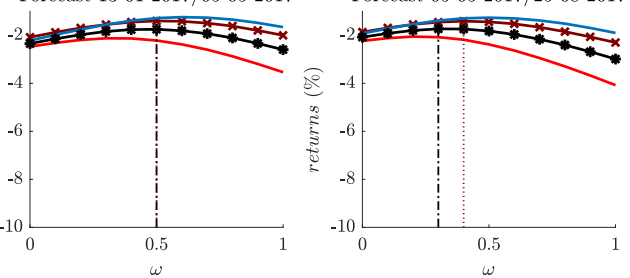

Forecast 06-04-2018/27-07-2018

Forecast 15-12-2017/06-04-2018
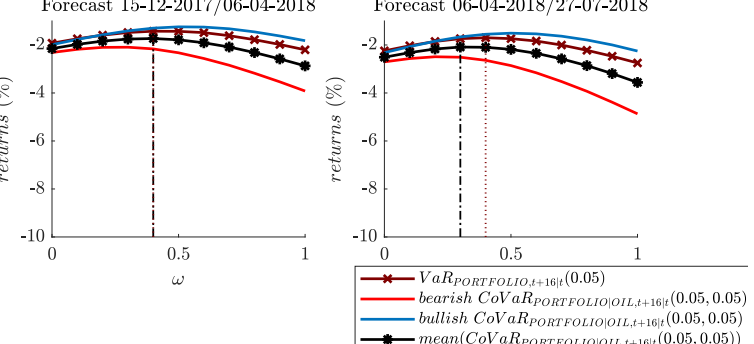

(a) Forecast $\operatorname{CoVaR}(0.05,0.05)$ and optimum weights between EUROSTOXX and HEALTH CARE sector
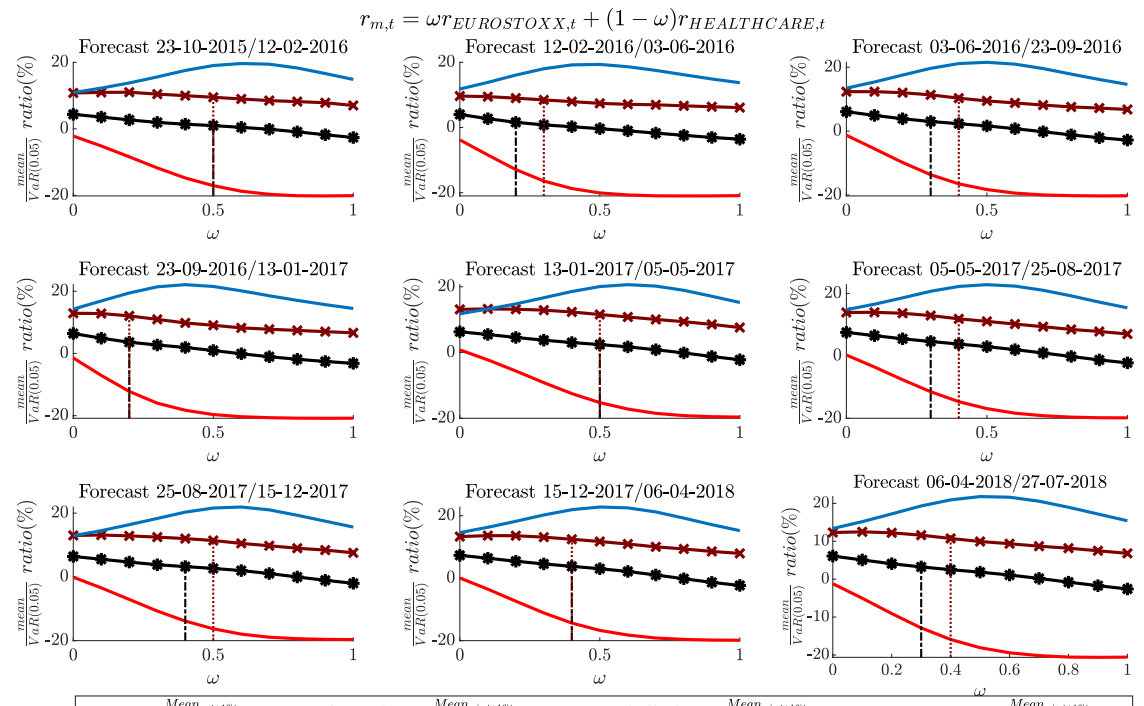

Forecast 06-04-2018/27-07-2018

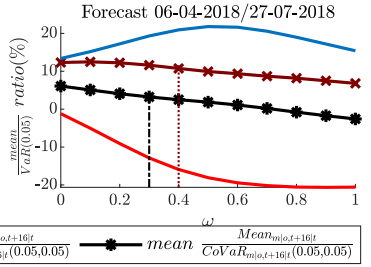

(b) Ratio between the median return of the portfolio and its $95 \%$ higher losses

A four-month period forecast for the bearish and bullish $\operatorname{CoVaR}(0.05,0.05)$, and the $\operatorname{VaR}(0.05)$ is calculated out-of-sample using Monte Carlo simulations (W=100000) for a portfolio of Eurostoxx and health care. Top subfigure shows the forecast estimation for the different four-month periods and the optimal portfolio weights to minimize the mean $\operatorname{CoVaR}(0.05,0.05)$, i.e. the mean between the bullish and the bearish $\operatorname{CoVaR}(0.05,0.05)$. Lower subfigure shows a performance measure, which consists of the ratio between the mean returns of the portfolio and its $\operatorname{CoVaR}(0.05,0.05)$ in absolute values. The higher this ratio is, the lower risk has to be faced by the investor for the same expected return. 
Figure 11: Empirical joint distribution during the out-of-sample period, where the current oil scenario is shaded in yellow

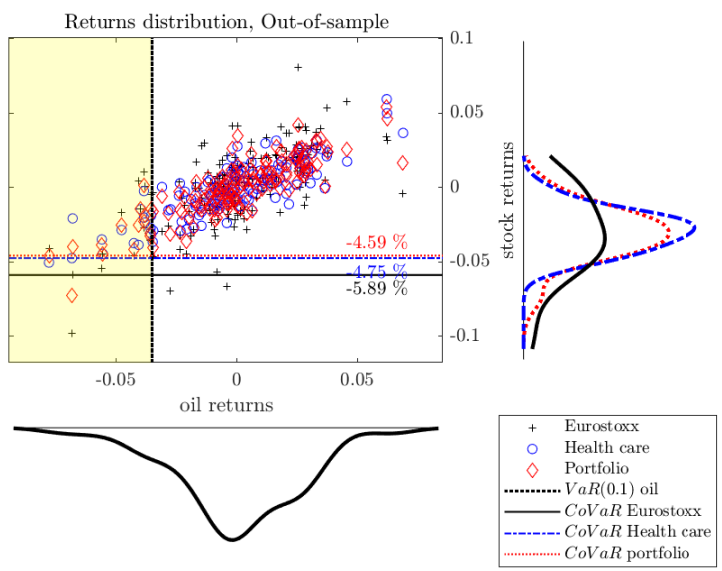

(a) Y-axis shows the conditional distribution for the stock portfolios given a downward movement in oil prices

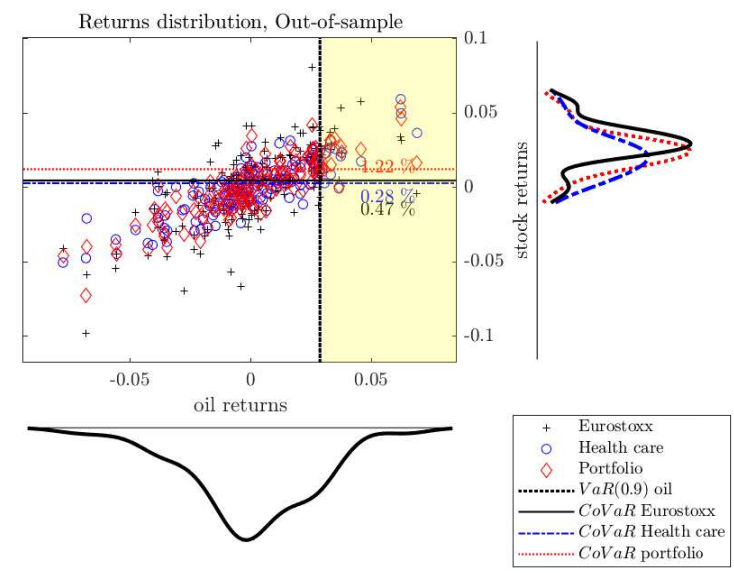

(b) Y-axis shows the conditional distribution for the stock portfolios given a upward movement in oil prices

The scatter plot shows the joint distribution between the returns of oil and equity. The x-axis shows the unconditional marginal distribution of the oil returns in the out-of-sample period. The y-axis shows the conditional distribution of the returns of

Eurostoxx, healthcare sector and our optimal portfolio given the oil scenario, defined as being below the $10 \%$ or above the $90 \%$ percentile. The yellowish are indicates these scenarios. The CoVaR shows the $10 \%$ worst case scenario for the Eurostoxx, healthcare sector and our portfolio. 


\section{Conclusions}

This article quantifies the spillovers from oil returns to the European stock market using CoVaR measures during the period 2000-2015. The Conditional Value-at-Risk helps us to understand better the unexpected link arising on extreme scenarios, i.e. it provides a more robust estimation to outliers than mean response results where non-linear spillovers and asymmetric tail dependence might be overlooked. Furthermore, the CoVaR measure is coherent with the risk aversion of economic agents, who are more interested on realising how adverse the portfolio behaviour can become than on knowing how its performance can be on average. The relationship between oil and stock markets is known to be characterised by non-linearities, asymmetric dependence and structural changes. A Switching Markov approach is then useful because it can identify hidden patterns in dependence across regimes and it can capture non-linear features and asymmetries that evolve over time. Allowing for a change not only in the copula parameter but in the copula itself provides us with an econometric analysis that can produce very significant results for risk management. I show that such flexibility in the model prevents us from mistaking negative dependence for null dependence.

The model identifies a switch from negative to positive lower tail dependence. During the period 2003-2008, lower quantiles in oil returns imply higher quantiles in stock returns while, after the financial crisis, lower quantiles in stock returns are associated with lower oil returns. This structural change in the oil-stock market relationship is led by the oil-intensive sectors, e.g. basic materials or consumer goods. The dependence switch might be closely related to the economic cycle. Indeed, the dependence on the negative lower tail indicates that a decrease in oil prices would generally increase the margin between final prices and the unit cost of production before the crisis, while a rise in oil prices may have usually been reflected in the final price. The increase in prices would not necessarily lead to a lower demand because the income increases in the expansion phase of the business cycle. This could explain the negative lower tail dependence and the absence of upper tail dependence. The 2008 crisis led to a credit crunch and losses for European companies that implied a drop in oil demand, which in turn led to a decrease in its price explaining the positive dependence on the lower tail. The link in the co-movement between the economic sectors and oil prices through the business cycle is already pointed out by [7] for the US economy.

The results are relevant for investors, who want to reduce the oil exposure of their stock portfolios. The healthcare sector helps to decrease the exposure of stock market portfolio to oil shocks without taking a short position in commodities. Such strategy decreases the dependence between the stock portfolio and oil returns reducing the maximum loss provided by the unconditional Value-at-Risk. The market authorities need a quantitative analysis of the impact of oil shifts on the stock market to properly monitor the behaviour of companies in the stock exchange. Given an extreme movement in oil prices or its expectation, CoVaR provides useful information that may suggest placing in trading halt a certain quote in the stock exchange, or to update the variation margin for some stock derivatives. Sector analysis has implications for policy makers who are concerned about the effect on stock markets of extreme changes in oil prices, as their consequences can be felt in terms of growth and employment. In fact, policy makers can use CoVaR as a short-term quantitative assessment of the effects of sharp movements in oil prices on the economic sectors to have an estimate of the consequences to households income through losses in their portfolios.

Further research should analyse the potential role of exchange rate to mitigate the negative effects of abrupt movements in oil prices on the stock market. Since oil prices are denominated in dollars that are then translated into Euros, a transitory shock in oil prices can be alleviated by the right movement in the exchange rate. Additional robustness checks can be performed by slightly modifying the model. As [64] claims, volatility may be the trigger conditioning the type of relationship between oil and the stock market. This hypothesis could be checked by building a Switching Markov model where the transition probabilities of the copula function depend on the transition probabilities of the volatility of the stock market. 
Acknowledgement: I thank my PhD supervisor, Prof. Alfonso Novales Cinca. I am grateful for the comments provided by Carlo Giovanni Boffa and Juan Carlos Reboredo. This article was presented at the CNMV (Spanish National Securities Market Commission) on 20 December 2018, at the 12th RGS Doctoral Conference in Economics on the 19 February 2019 and at the University of Basque Country (UPV/EHU) on 1 March 2019. I really appreciate useful advice and comments provided by the participants at these seminars. This research was supported by the Ministry of Education of Spain (FPU scholarship: FPU15/04241).

\section{Appendices}

\section{A Bivariate Copula set}

Gaussian and Student copula are elliptical copulas, i.e., the bivariate joint density under these copulas has elliptic isodensities.

Gumbel, Clayton and BB1 are Archimedean copulas, which implies that can be expressed as a function of the generate function $\phi$ and its inverse $\phi^{-1}$, i.e. $C\left(u_{1}, u_{2}, \theta\right)=\phi^{-1}\left[\phi\left(u_{1} ; \theta\right)+\phi\left(u_{2} ; \theta\right) ; \theta\right]$ where $\theta$ is the copula parameter.

To enhance the features of copulas that only allow for positive dependence, they are rotated to capture negative tail dependence. The next table shows the tail dependence for the $90^{\circ}$ rotated copulas. The $90^{\circ}$ rotated copulas are built modifying slightly the standard copula, i.e.

$$
C_{90}\left(u_{1}, u_{2}\right)=u_{2}-C\left(1-u_{1}, u_{2}\right)
$$

\section{A.0.1 Gaussian copula.}

This copula has a parameter $\rho$ that gathers linear correlation. When $\rho=1$ the tail dependence is 1 , otherwise this copula does not present tail dependence. There is not a closed form expression due to the fact that Gaussian copula is an implicit copula. [52] takes a in-depth look at this copula.

The copula probability density function is

$$
c\left(u_{1}, u_{2} ; \rho\right)=\frac{1}{\sqrt{1-\rho^{2}}} \exp \left\{-\frac{\rho^{2} \Phi^{-1}\left(u_{1}\right)^{2}-2 \rho \Phi^{-1}\left(u_{1}\right) \Phi^{-1}\left(u_{2}\right)+\rho^{2} \Phi^{-1}\left(u_{2}\right)^{2}}{2\left(1-\rho^{2}\right)}\right\},
$$

where $\Phi^{-1}$ stands for the Gaussian inverse cumulative distribution function.

The conditional copula $C_{2 \mid 1}\left(u_{2} \mid u_{1} ; \rho\right)$ is

$$
\Phi\left(\frac{\Phi^{-1}\left(u_{2}\right)-\rho \Phi^{-1}\left(u_{1}\right)}{\sqrt{1-\rho^{2}}}\right) .
$$

\section{A.0.2 Student copula.}

This copula allows for positive and negative symmetric tail dependence. The parameter $\rho$ measures correlation and the parameter $\eta$, the number of degrees of freedom, controls the probability mass assigned to extreme joint co-movements of risk factors changes. ${ }^{9}$ When $\eta \rightarrow \infty$ corresponds to the Gaussian copula. ${ }^{10}$ Student copula has not a closed form because it is a implicit copula.

9 For more information about the properties of the t-Student copula see [27]

10 The Gaussian copula underestimates the probability of joint extreme co-movements in high volatility and correlation scenarios (see [13]) 
Table 12: Tail dependence for the $90^{\circ}$ rotated copulas

\begin{tabular}{lcc}
\hline & $\tau_{L \mid U}$ & $\tau_{U \mid L}$ \\
\hline $90^{\circ} R$ Clayton & $2^{-1 / \theta}$ & - \\
$90^{\circ} R$ Gumbel & - & $2-2^{1 / \theta}$ \\
$90^{\circ} R$ BB1 & $2^{\frac{-1}{\theta \delta}}$ & $2-2^{1 / \delta}$ \\
\hline
\end{tabular}

$\theta$ and $\delta$ are the copula parameters from the original copula. Further information about the rotated copula can be found in [18], [20], [31] and [49]. Let $u_{1}$ and $u_{2}$ denote two variables uniformly distributed across $(0,1)$.

- The negative lower tail dependence, $\tau_{L \mid U}$, is defined as $\tau_{L \mid U}=$ $\lim _{q \rightarrow 0} P\left(u_{2}<q \mid u_{1}>1-q\right)$.

- The negative upper tail dependence, $\tau_{U \mid L}$ is defined as $\tau_{U \mid L}=$ $\lim _{q \rightarrow 1} P\left(u_{2}>q \mid u_{1}<1-q\right)$.

Figure 12 shows an example of how change the distribution and the tail joint behaviour when the $90^{\circ}$ rotated copula is employed. See [76] for further details about negative tail dependence.

The copula probability density function is

$$
\begin{aligned}
c\left(u_{1}, u_{2} ; \eta, \rho\right)= & K \frac{1}{\sqrt{1-\rho^{2}}} \\
& {\left[1+\frac{T_{\eta}^{-1}\left(u_{1}\right)^{2}-2 \rho T_{\eta}^{-1}\left(u_{1}\right) T_{\eta}^{-1}\left(u_{2}\right)+T_{\eta}^{-1}\left(u_{2}\right)^{2}}{\eta\left(1-\rho^{2}\right)}\right]^{-\frac{\eta+2}{2}} } \\
& {\left[\left(1+\eta^{-1} T_{\eta}^{-1}\left(u_{1}\right)^{2}\right)\left(1+\eta^{-1} T_{\eta}^{-1}\left(u_{2}\right)^{2}\right)\right]^{\frac{\eta+1}{2}}, }
\end{aligned}
$$

where $K=\Gamma\left(\frac{\eta}{2}\right) \Gamma\left(\frac{\eta+1}{2}\right)^{-2} \Gamma\left(\frac{\eta+2}{2}\right)$.

The conditional copula $C_{2 \mid 1}\left(u_{2} \mid u_{1} ; \rho, \eta\right)$ is

$$
T_{\eta+1}\left(\sqrt{\frac{\eta+1}{\eta+\left(T_{\eta}^{-1}\left(u_{1}\right)\right)^{2}}} \frac{T_{\eta}^{-1}\left(u_{2}\right)-\rho T_{\eta}^{-1}\left(u_{1}\right)}{\sqrt{1-\rho^{2}}}\right)
$$

where $T_{\eta}$ is the cdf of a t-Student with the numbers of degrees of freedom equal to $\eta$ and $T_{\eta}^{-1}$ represents its inverse footnoteSee for instance [20] 
Figure 12: Rotated copulas employed to capture negative tail dependence
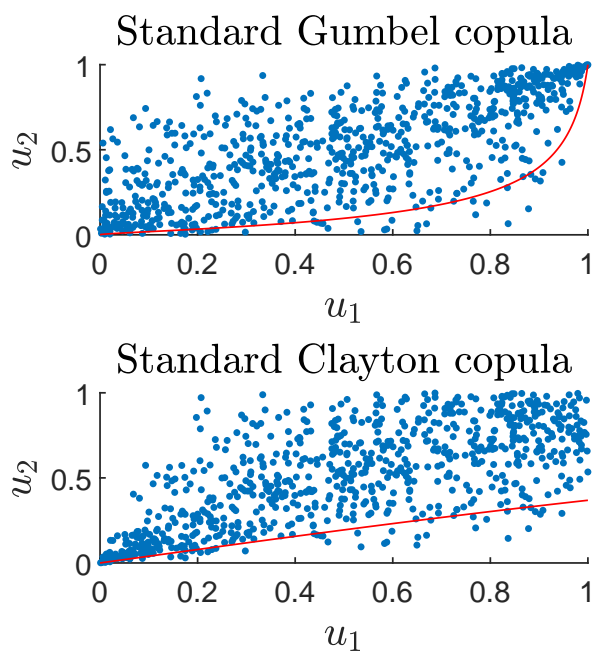

Standard BB1 copula

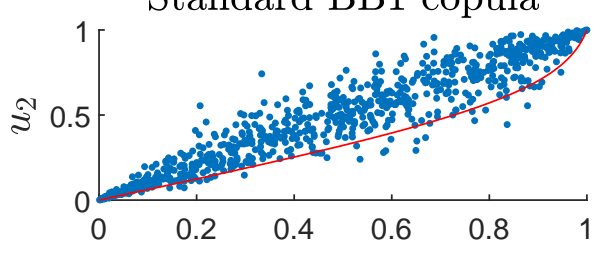

$90^{\circ}$ rotated Gumbel copula

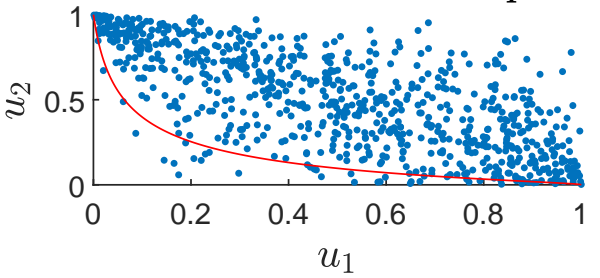

$90^{\circ}$ rotated Clayton copula

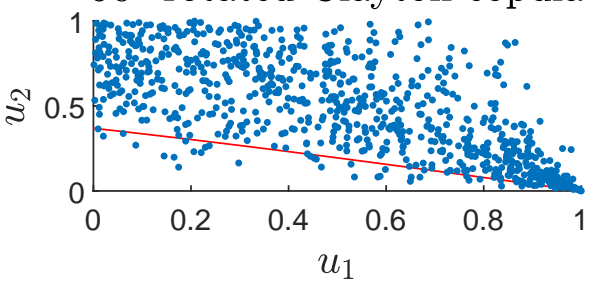

$90^{\circ}$ rotated $\mathrm{BB} 1$ copula

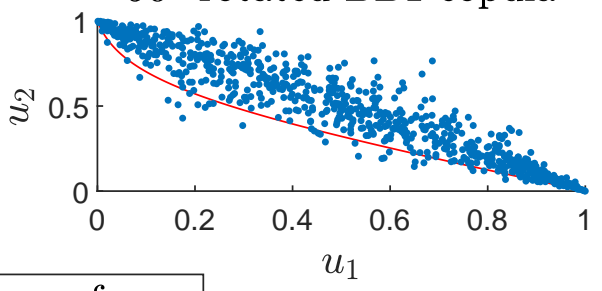

5-quantile curve for $u_{2}$

This figure shows 800 simulations from the same seed but under different copula assumptions. Rotating 90 degrees allows us to capture negative upper tail dependence $\left(90^{\circ}\right.$ rotated Gumbel), negative lower tail dependence $\left(90^{\circ}\right.$ rotated Clayton) or negative asymmetric tail dependence $\left(90^{\circ}\right.$ rotated BB1). The red line indicates the threshold below which the $5 \%$ of the $u_{2}$ are found given the values taken by $u_{1}$. Gumbel and Clayton copula has a copula parameter $\theta=2$. BB1 has copula parameters $\theta=2$ and $\delta=2.5$.

\section{A.0.3 Clayton copula.}

This copula allows positive dependence and asymmetric lower tail dependence. The Clayton copula has a dependence parameter $\theta \in(0,+\infty)$. When $\theta \rightarrow 0$ implies independence and when $\theta \rightarrow \infty$ implies perfect dependence.

The Clayton copula is

$$
C\left(u_{1}, u_{2} ; \theta\right)=\left(u_{1}^{-\theta}+u_{2}^{-\theta}-1\right)^{-1 / \theta},
$$

and the copula probability density function is

$$
c\left(u_{1}, u_{2} ; \theta\right)=(\theta+1)\left(u_{1}^{-\theta}+u_{2}^{-\theta}-1\right)^{-2-\frac{1}{\theta}}\left(u_{1} u_{2}\right)^{-\theta-1} .
$$

The conditional copula $C_{2 \mid 1}\left(u_{2} \mid u_{1} ; \theta\right)$ is

$$
\left(u_{1}^{-\theta}+u_{2}^{-\theta}-1\right)^{-\frac{1+\theta}{\theta}} u_{1}^{-\theta-1}
$$

\section{A.0.4 Gumbel copula.}

This copula allows for positive dependence and asymmetric upper tail dependence. The Gumbel copula has a dependence parameter $\theta \in[1,+\infty)$. When $\theta=1$ implies independence and when $\theta \rightarrow \infty$ implies perfect dependence. 
The Gumbel copula is

$$
C\left(u_{1}, u_{2} ; \theta\right)=\exp \left(-\left\{\left(-\log u_{1}\right)^{\theta}+\left(-\log u_{2}\right)^{\theta}\right\}^{1 / \theta}\right),
$$

and the copula probability density function is

$$
\begin{aligned}
c\left(u_{1}, u_{2} ; \theta\right)= & (A+\theta-1) A^{1-2 \theta} \exp (-A) \\
& \left(u_{1} u_{2}\right)^{-1}\left(-\log u_{1}\right)^{\theta-1}\left(-\log u_{2}\right)^{\theta-1},
\end{aligned}
$$

where $A=\left[\left(-\log u_{1}\right)^{\theta}+\left(-\log u_{2}\right)^{\theta}\right]^{\frac{1}{\theta}}$.

The conditional copula $C_{2 \mid 1}\left(u_{2} \mid u_{1} ; \theta\right)$ is

$$
\exp \left(-\left\{\left(-\log u_{1}\right)^{\theta}+\left(-\log u_{2}\right)^{\theta}\right\}^{1 / \theta}\right)\left\{\left(-\log u_{1}\right)^{\theta}+\left(-\log u_{2}\right)^{\theta}\right\}^{1 / \theta-1}\left(-\log u_{1}\right)^{\theta-1} \frac{1}{u_{1}}
$$

\section{A.0.5 BB1 copula.}

The BB1 copula, also known as the Clayton-Gumbel copula, allows asymmetric tail dependence. The BB1 copula has two dependence parameters: one for the Clayton behaviour $\theta \in(0,+\infty)$ and another one for the Gumbel behaviour $\delta \in[1,+\infty)$. When $\delta=1$ and $\theta>0$ we get the Clayton copula and as a consequence upper tail independence and lower tail dependence. When $\theta \rightarrow 0$ and $\delta>0$ the Gumbel copula is obtained with upper tail dependence only. In the case of $\theta \rightarrow 0$ and $\delta=1$ we get upper and lower tail independence. ${ }^{11}$ The BB1 copula is

$$
C\left(u_{1}, u_{2} ; \theta, \delta\right)=\left(1+\left[\left(u_{1}^{-\theta}-1\right)^{\delta}+\left(u_{2}^{-\theta}-1\right)^{\delta}\right]^{1 / \delta}\right)^{-1 / \theta},
$$

and the copula probability density function is

$$
c\left(u_{1}, u_{2} ; \theta, \delta\right)=\left(u_{1} u_{2}\right)^{-\theta-1}(a b)^{\delta-1} c^{\frac{1}{\delta}-2} d^{-\frac{1}{\theta}-1}\left\{d^{-1} c^{\frac{1}{\delta}}(1+\theta)+\theta(\delta-1)\right\},
$$

where $a=u_{1}^{-\theta}-1, b=u_{2}^{-\theta}-1, c=a^{\delta}+b^{\delta}$ and $d=1+c^{\frac{1}{\delta}}$.

The conditional copula $C_{2 \mid 1}\left(u_{2} \mid u_{1} ; \theta, \delta\right)$

$$
\left(1+\left[A^{\delta}+B^{\delta}\right]^{1 / \delta}\right)^{-\frac{1+\theta}{\theta}}\left[A^{\delta}+B^{\delta}\right]^{\frac{1}{\delta}-1} A^{\delta-1} u_{1}^{-\theta-1}
$$

where $A=\left(u_{1}^{-\theta}-1\right)$ and $B=\left(u_{2}^{-\theta}-1\right)$

\section{B Switching Markov specification for modelling joint dependence}

This appendix sums up briefly the Switching Markov estimation procedure of the joint distribution using a copula approach.

Given the [72]'s representation of the joint distribution in terms of copulas, we can assumed that the dependence between variables depends on an unobservable regime. This assumption means rewriting Equation (1) as Equation (7). Equation (11) shows the result of deriving Equation (7) from its inputs. We obtain the joint density function as the product of the marginal density functions and the copula density function.

Let us define $\Psi$ as a vector $2 \mathrm{x} 1$ that gathers the conditional copula density between $r_{o, t}$ and $r_{m, t}$ for each of the two different regimes, i.e.

$$
\Psi=\left[\begin{array}{l}
c\left(u_{o, t}, u_{m, t} ; \theta_{s_{t}=1}, s_{t}=1\right) \\
c\left(u_{o, t}, u_{m, t} ; \theta_{s_{t}=2}, s_{t}=2\right)
\end{array}\right]
$$

$\overline{11}$ See for instance [74] or [57] 
where $\theta_{s_{t}}$ is the copula parameter under the regime $s_{t}$ and $u_{o, t}$ and $u_{m, t}$ refer to the marginal cumulative distribution function of oil and stock market returns.

I assume that these conditional densities depend only on the current regime $s_{t}$ but not on previous regimes, i.e. $c\left(u_{o, t}, u_{m, t} ; I_{t-1}, s_{t}=j ; \theta_{s_{t}=j}\right)=c\left(u_{o, t}, u_{m, t} ; I_{t-1}, s_{t}=j, s_{t-1}=i, \ldots ; \theta_{s_{t}=j}\right)$ for $i, j=1,2$ and $I_{t-1}$ refers to the information set at $t-1$. I assume that the evolution of $s_{t}$ follows a first order Markov chain independent from past observations for oil and stock market returns, i.e.

$$
p_{i j}=P\left(s_{t}=j \mid s_{t-1}=i\right)=P\left(s_{t}=i \mid s_{t-1}=j, s_{t-2}=k, I_{t-1}\right),
$$

for $i, j, k=1,2$.

The transition matrix is shown in Equation (9) where each column $i$ indicates the probability of remaining on the state $i\left(p_{i i}\right)$ or moving to state $j\left(p_{i j}\right)$ conditioned to the fact that we are currently at state $i$ for $i, j=1,2$ and $i \neq j$. Obviously, $p_{i i}+p_{i j}=1$ because we only consider two states. That is the reason why Equation (9) presents $p_{i j}$ as $1-p_{i i}$. We can obtain two concepts with significant economic implications from the transition matrix: the expected duration and the unconditional probabilities of each state.

The expected length for state $i$ can be assessed as

$$
\frac{1}{1-p_{i i}},
$$

for $i=1,2$. [34, Chapter 22]. The expected length for each state can give us an idea about the persistence in the dependence given by each regime, which is extremely useful from an economic point of view.

The unconditional probability of each state is the results of computing the ergodic probabilities. These probabilities make up the eigenvector of the matrix P from Equation (9) associated to the unit eigenvalue, such that its elements sums one, i.e.

$$
P \pi=\pi,
$$

where $\pi=(\alpha, 1-\alpha)^{\prime}$ Hence, $p_{11} \alpha+\left(1-p_{22}\right)(1-\alpha)=\alpha$ so the unconditional probability of being in the state 1 is $\alpha=\frac{1-p_{22}}{2-p_{11}-p_{22}}$ and for the state 2 is $1-\alpha=\frac{1-p_{11}}{2-p_{11}-p_{22}}$.

Let us assume that the marginal distribution of the variables employed as input in the copula and the set of copula parameters $\theta$ are known. Let us gather the probability assigned to the observation at time $t$ of being the result of regime $j$, i.e. $P\left(s_{t}=j \mid I_{t} ; \theta\right)$, in a vector $\hat{\xi}_{t \mid t}$,

$$
\hat{\xi}_{t \mid t}=\left[P\left(s_{t}=1 \mid I_{t} ; \theta\right), P\left(s_{t}=2 \mid I_{t} ; \theta\right)\right]^{\prime} .
$$

$\hat{\xi}_{t \mid t}$ comprises the inference about the regime at time $t$ given the information available at that period. The probability assigned to the observation at time $t+1$ of being the result of regime $j$ given the information at time $t$ is collected in vector $\hat{\xi}_{t+1 \mid t}$,

$$
\hat{\xi}_{t+1 \mid t}=\left[P\left(s_{t}=1 \mid I_{t-1} ; \theta\right), P\left(s_{t}=2 \mid I_{t-1} ; \theta\right)\right]^{\prime} .
$$

$\hat{\xi}_{t+1 \mid t}$ is the probability forecast of being in the next period $t+1$ at each regime given the information available at $t$.

The link between $\hat{\xi}_{t \mid t}$ and $\hat{\xi}_{t+1 \mid t}$ is obtained by the updated probabilities. The updated probabilities include the new available information through Bayes' theorem, i.e.

$$
P\left(s_{t}=j \mid I_{t} ; \theta\right)=\frac{P\left(s_{t}=j \mid I_{t-1} ; \theta\right) f\left(r_{o, t}, r_{m, t} \mid I_{t-1} ; \Theta_{s_{t}=j}\right)}{L_{t}\left(r_{o, t}, r_{m, t} ; I_{t-1}, \Theta\right)},
$$

where $f\left(r_{o, t}, r_{m, t} \mid I_{t-1} ; \Theta_{S_{t}=j}\right)$ is given by Equation (11) and $L_{t}\left(r_{o, t}, r_{m, t} ; I_{t-1}, \Theta\right)$ is the likelihood function in Equation (10). Observe that in Equation (10) we are multiplying the joint density of $r_{o, t}$ and $r_{m, t}$ conditioned to the occurrence of each possible state at $t$ by its probability at $t$ given the information set at $t-1$. Assuming that the marginal behaviour of each variable does not depend on the state and only the dependence changes across states we can rewrite the previous equation that connects $\hat{\xi}_{t \mid t}$ and $\hat{\xi}_{t+1 \mid t}$ in a matrix form as

$$
\hat{\xi}_{t \mid t}=\frac{\hat{\xi}_{t \mid t-1} \odot \Psi}{1_{2}^{\prime}\left(\hat{\xi}_{t \mid t-1} \odot \Psi\right)},
$$


where $\Psi$ was defined in Equation (12) while the forecast probability for the next period is obtained as the product of the inference probability by the transition matrix, i.e.

$$
\hat{\xi}_{t+1 \mid t}=P \hat{\xi}_{t \mid t}
$$

To start the iteration we need a value for $\hat{\xi}_{1 \mid 0}$, for which I use the unconditional probabilities of each state that can be expressed in a matrix form as

$$
\hat{\xi}_{1 \mid 0}=\pi=\left(A^{\prime} A\right)^{-1} A^{\prime}(0,0,1)^{\prime}
$$

where

$$
A=\left[\begin{array}{c}
I_{2}-P \\
1_{2}^{\prime}
\end{array}\right]=\left[\begin{array}{cc}
1-p_{11} & p_{22}-1 \\
p_{11}-1 & 1-p_{22} \\
1 & 1
\end{array}\right] .
$$

To finish this appendix I present the [47]'s algorithm to obtain smoothed inferences, which are used to present the probabilities of being in each state at each time $t$ given the complete sample $T$, i.e.

$$
\hat{\xi}_{t \mid T}=\hat{\xi}_{t \mid t} \odot\left\{P^{\prime}\left[\hat{\xi}_{t+1 \mid T}(\dot{\div}) \hat{\xi}_{t+1 \mid t}\right]\right\},
$$

where $\odot$ and $(\div)$ represents the element-wise product and division respectively.

\section{Algorithms employed to simulate returns under the data generating process}

\section{Extra figures}



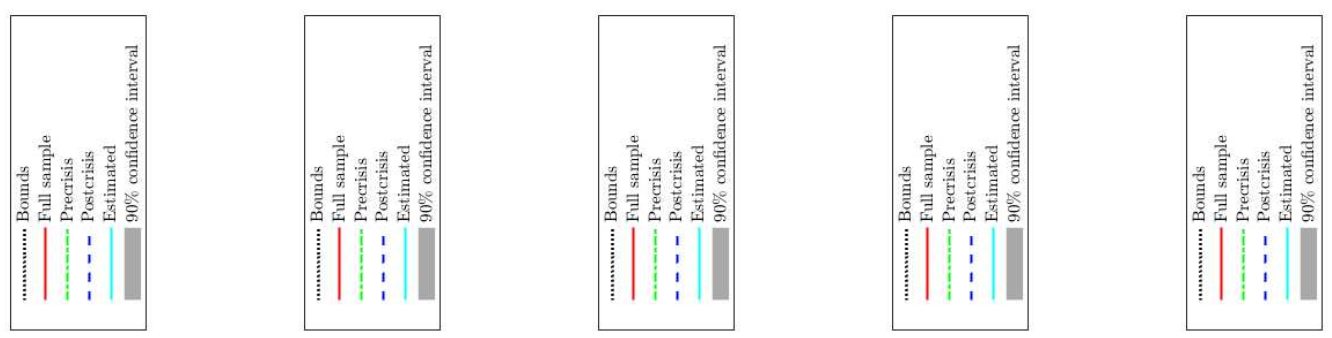

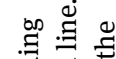

要

긍

¿

总宫

증 홍

흘

焉.

焉范

要

ฮี
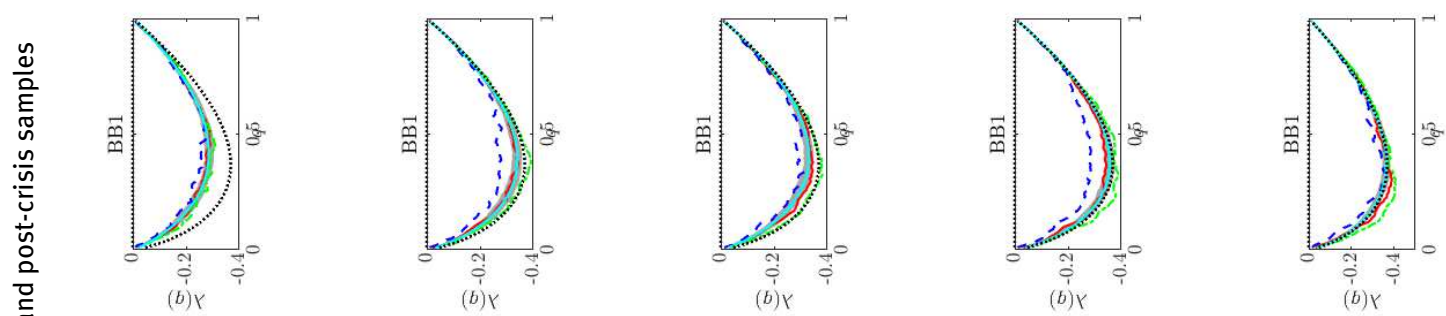

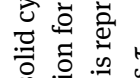

焉

क

严苜

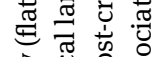
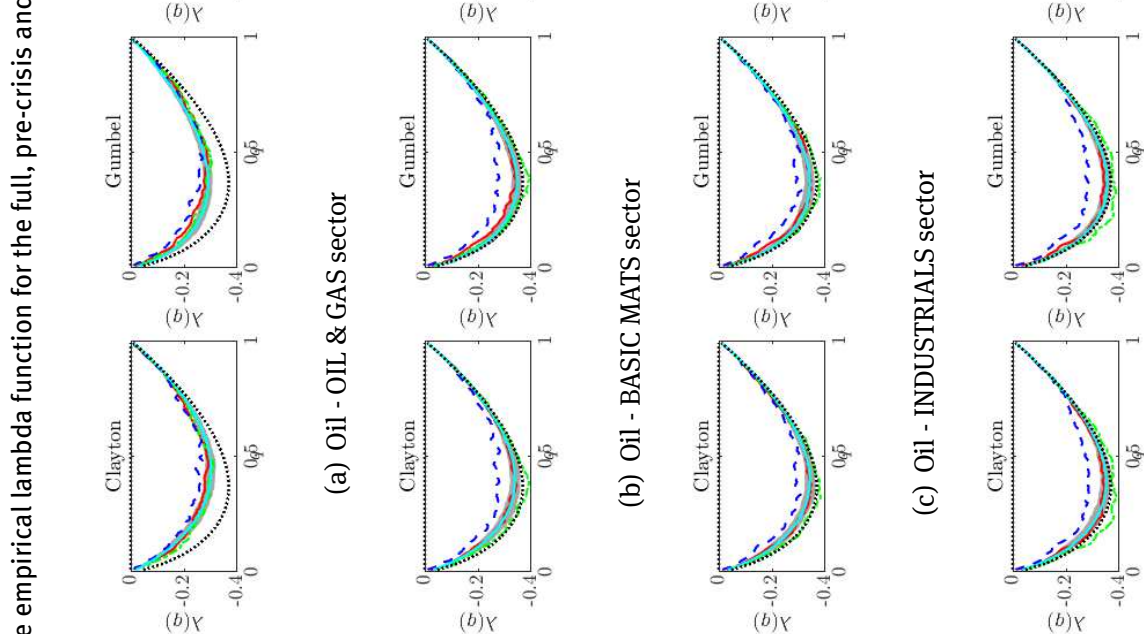

(b) Y

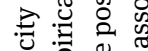

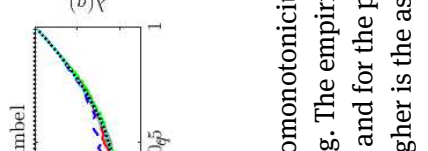

둥
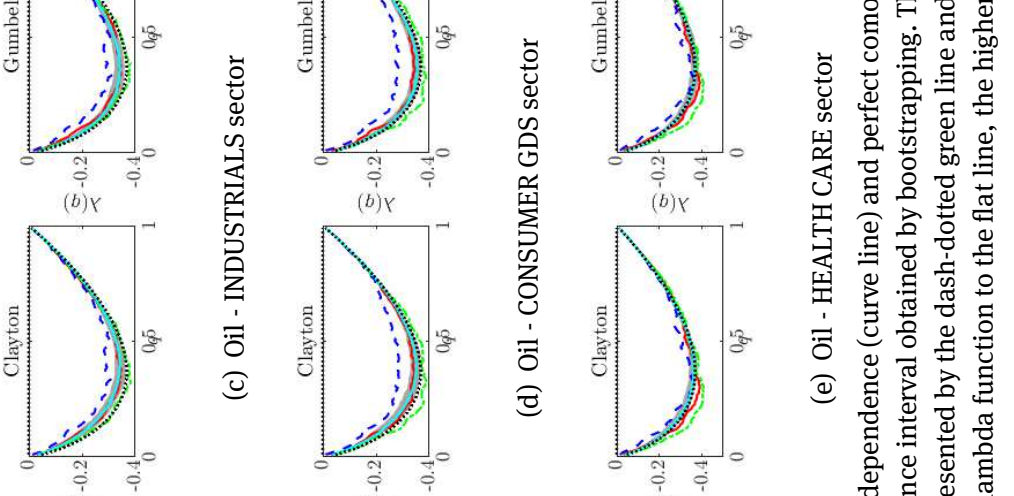

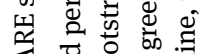

0
0
0
$\sum^{0}$
0
0
0
$\vdots$
0
0
0
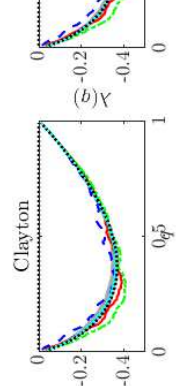

తิ

焉合 훙

넢

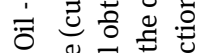

(9)

远㱏

苋苋苋

(b) $Y$
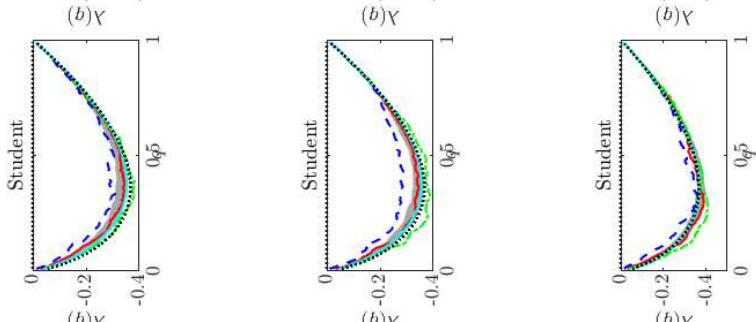

空 \&
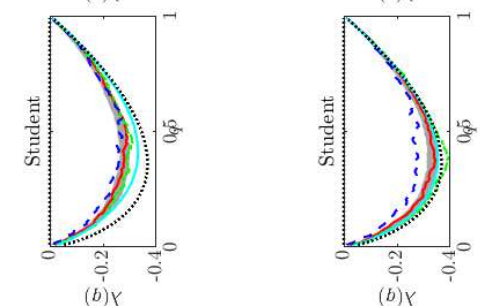

(b) Y
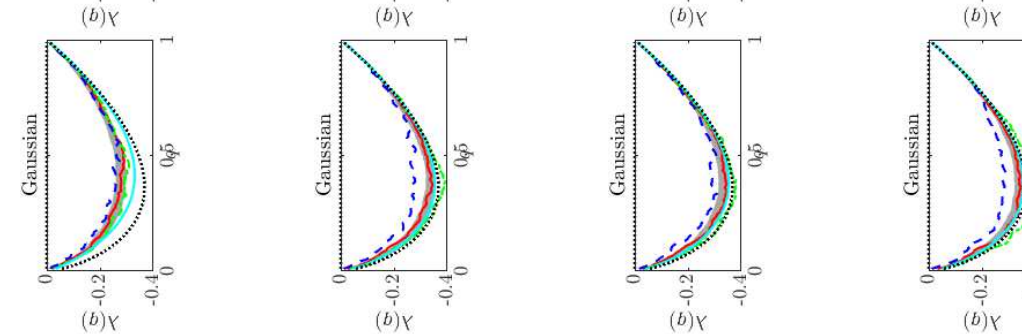

(b) $Y$

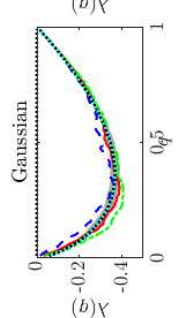

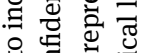

कo 용. 뭉

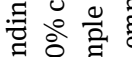

क人

क्ष.

㐘 $\frac{\infty}{0}$

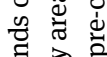

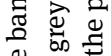

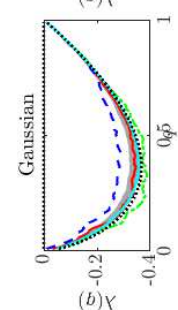

要焉

氚

递芯志

密

号焉

형

SVэ)TIO

S.LWWistg

STVIULSASANI

S๔๖ยสพกSNO

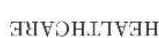

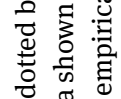

帝高 

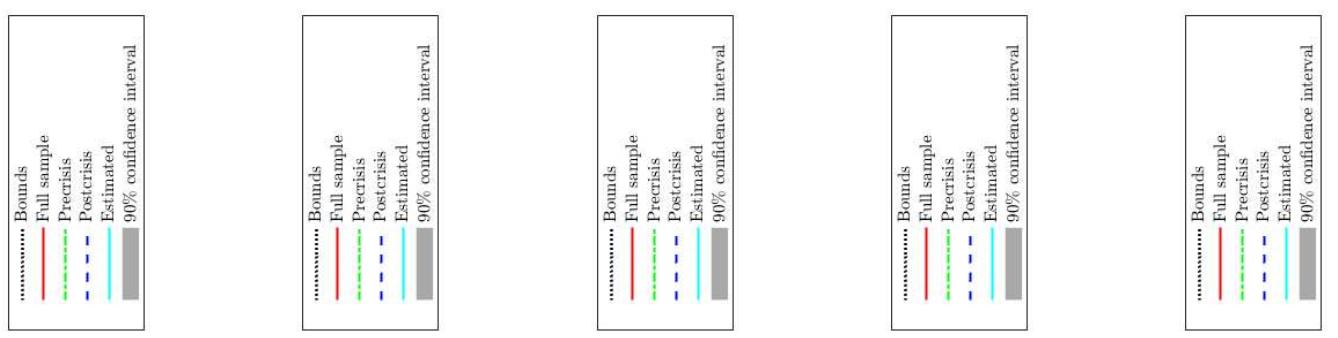

$\stackrel{\infty}{\Xi} \cong$

象

क्ष 윰

ช ฏ

完完

률

흠 홍

च्ञ

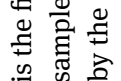

킹

도 ᄚ
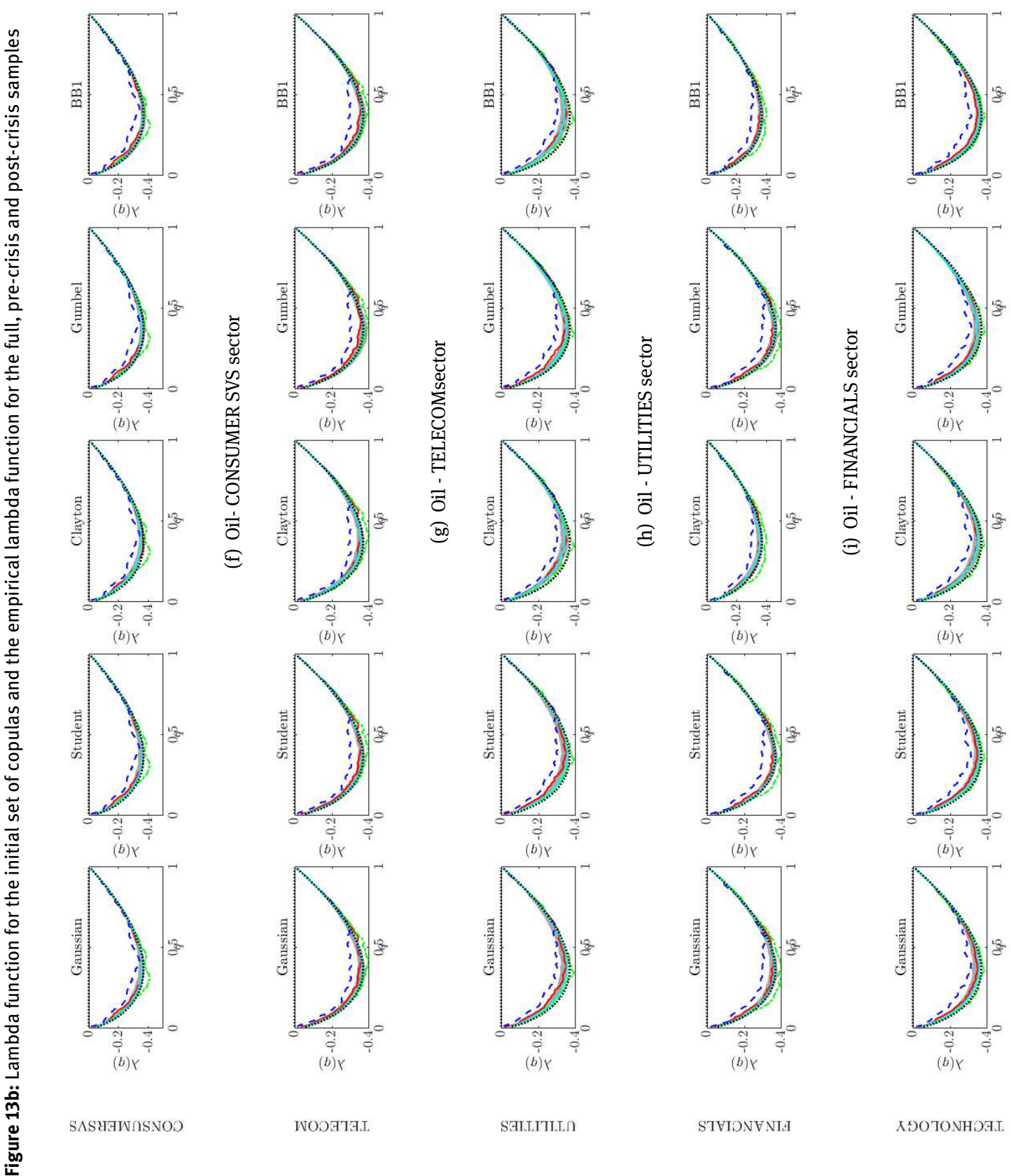

ป⿱一兀) 苍

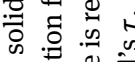

氙芯突

ब

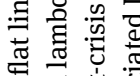

正 党

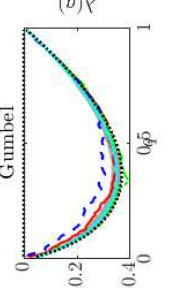

(b) $Y$

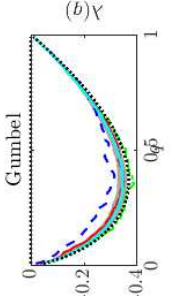

:

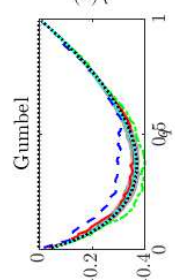

\& 훙.s

돕 물

- 仓ิ

总苞言完

क्ष
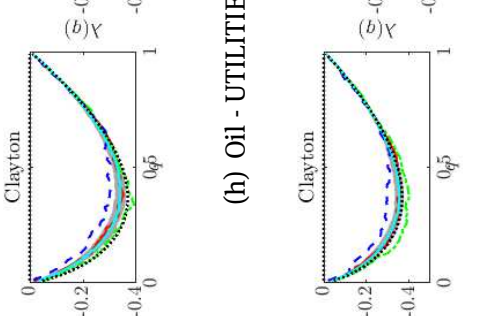

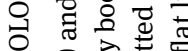

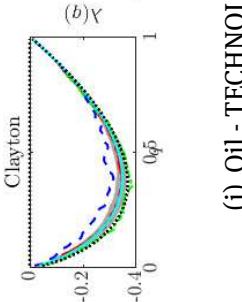

卷

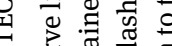

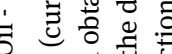

今)

过苛

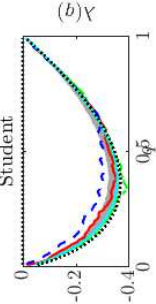

(b) Y

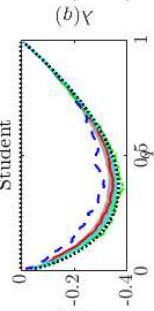

웡 屯

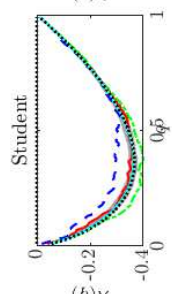

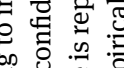

on 원

ํํㅇํㄹ

के ज्ञ

竞

\&

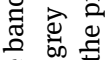
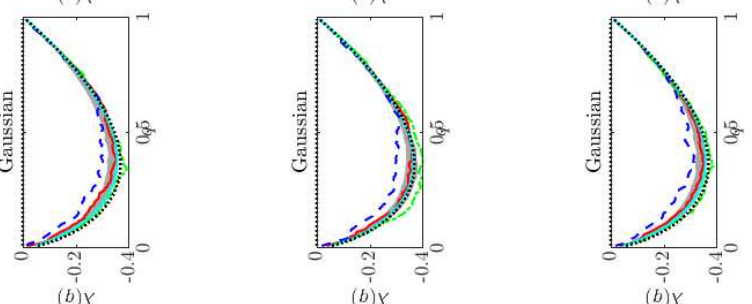

‡્ّ

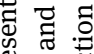

总焉

政

品

䒕

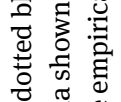

SAI.ITILIS

STVIONVNIA

ХફОTONHОA.

炡商 

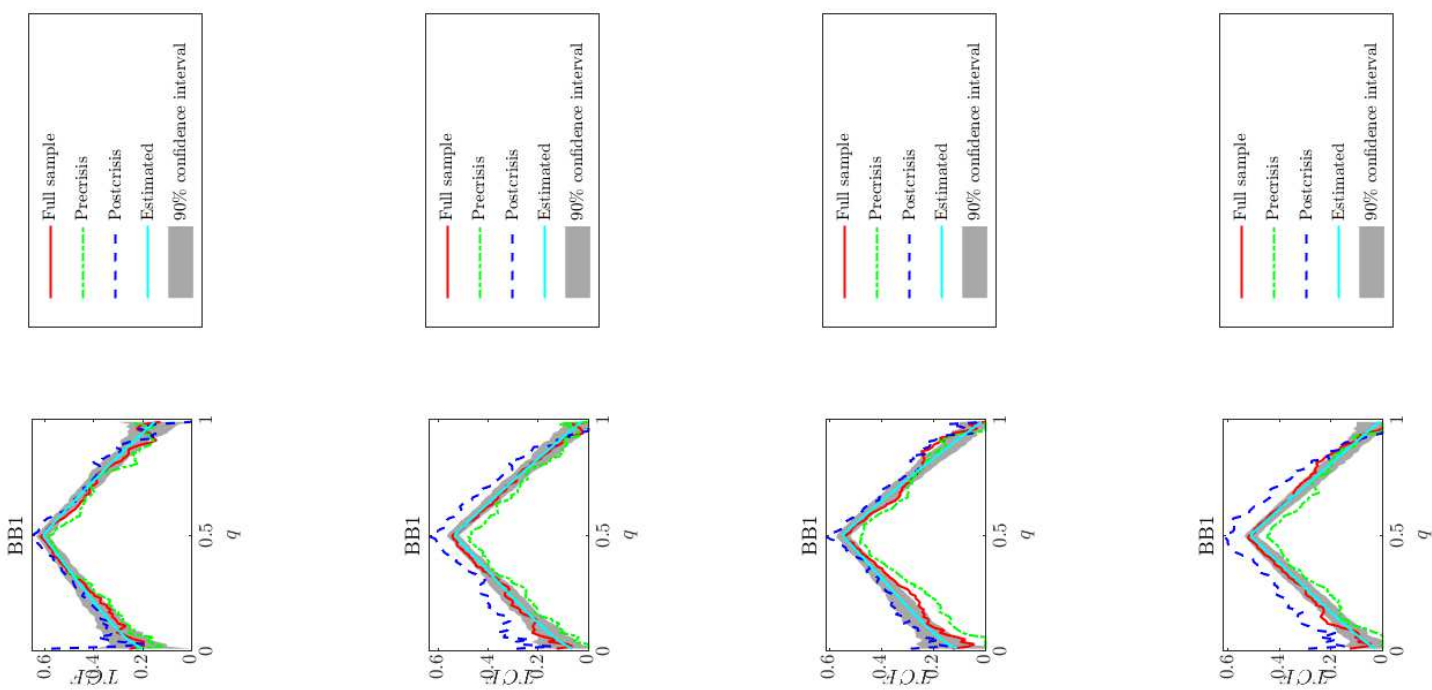

营 泀

임.

岁

坐

ตำ

合

矛

웡

空

范

ㅎㅀ

응 छั

टี๊

节

氙 吾

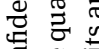

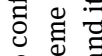

ㅇํㄹ

के 융

क ज्ञ
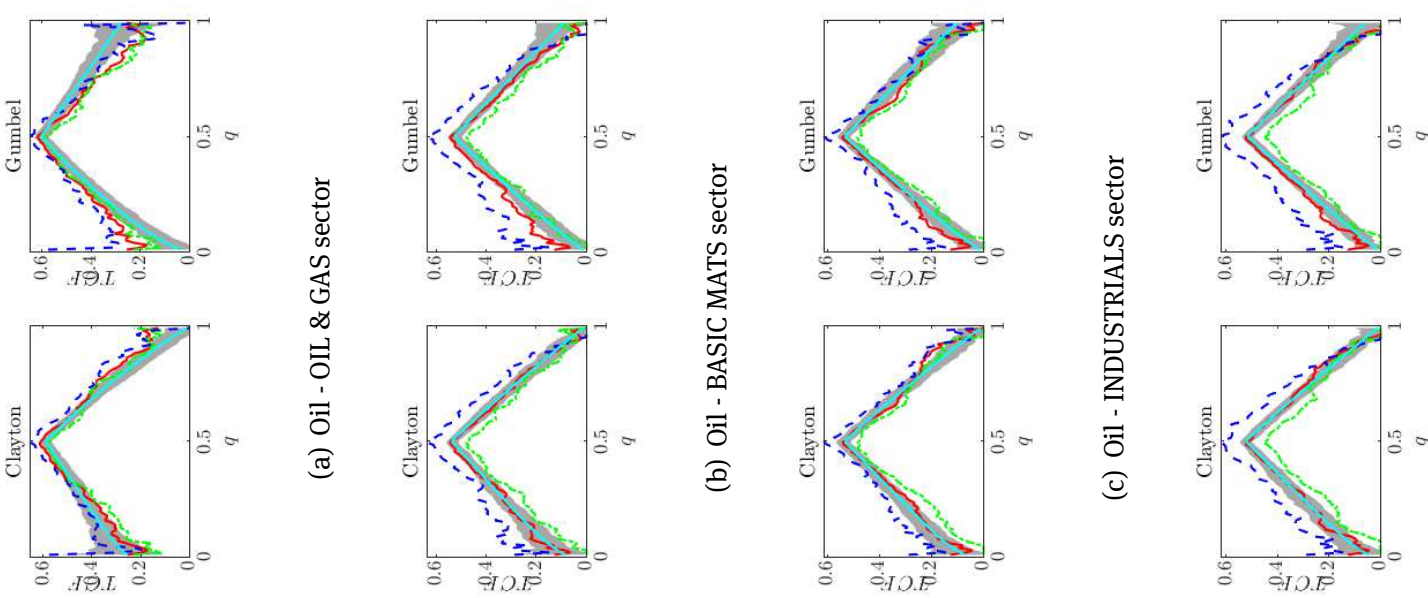

ฮี ప ప

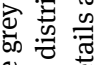

ᄒे

总 듬

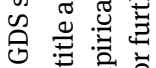
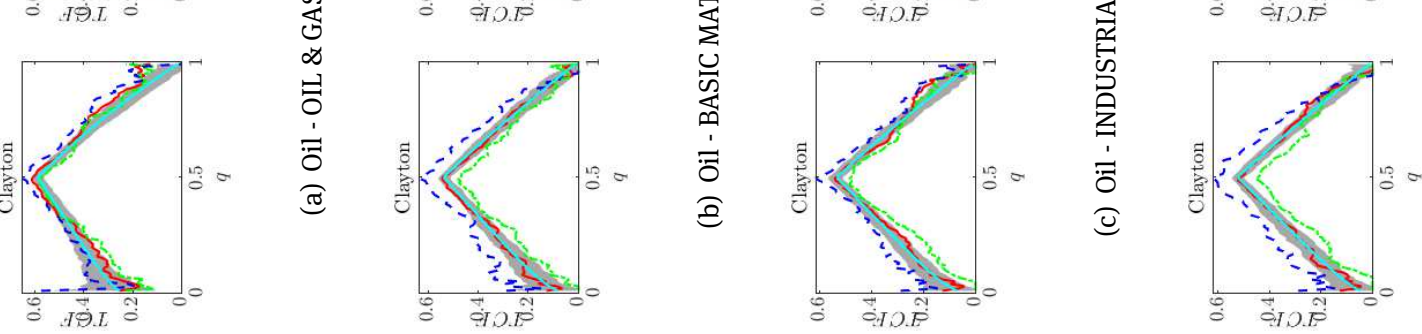

눅 형
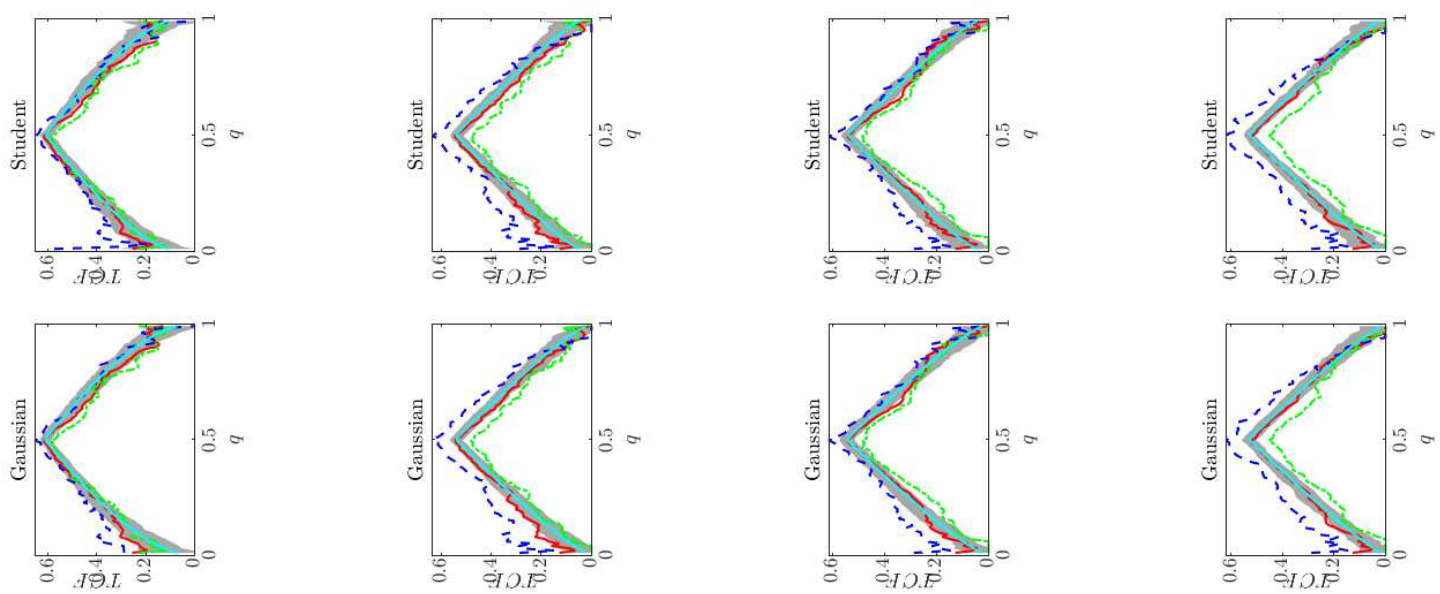

SVפTIO

S.LVINDISVG

STEIULSOANT

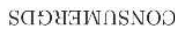

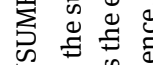

号吾焉

บ ह ㅎํㄹ

-7 क

(일

엉 으

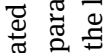

亲

\&

表芆

동 ส

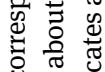

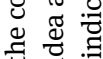

弚

岂

ए का

击

吾

.2)

종

ड़ 웜

궁 휴

ङ 

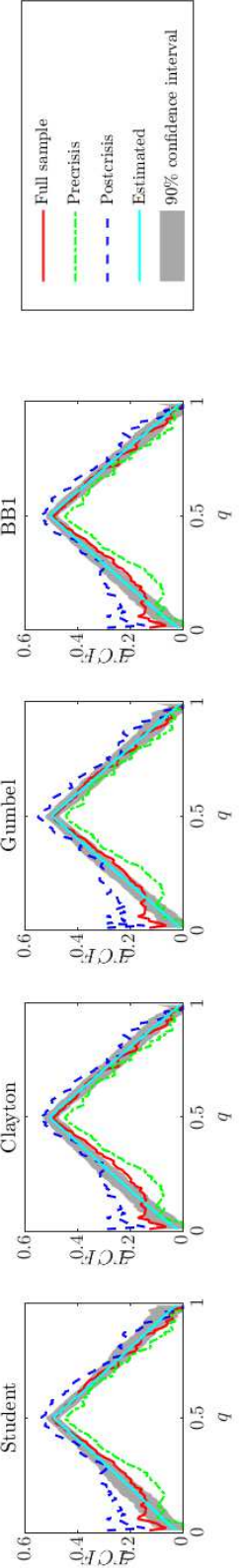

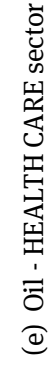

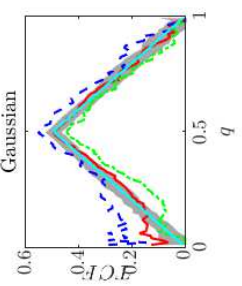

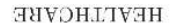
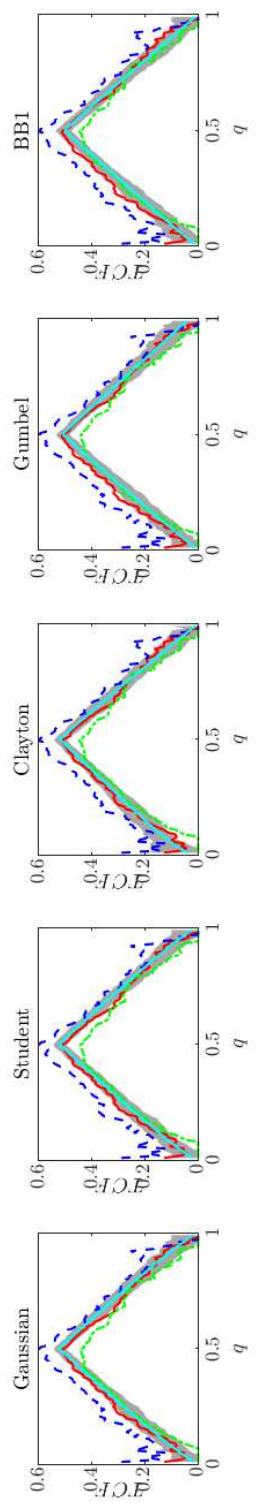

SASHAINASNOO
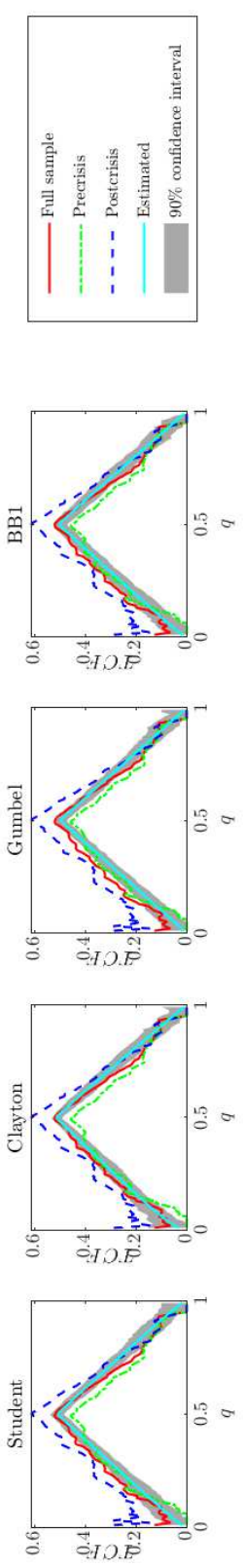

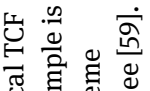

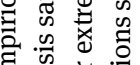

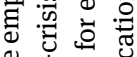

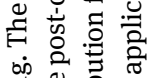

का

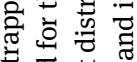

흉 플

苋苋

ठ ญ्:

元

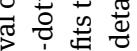

芴

ष

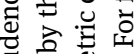

ฮี छ छ

今े चี

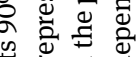

원

ส 3

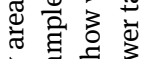

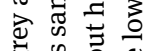

के

过

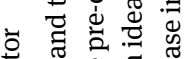

过

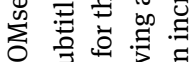

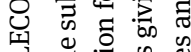

凷焉 总

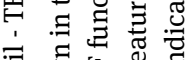

б) 도웛

की 0 की

承苋苋

웅 言这

卷导 :

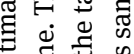

on

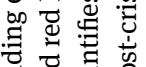

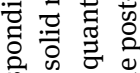

焉吉壳

造会至

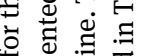

嵌

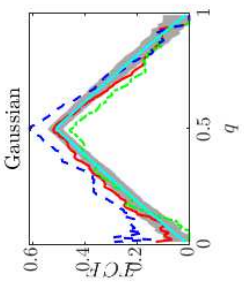

형릉

焉蛋

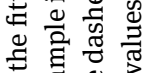

.

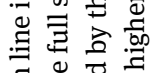

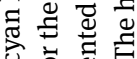

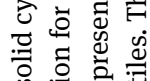

พNOOสTล.I. 

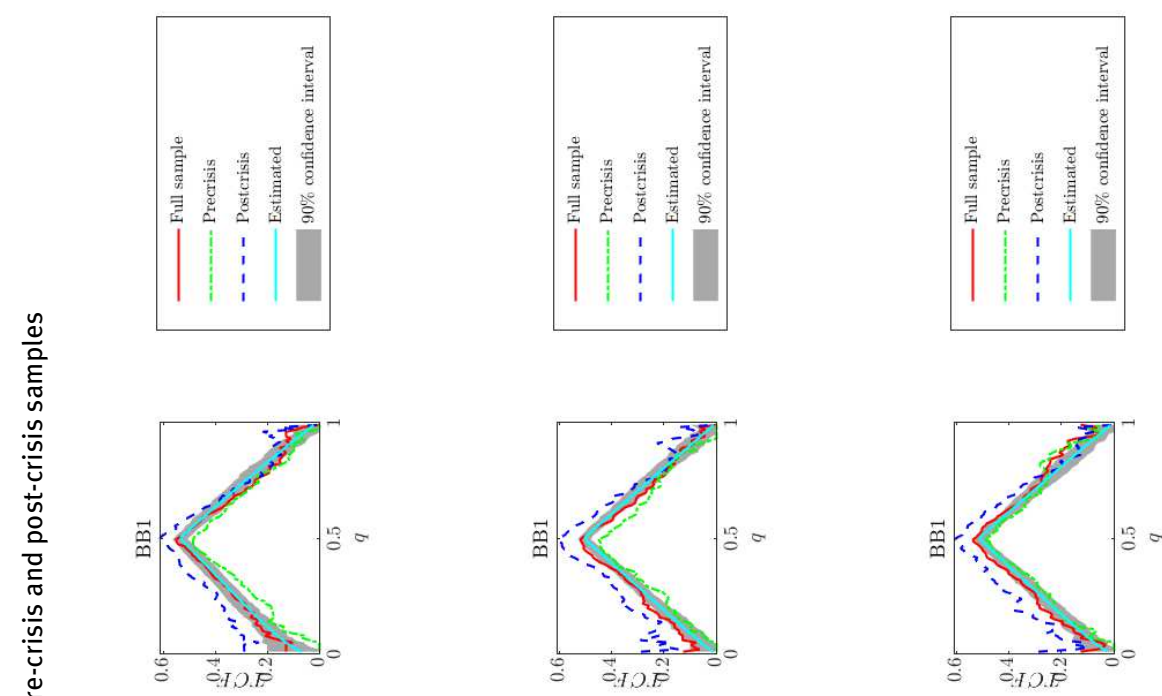

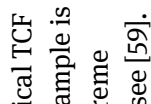

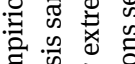

है

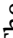
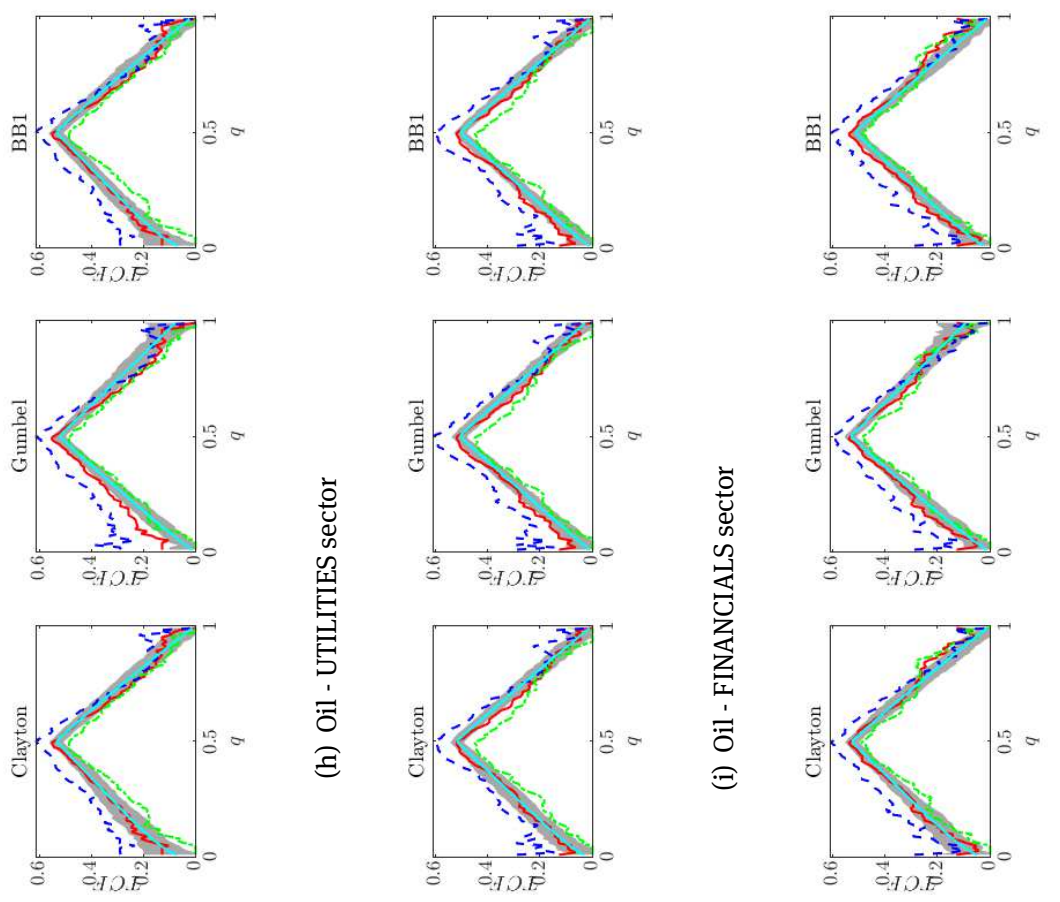

舫

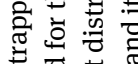

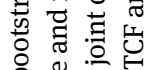

忩焉

焉蒙

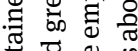

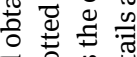

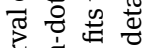

焉要

\& 80

苍荳

记

¿ चี

울 월

$\stackrel{0}{=}$

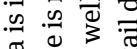

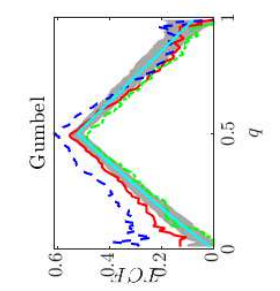

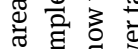

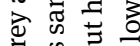

का की

官

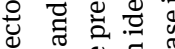

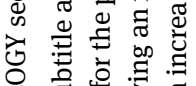
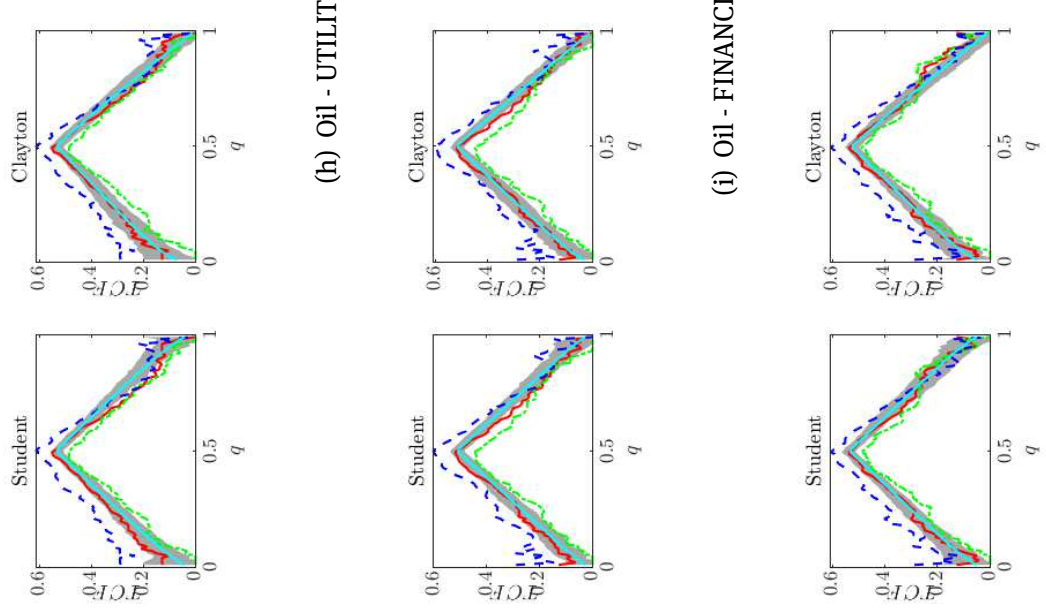

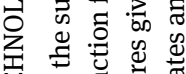

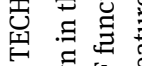

专出焉

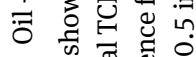

$\Xi$ 跣

完言苛

过 完
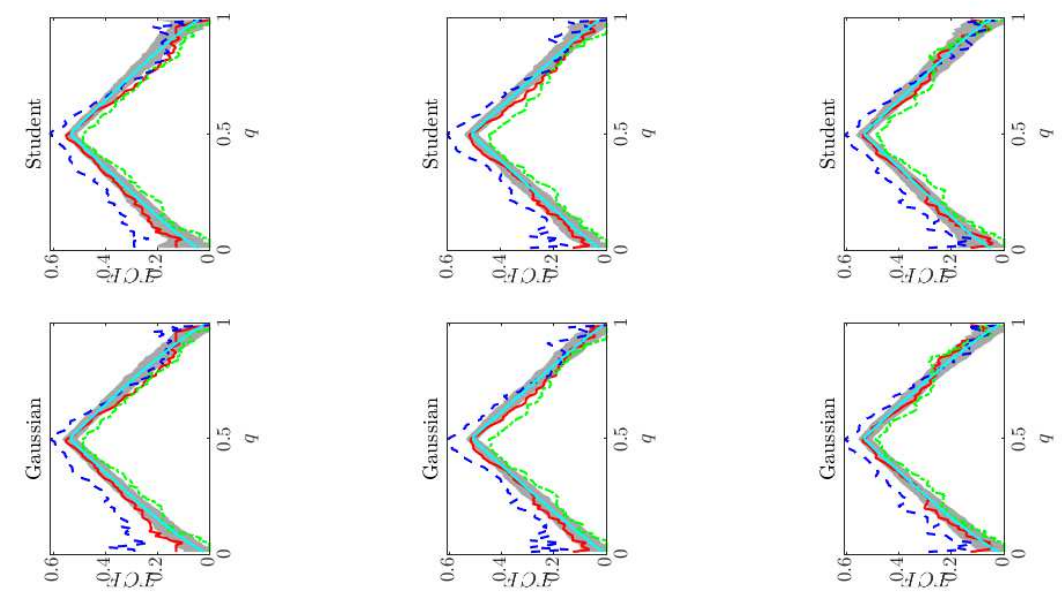

界

क

on

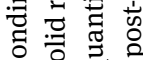

के

边

造客远

造焉

氙苛吉

屶递吾

要表

击运岳

ह 둥

.

寻䒠合些

돌 छ

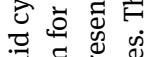

Х.ОТОМНОЯ.

STVIONVNII 
Figure 15a: Model risk assessment when we assume a constant dependence compared to the time-varying model.
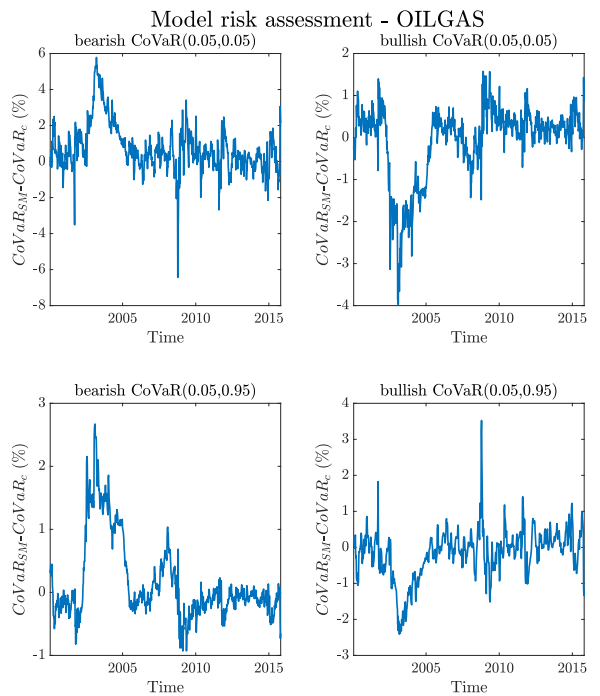

Model risk assessment - INDUSTRIALS
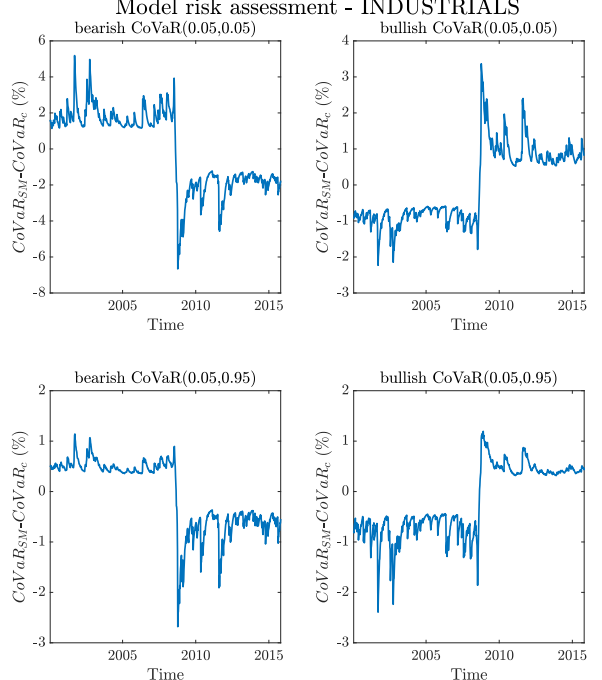
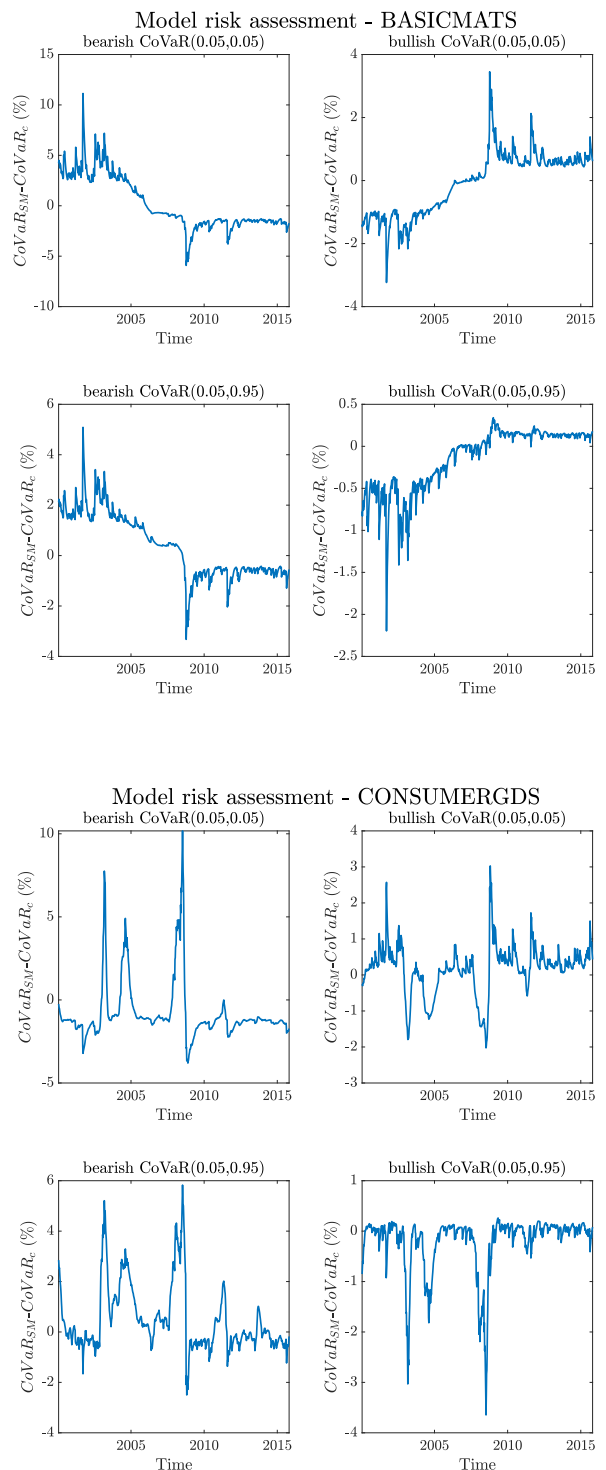

These figures show the difference between the estimation of the same percentile of stock sector returns under the same oil-related scenario using the Switching Markov model that allows for changes in the copula against the constant model. Top figures focuses on a low quantile ( $\beta=5 \%$ ) whilst bottom graphs estimate the high quantile $(\beta=95 \%)$. Left figures show a percentile of stock returns under a bearish scenario for oil returns, i.e. oil returns below its percentile $5 \%$, and right figures show a percentile of stock returns under a bullish scenario for oil returns, i.e. oil returns above its percentile $95 \%$. These charts indicate the higher model risk in the lower tail than in the upper tail when assuming a constant dependence across markets. 
Figure 15b: Model risk assessment when we assume a constant dependence compared to the time-varying model.
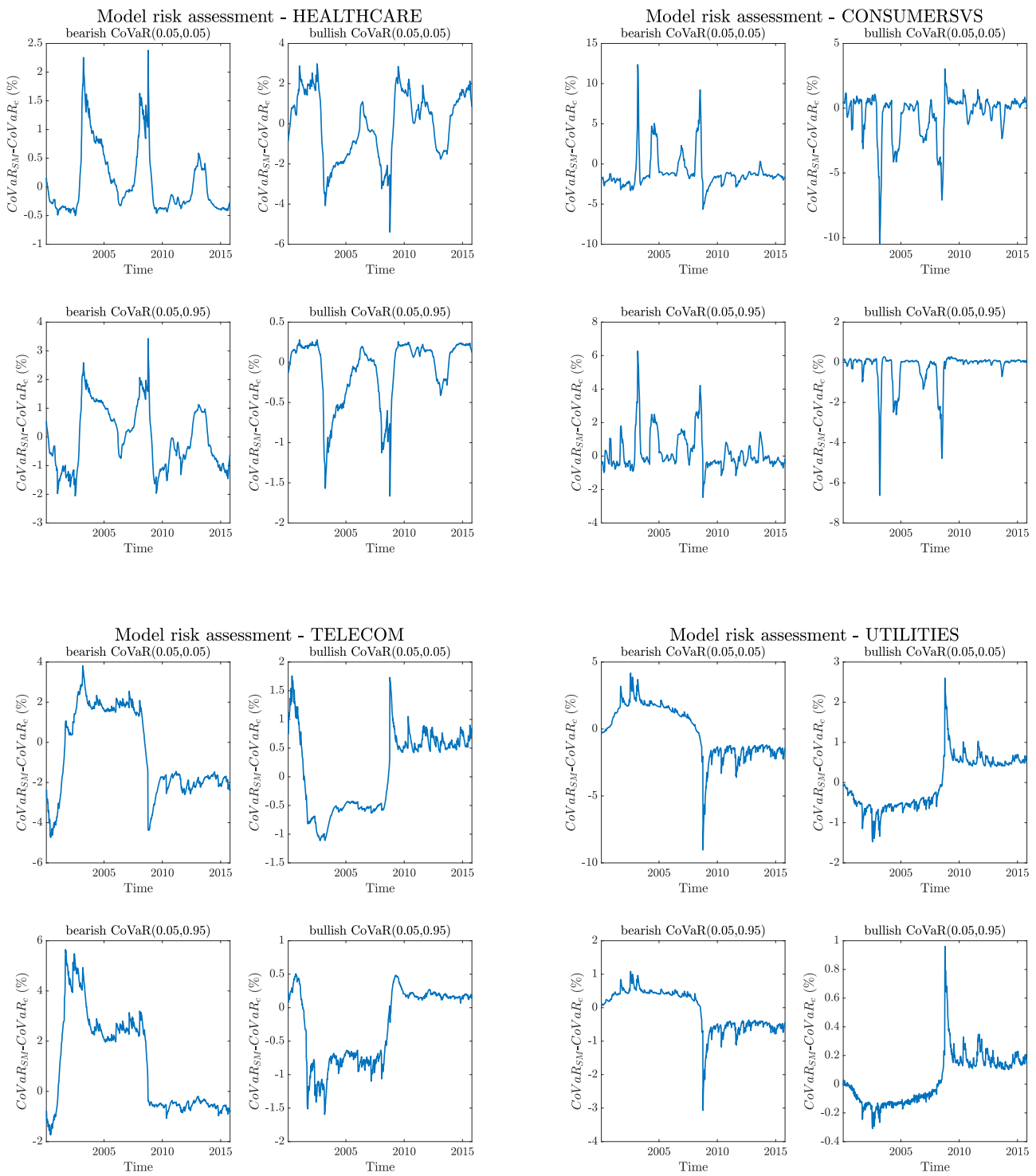

These figures show the difference between the estimation of the same percentile of stock sector returns under the same oil-related scenario using the Switching Markov model that allows for changes in the copula against the constant model. Top figures focuses on a low quantile ( $\beta=5 \%$ ) whilst bottom graphs estimate the high quantile $(\beta=95 \%)$. Left figures show a percentile of stock returns under a bearish scenario for oil returns, i.e. oil returns below its percentile $5 \%$, and right figures show a percentile of stock returns under a bullish scenario for oil returns, i.e. oil returns above its percentile 95\%. These charts indicate the higher model risk in the lower tail than in the upper tail when assuming a constant dependence across markets. 


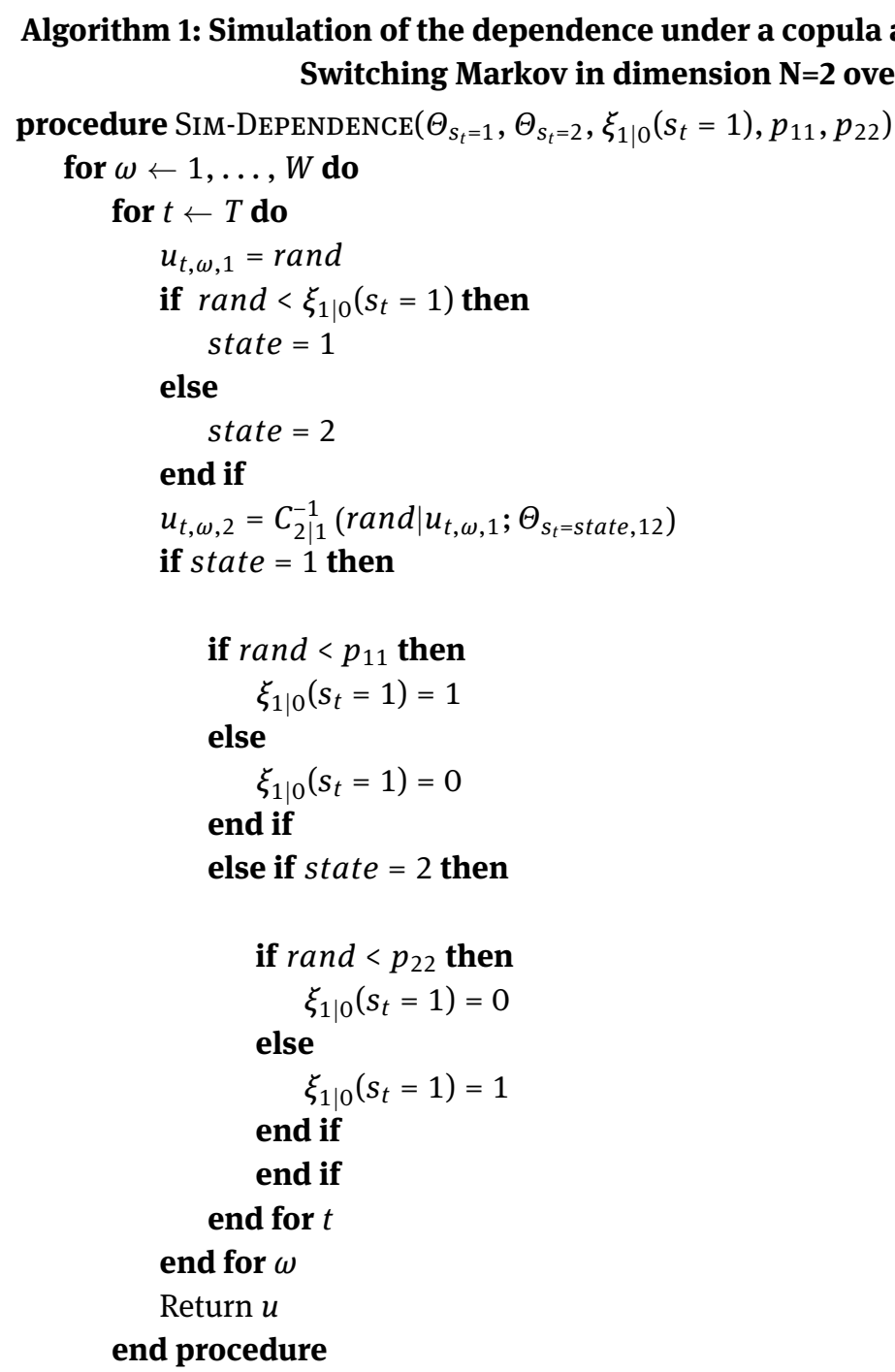

$\Theta_{s_{t}=1}$ and $\Theta_{s_{t}=2}$ are the set of parameters for the copula structure under state 1 and $2 . \xi_{1 \mid 0}\left(s_{t}=1\right)$ is the unconditional probability of being in state 1, i.e. $\xi_{1 \mid 0}\left(s_{t}=1\right)=\frac{1-p_{22}}{2-p_{11}-p_{22}}$.

$p_{11}$ and $p_{22}$ are the diagonal values from the transition matrix (see Equation (9)).

rand refers to an uniform-distributed random realization.

The OUTPUT $u$ is a uniform-distributed matrix that has the joint dependence presented in the model of size $T x W x 2$ 


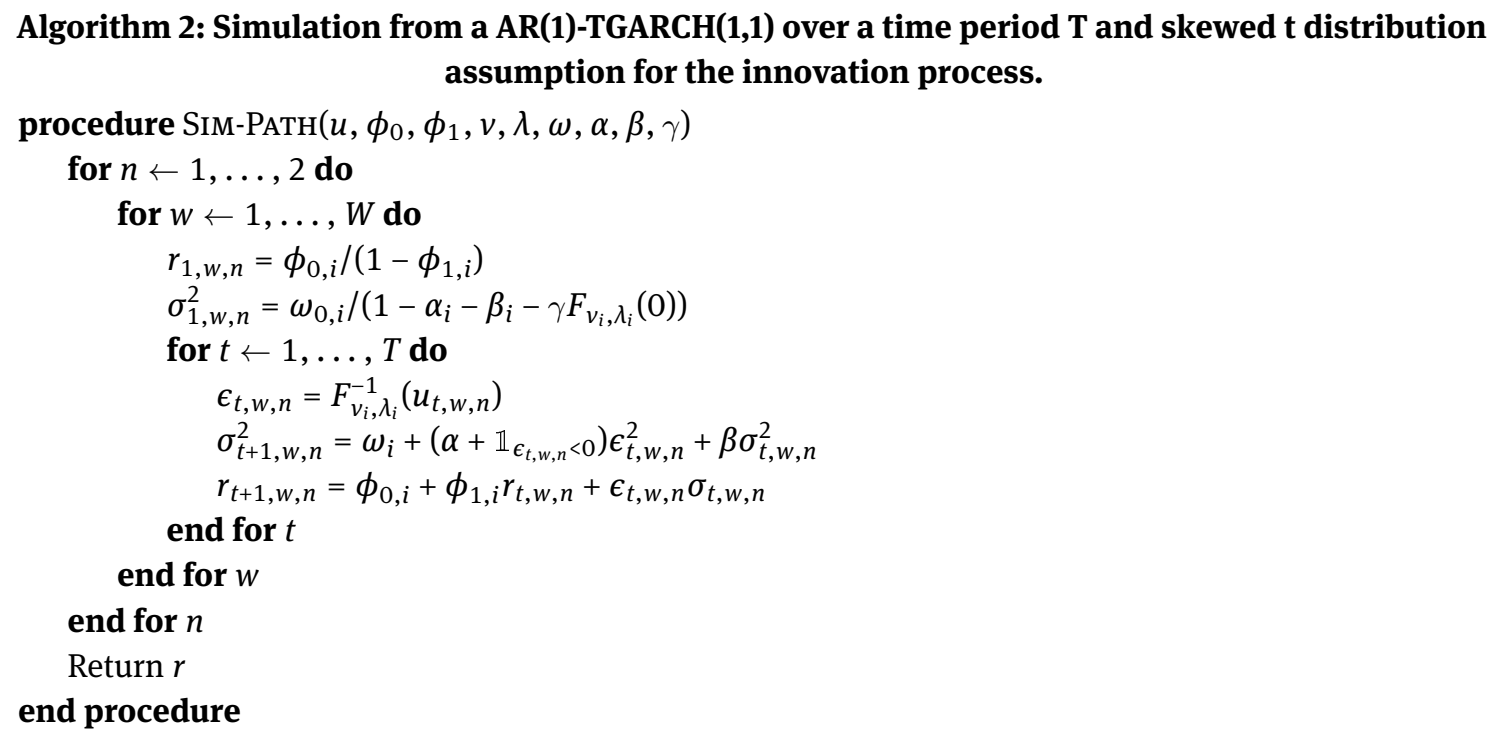

$u$ is a three-dimension matrix ( $T x W x 2)$ obtained from previous algorithm.

$\phi_{0}$ and $\phi_{1}$ are vectors of parameters of length $N=2$ that drive the dynamic in Equation (4).

$\omega, \alpha, \beta$ and $\gamma$ are vectors of parameters of length $N=2$ that drive the dynamic in Equation (5).

$v$ and $\lambda$ are vectors of length $N$ gathering the values of asymmetry and number of degrees of freedom from Equation (6).

The OUTPUT $r$ is a three dimension matrix $((T+1) \times W \times 2)$ of $W$ simulated paths of length $T+1$ for the $N=2$ returns.

Figure 15c: Model risk assessment of when we assume a constant dependence compared to the time-varying model.
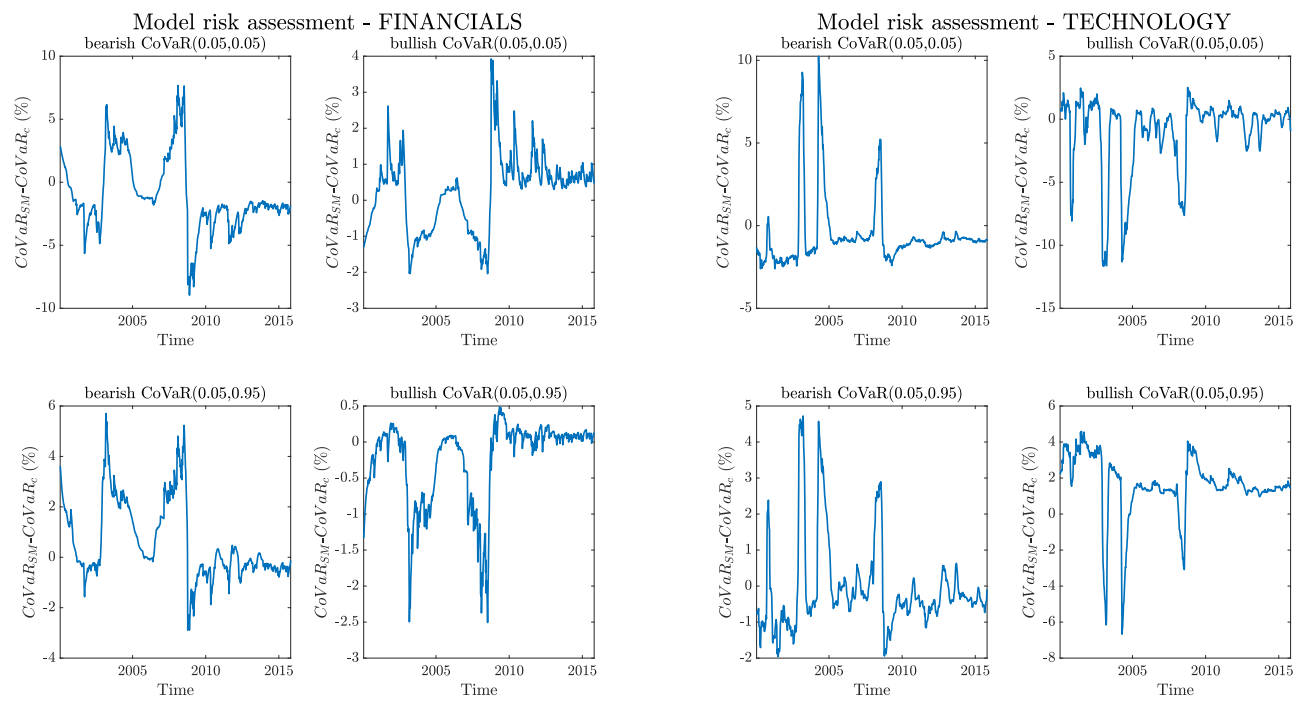

These figures show the difference between the estimation of the same percentile of stock sector returns under the same oil-related scenario using the Switching Markov model that allows for changes in the copula against the constant model. Top figures focuses on a low quantile $(\beta=5 \%)$ whilst bottom graphs estimate the high quantile $(\beta=95 \%)$. Left figures show a percentile of stock returns under a bearish scenario for oil returns, i.e. oil returns below its percentile $5 \%$, and right figures show a percentile of stock returns under a bullish scenario for oil returns, i.e. oil returns above its percentile $95 \%$. These charts indicate the higher model risk in the lower tail than in the upper tail when assuming a constant dependence across markets. 


\section{Algorithm 3: Assessment of the risk measures of the stock market returns at time $t$ under a certain scenario for oil returns.}

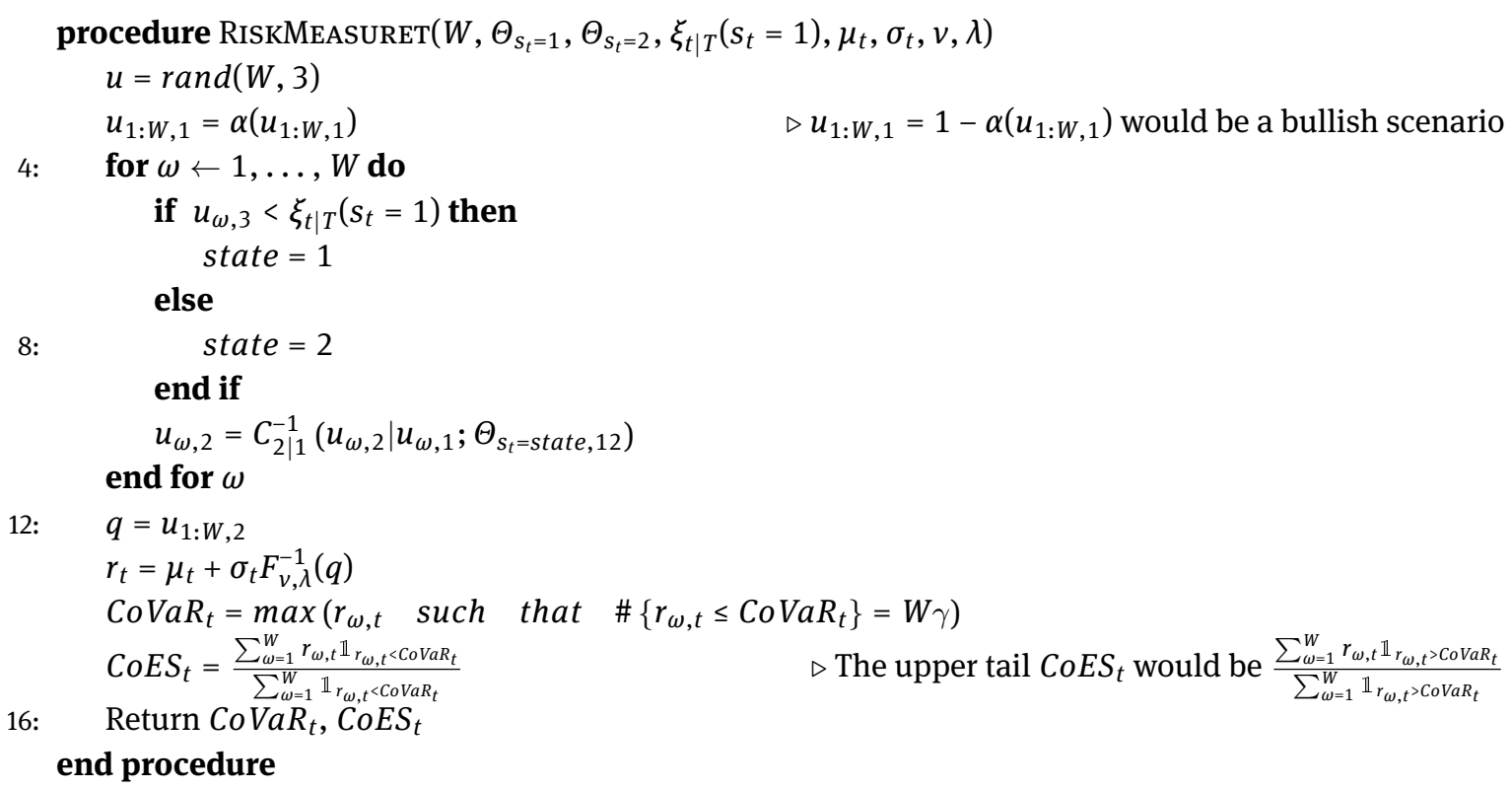

$\Theta_{S_{t}=1}$ and $\Theta_{S_{t}=2}$ are the set of parameters for the copula structure under state 1 and $2 . \xi_{t \mid T}\left(s_{t}=1\right)$ is the smoothed probability of being in state 1 at time $t$.

$\mu_{t}$ refers to the conditional mean at time $t$ obtained from Equation (4).

$\sigma_{t}$ is the conditional standard deviation at time $t$ obtained from Equation (5).

$v$ and $\lambda$ gather the values of asymmetry and number of degrees of freedom from Equation (6). $\operatorname{rand}(W, N)$ refers to a matrix of $W$ uniform-distributed random realizations for $N$ variables.

The OUTPUT contains the CoVaR and the CoES measures. 
Figure 16a: $\operatorname{CoVaR}_{m \mid o, t}(0.05,0.95)$ for a certain sector given a bearish scenario for oil prices

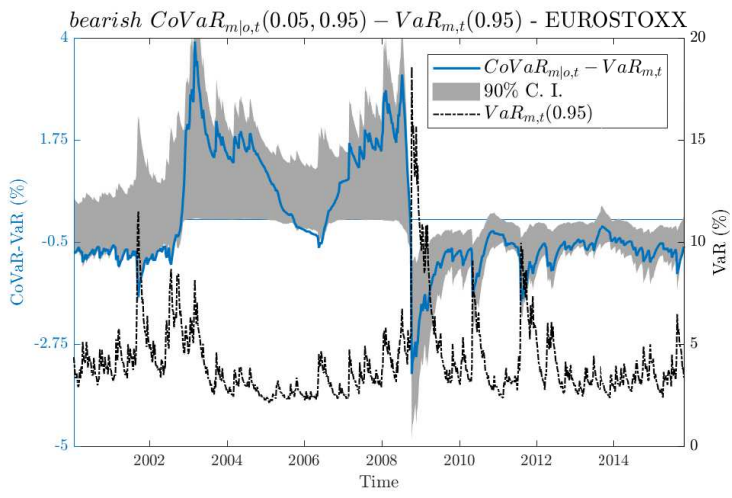

(a) Oil- EUROSTOXX index

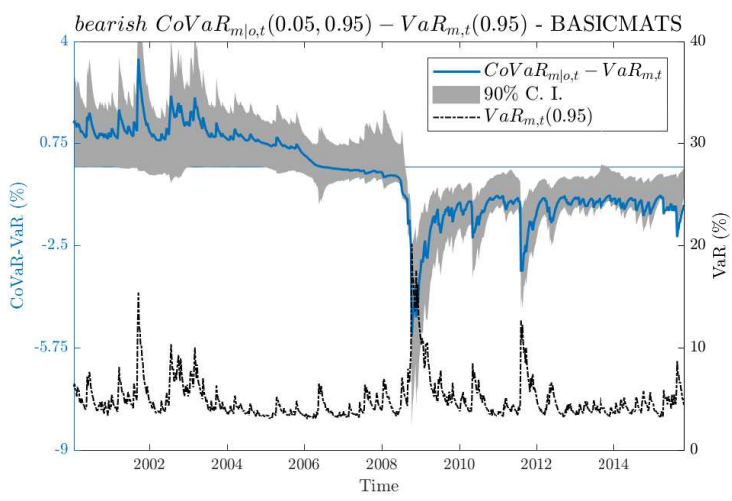

(c) Oil - BASIC MATS sector

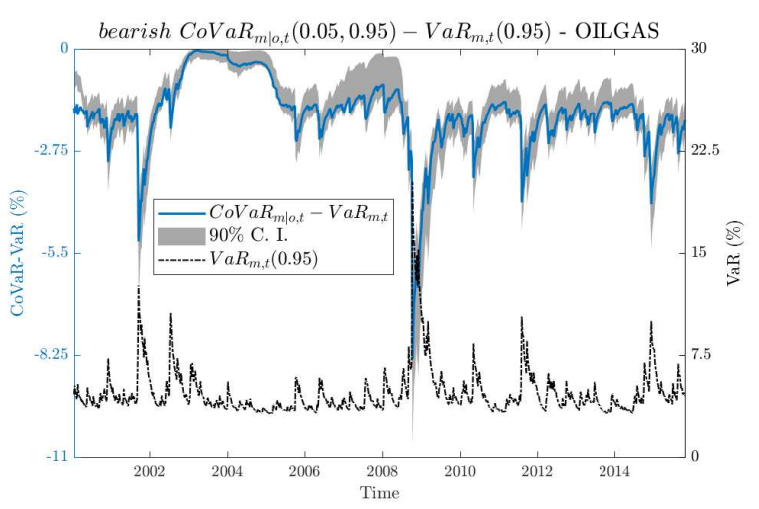

(b) Oil - OIL \& GAS sector

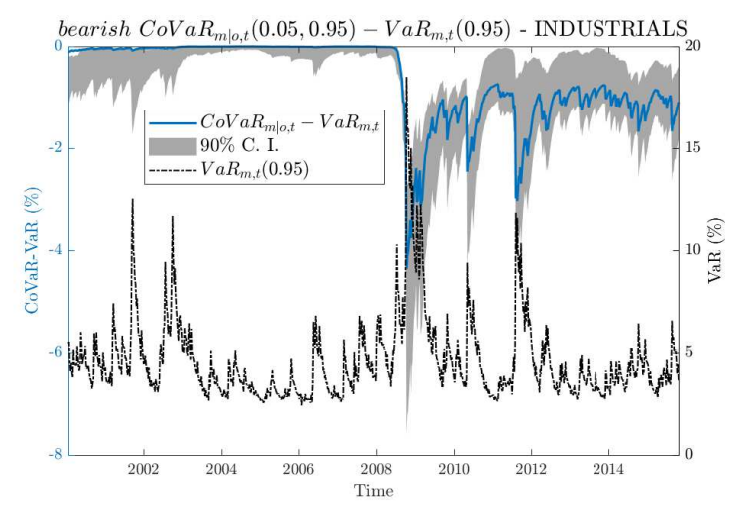

(d) Oil - INDUSTRIALS sector

Left axis shows the difference in percentage between the $\operatorname{CoVaR}_{m, t}(0.05,0.95)$ of the returns for a certain sector under a extreme downward movement in oil prices, i.e. below its 5-th quantile, and its unconditional $V a R_{m, t}(0.95)$. Solid blue line shows this difference given the best copula mixture according to Table 6 . Grey area indicates the $90 \%$ confidence interval of the difference between $\operatorname{CoVaR}_{m \mid o, t}(0.05,0.95)$ and $\operatorname{VaR}_{m, t}(0.95)$ following a Monte Carlo technique explained in Appendix C. The right axes shows the value of the $\operatorname{VaR}_{m, t}(0.95)$ in percentage. The dash-dotted black line indicate the VaR level over time. 
Figure 16b: $\operatorname{CoVaR}_{m \mid o, t}(0.05,0.95)$ for a certain sector given a bearish scenario for oil prices

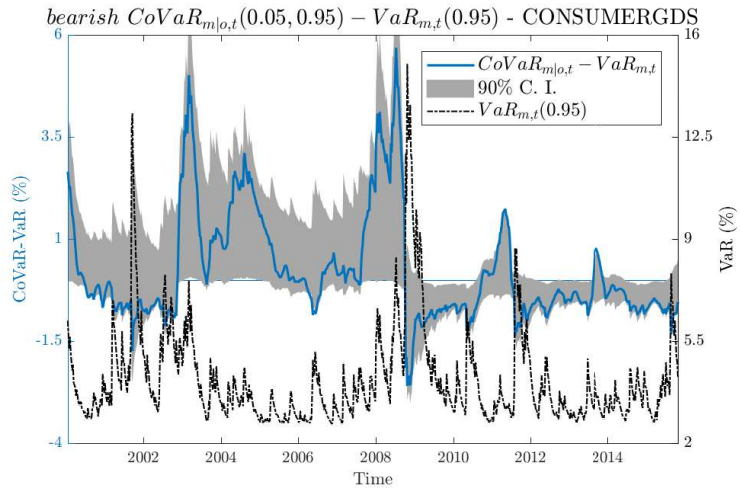

(e) Oil - CONSUMER GDS sector

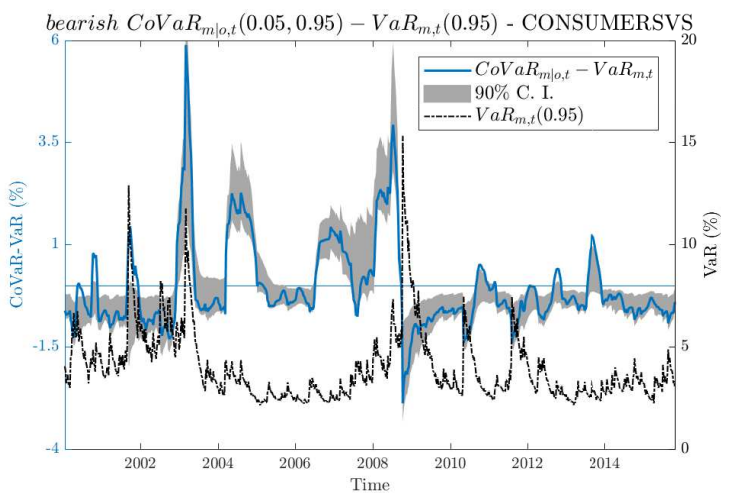

(g) Oil- CONSUMER SVS sector

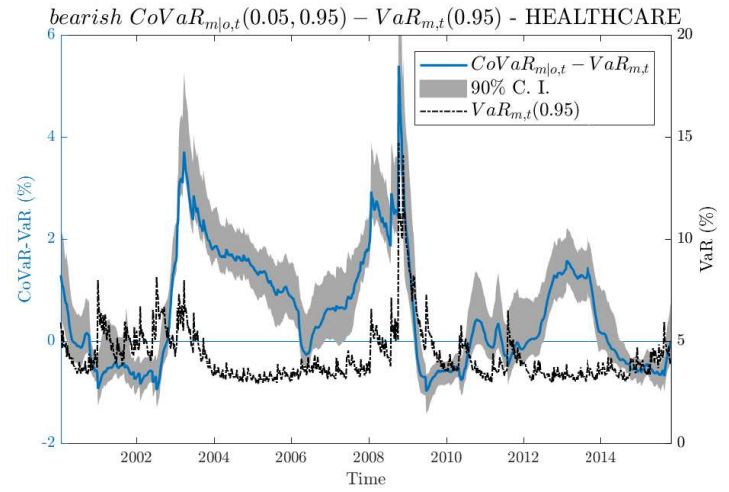

(f) Oil - HEALTH CARE sector

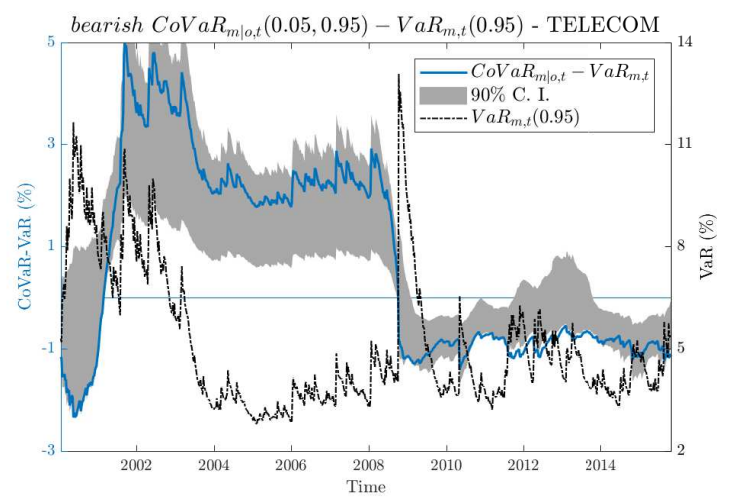

(h) Oil - TELECOM sector

Left axis shows the difference in percentage between the $\operatorname{CoVaR} R_{m, t}(0.05,0.95)$ of the returns for a certain sector under a extreme downward movement in oil prices, i.e. below its 5-th quantile, and its unconditional $V_{a} R_{m, t}(0.95)$. Solid blue line shows this difference given the best copula mixture according to Table 6 . Grey area indicates the $90 \%$ confidence interval of the difference between $\operatorname{CoVaR}_{m \mid o, t}(0.05,0.95)$ and $\operatorname{VaR}_{m, t}(0.95)$ following a Monte Carlo technique explained in Appendix C. The right axes shows the value of the $\operatorname{VaR}_{m, t}(0.95)$ in percentage. The dash-dotted black line indicate the VaR level over time. 
Figure 16c: $\operatorname{CoVaR}_{m \mid o, t}(0.05,0.95)$ for a certain sector given a bearish scenario for oil prices

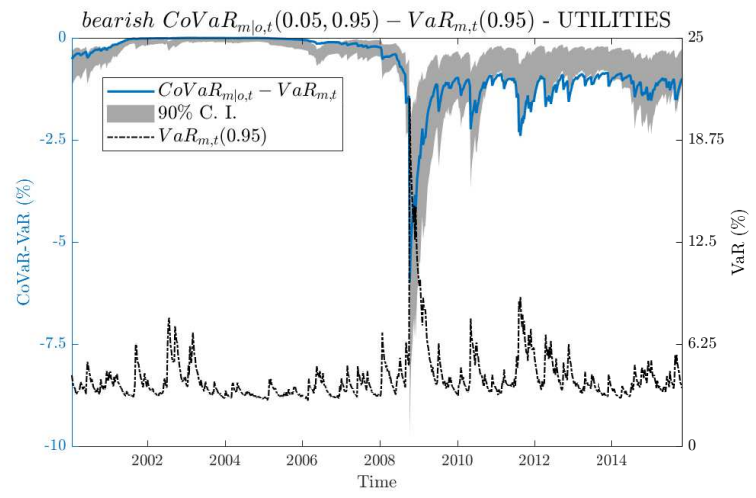

(i) Oil - UTILITIES sector

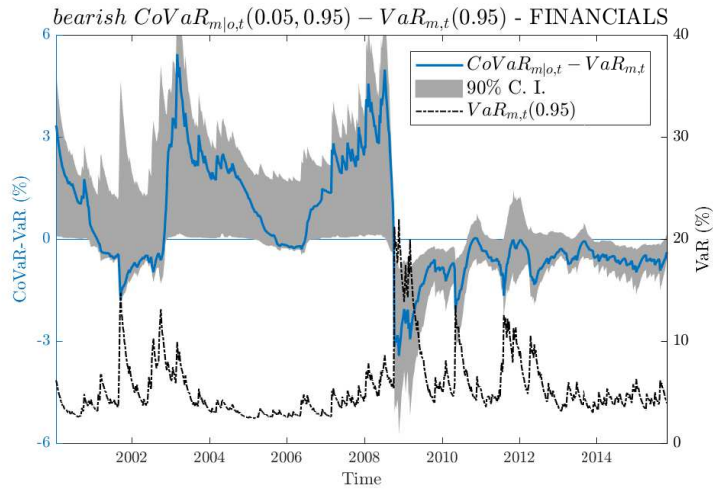

(j) Oil - FINANCIALS sector

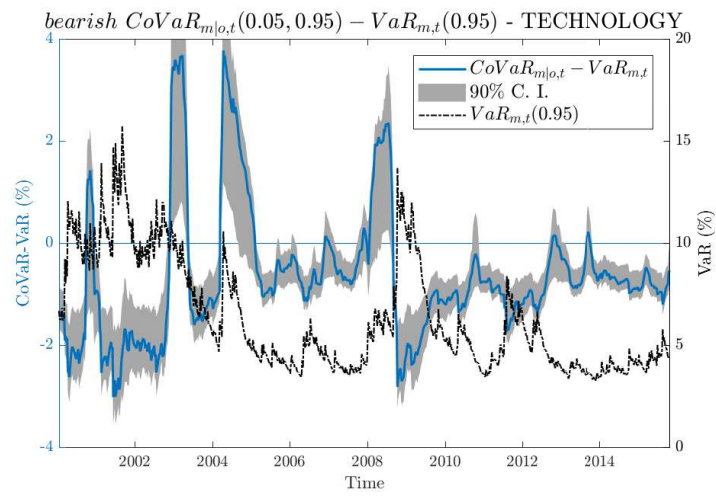

(k) Oil - TECHNOLOGY sector

Left axis shows the difference in percentage between the $\operatorname{CoVaR}_{m, t}(0.05,0.95)$ of the returns for a certain sector under a extreme downward movement in oil prices, i.e. below its 5-th quantile, and its unconditional $V a R_{m, t}(0.95)$. Solid blue line shows this difference given the best copula mixture according to Table 6 . Grey area indicates the $90 \%$ confidence interval of the difference between $\operatorname{CoVaR}_{m \mid o, t}(0.05,0.95)$ and $\operatorname{VaR}_{m, t}(0.95)$ following a Monte Carlo technique explained in Appendix C. The right axes shows the value of the $\operatorname{VaR}_{m, t}(0.95)$ in percentage. The dash-dotted black line indicate the VaR level over time. 
Figure 17a: $\operatorname{CoVaR}_{m \mid o, t}(0.05,0.95)$ for a certain sector given a bullish scenario for oil prices

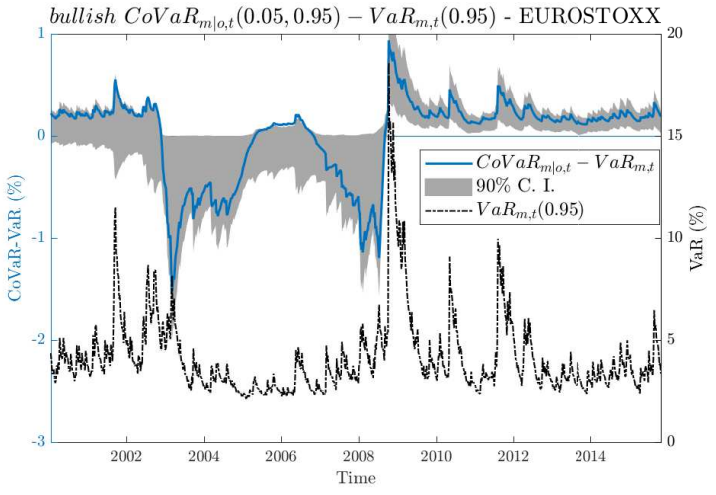

(a) Oil- EUROSTOXX index

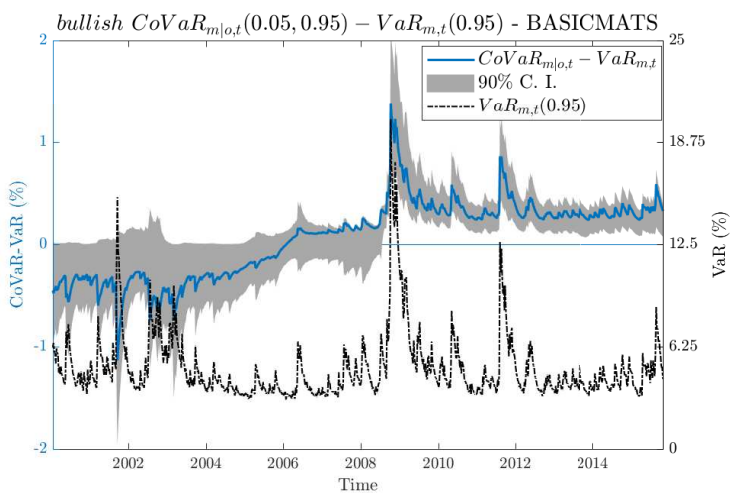

(c) Oil - BASIC MATS sector

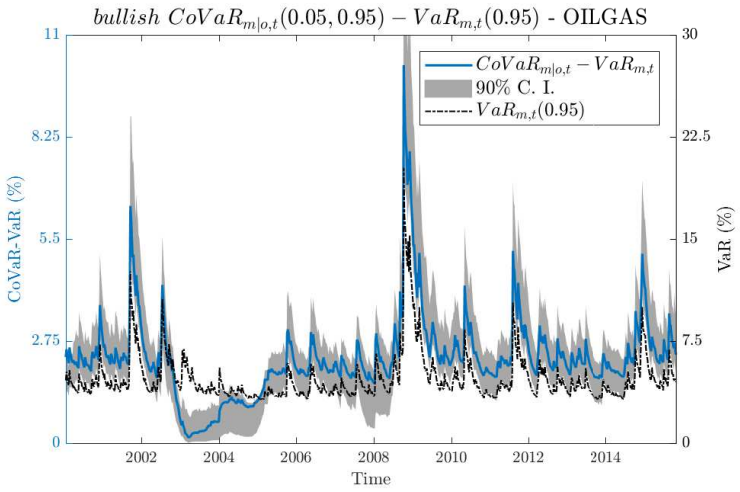

(b) Oil - OIL \& GAS sector

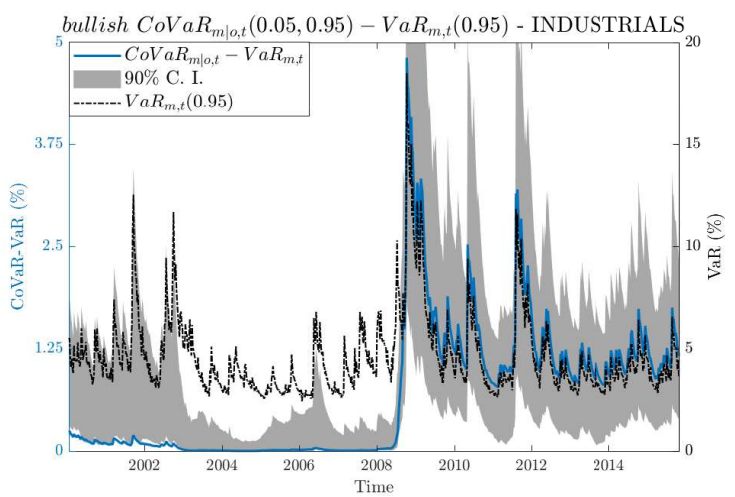

(d) Oil - INDUSTRIALS sector

Left axis shows the difference in percentage between the $\operatorname{CoVaR}_{m, t}(0.05,0.95)$ of the returns for a certain sector under a extreme upward movement in oil prices, i.e. above its 95 -th quantile, and its unconditional $\operatorname{VaR}_{m, t}(0.95)$. Solid blue line shows this difference given the best copula mixture according to Table 6 . Grey area indicates the $90 \%$ confidence interval of the difference between $\operatorname{CoVaR}_{m \mid o, t}(0.05,0.95)$ and $\operatorname{VaR}_{m, t}(0.95)$ following a Monte Carlo technique explained in Appendix C. The right axes shows the value of the $\operatorname{VaR}_{m, t}(0.95)$ in percentage. The dash-dotted black line indicate the VaR level over time. 
Figure 17b: $\operatorname{CoVaR}_{m \mid o, t}(0.05,0.95)$ for a certain sector given a bullish scenario for oil prices

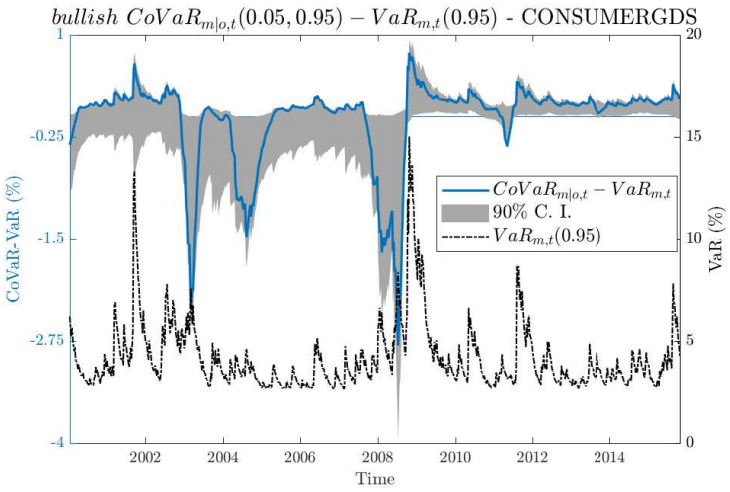

(e) Oil - CONSUMER GDS sector

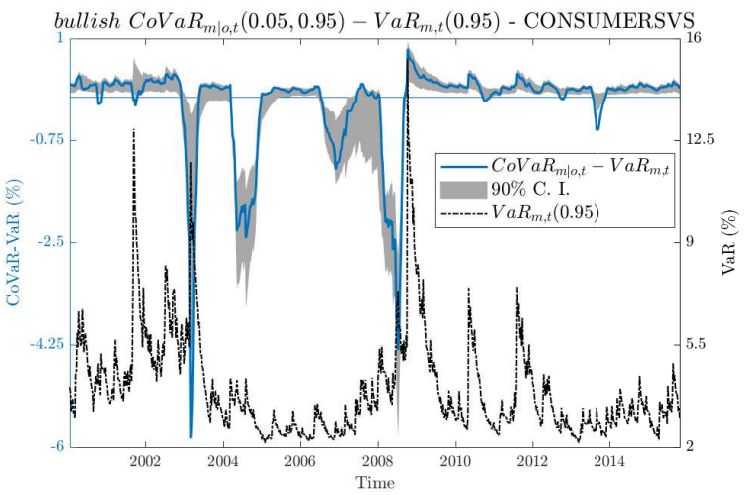

(g) Oil- CONSUMER SVS sector

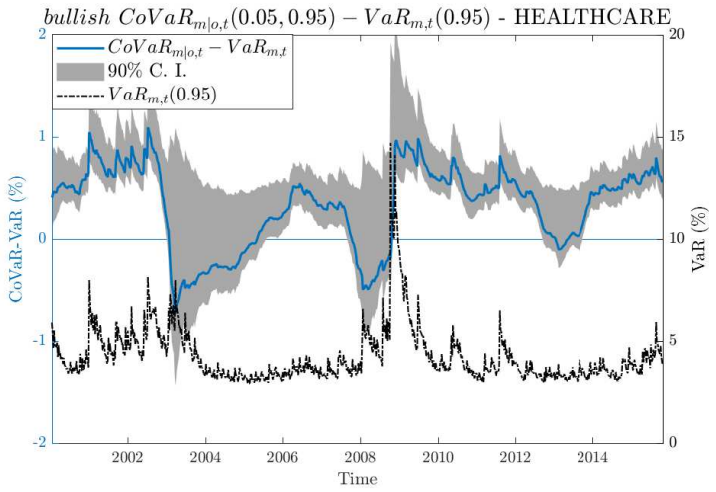

(f) Oil - HEALTH CARE sector

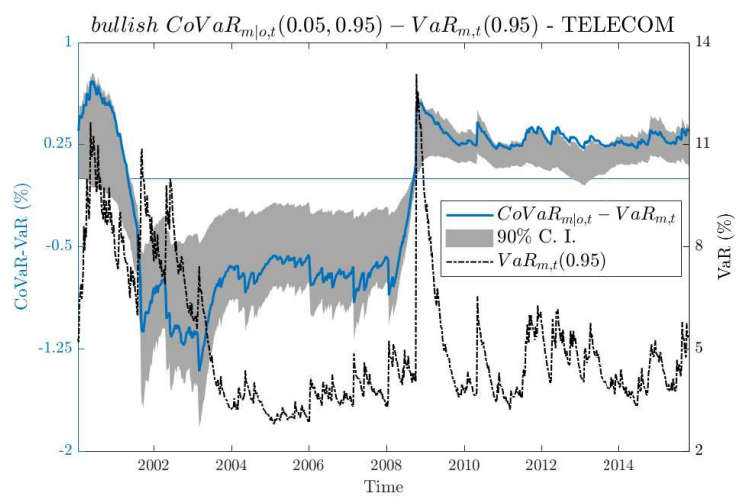

(h) Oil - TELECOM sector

Left axis shows the difference in percentage between the $\operatorname{CoVaR}_{m, t}(0.05,0.95)$ of the returns for a certain sector under a extreme upward movement in oil prices, i.e. above its 95-th quantile, and its unconditional $\operatorname{VaR}_{m, t}(0.95)$. Solid blue line shows this difference given the best copula mixture according to Table 6.Grey area indicates the $90 \%$ confidence interval of the difference between $\operatorname{CoVaR}_{m \mid o, t}(0.05,0.95)$ and $\operatorname{VaR}_{m, t}(0.95)$ following a Monte Carlo technique explained in Appendix C. The right axes shows the value of the $\operatorname{VaR}_{m, t}(0.95)$ in percentage. The dash-dotted black line indicate the VaR level over time. 
Figure 17c: $\operatorname{CoVaR}_{m \mid o, t}(0.05,0.95)$ for a certain sector given a bullish scenario for oil prices

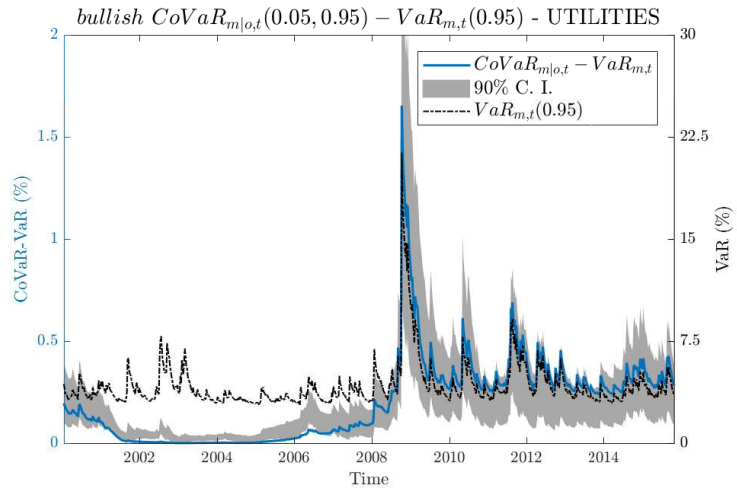

(i) Oil - UTILITIES sector

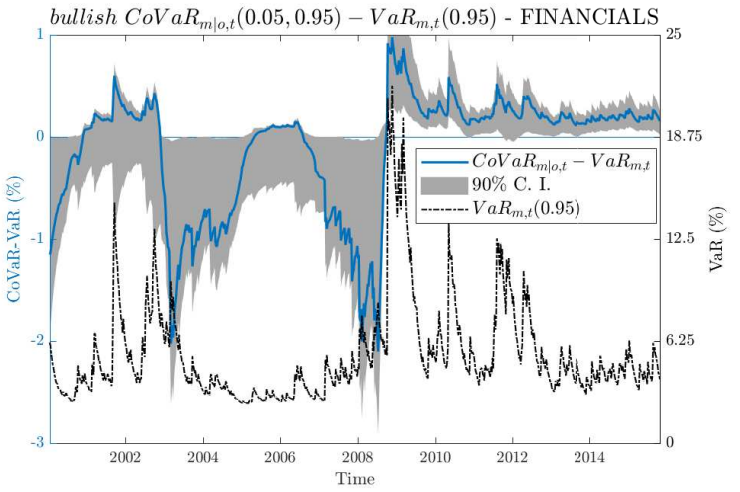

(j) Oil - FINANCIALS sector

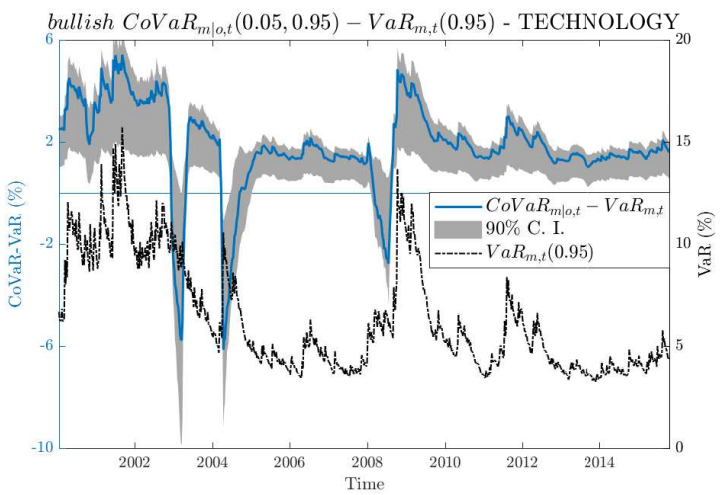

(k) Oil - TECHNOLOGY sector

Left axis shows the difference in percentage between the $\operatorname{CoVaR}_{m, t}(0.05,0.95)$ of the returns for a certain sector under a extreme upward movement in oil prices, i.e. above its 95 -th quantile, and its unconditional $\operatorname{VaR}_{m, t}(0.95)$. Solid blue line shows this difference given the best copula mixture according to Table 6.Grey area indicates the $90 \%$ confidence interval of the difference between $\operatorname{CoVaR}_{m \mid o, t}(0.05,0.95)$ and $\operatorname{VaR}_{m, t}(0.95)$ following a Monte Carlo technique explained in Appendix C. The right axes shows the value of the $\operatorname{VaR}_{m, t}(0.95)$ in percentage. The dash-dotted black line indicate the VaR level over time. 
Figure 18a: $\operatorname{CoES}_{m \mid o, t}(0.05,0.05)$ for a certain sector given a bearish scenario for oil prices

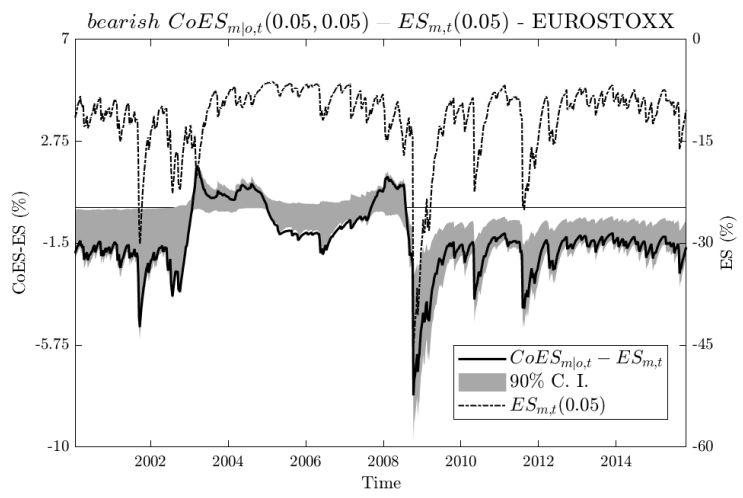

(a) Oil- EUROSTOXX index

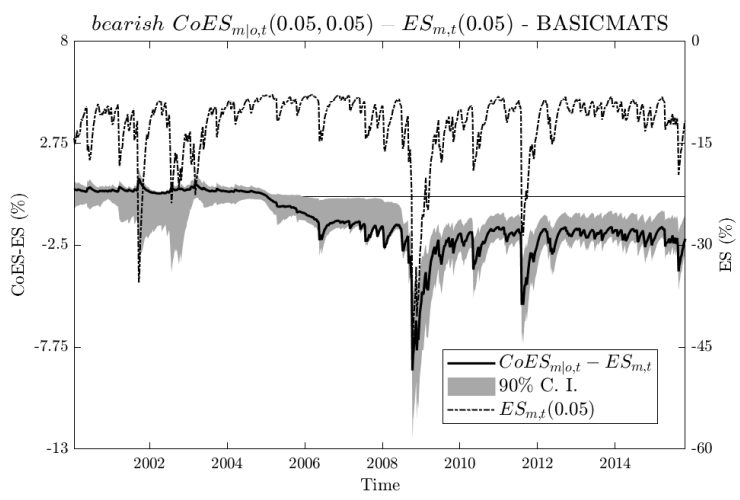

(c) Oil - BASIC MATS sector

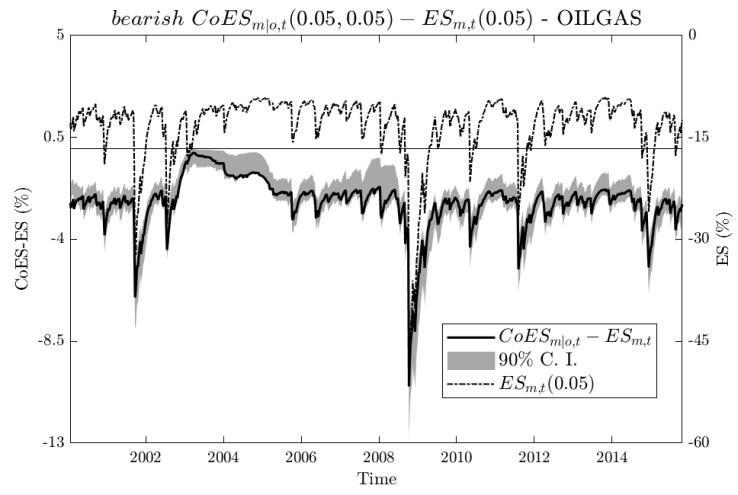

(b) Oil - OIL \& GAS sector

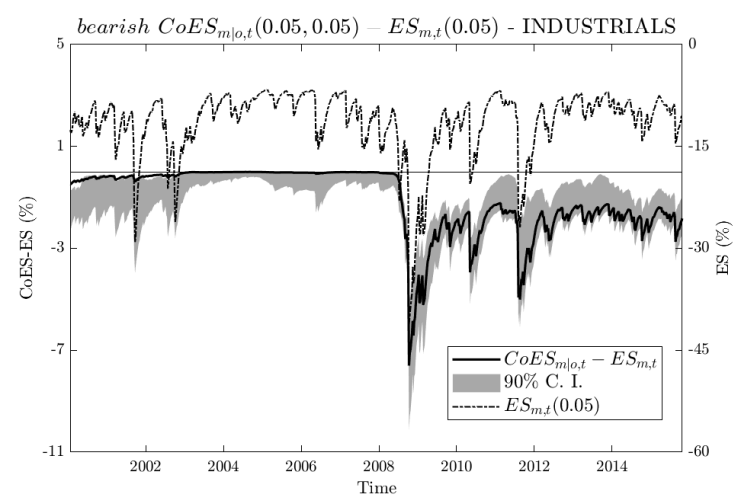

(d) Oil - INDUSTRIALS sector

Left axis shows the difference in percentage between the $\operatorname{CoES}_{m, t}(0.05,0.05)$ of the returns for a certain sector under a extreme downward movement in oil prices, i.e. below its 5 -th quantile, and its unconditional $E S_{m, t}(0.05)$. Solid blue line shows this difference given the best copula mixture according to Table 6 . Grey area indicates the $90 \%$ confidence interval of the difference between $\operatorname{CoES}_{m \mid o, t}(0.05,0.05)$ and $E S_{m, t}(0.05)$ following a Monte Carlo technique explained in Appendix C. The right axes shows the value of the $E S_{m, t}(0.05)$ in percentage. The dash-dotted black line indicate the $E S$ level over time. 
Figure 18b: $\operatorname{CoES}_{m \mid o, t}(0.05,0.05)$ for a certain sector given a bearish scenario for oil prices

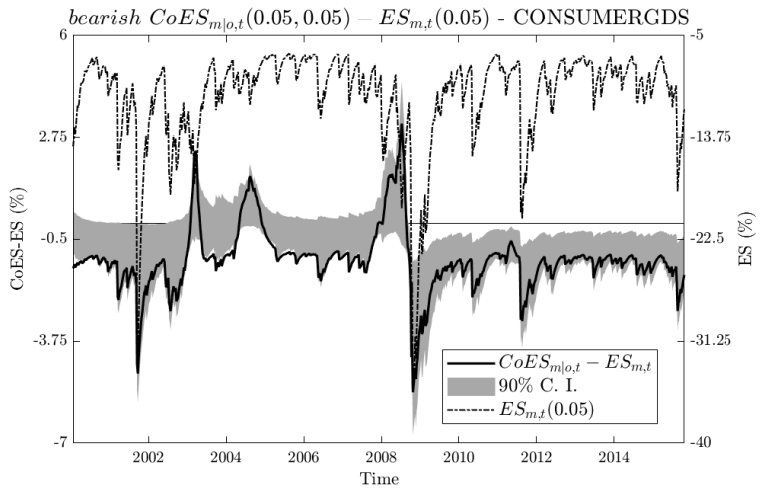

(e) Oil - CONSUMER GDS sector

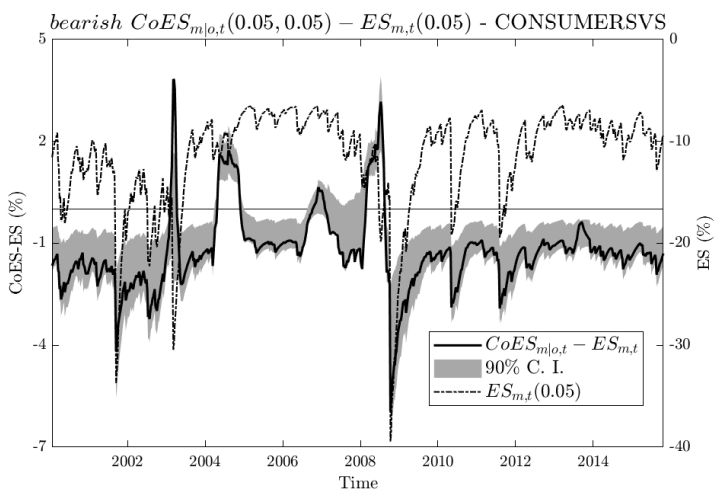

(g) Oil- CONSUMER SVS sector

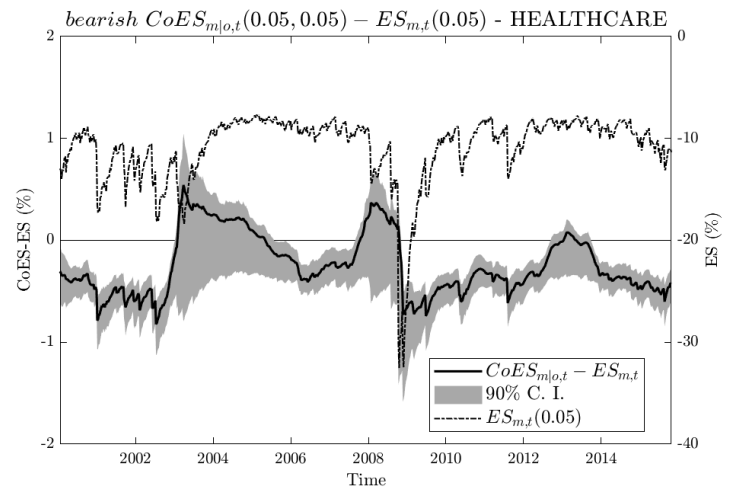

(f) Oil - HEALTH CARE sector

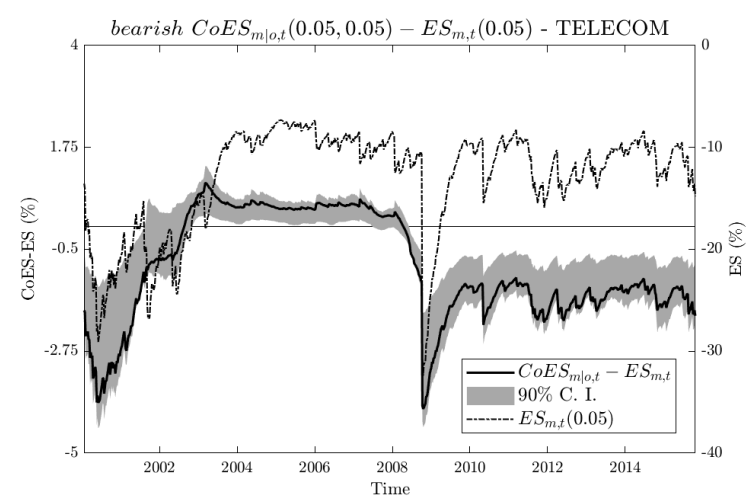

(h) Oil - TELECOM sector

Left axis shows the difference in percentage between the $\operatorname{CoES}_{m, t}(0.05,0.05)$ of the returns for a certain sector under a extreme downward movement in oil prices, i.e. below its 5-th quantile, and its unconditional $E S_{m, t}(0.05)$. Solid blue line shows this difference given the best copula mixture according to Table 6 . Grey area indicates the $90 \%$ confidence interval of the difference between $\operatorname{CoES}_{m \mid o, t}(0.05,0.05)$ and $E S_{m, t}(0.05)$ following a Monte Carlo technique explained in Appendix C. The right axes shows the value of the $\operatorname{VaR}_{m, t}(0.05)$ in percentage. The dash-dotted black line indicate the $E S$ level over time. 
Figure 18c: $\operatorname{CoES}_{m \mid o, t}(0.05,0.05)$ for a certain sector given a bearish scenario for oil prices

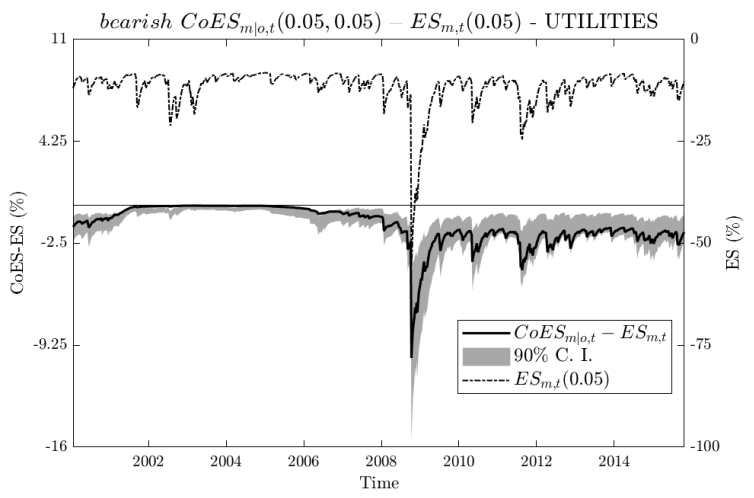

(i) Oil - UTILITIES sector

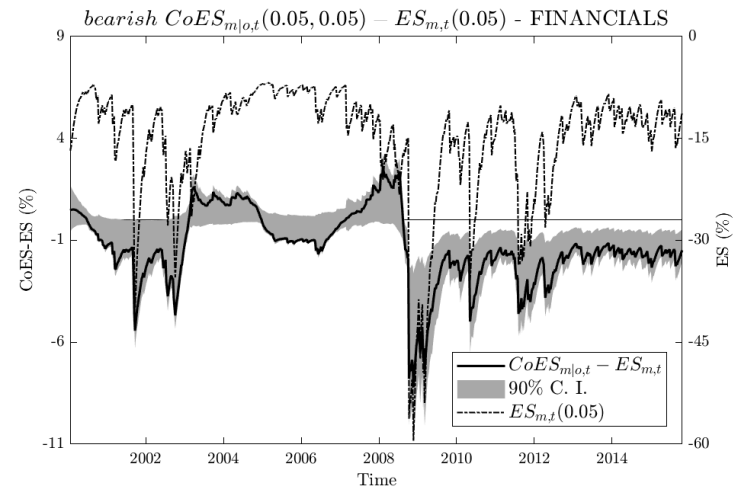

(j) Oil - FINANCIALS sector

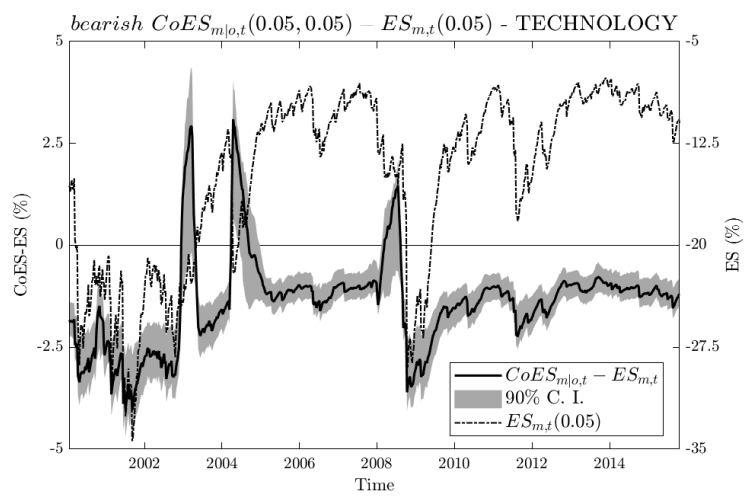

(k) Oil - TECHNOLOGY sector

Left axis shows the difference in percentage between the $\operatorname{CoES}_{m, t}(0.05,0.05)$ of the returns for a certain sector under a extreme downward movement in oil prices, i.e. below its 5-th quantile, and its unconditional $E S_{m, t}(0.05)$. Solid blue line shows this difference given the best copula mixture according to Table 6 . Grey area indicates the $90 \%$ confidence interval of the difference between $\operatorname{CoES}_{m \mid o, t}(0.05,0.05)$ and $E S_{m, t}(0.05)$ following a Monte Carlo technique explained in Appendix C. The right axes shows the value of the $E S_{m, t}(0.05)$ in percentage. The dash-dotted black line indicate the $E S$ level over time. 
Figure 19a: $\operatorname{CoES}_{m \mid 0, t}(0.05,0.05)$ for a certain sector given a bearish scenario for oil prices

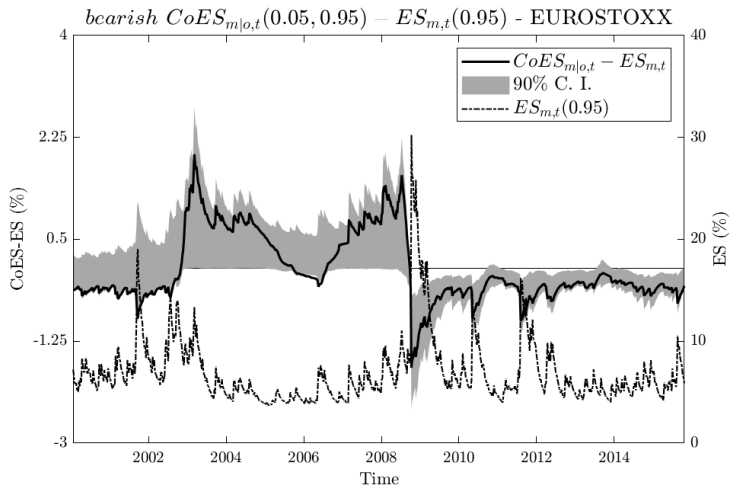

(a) Oil- EUROSTOXX index

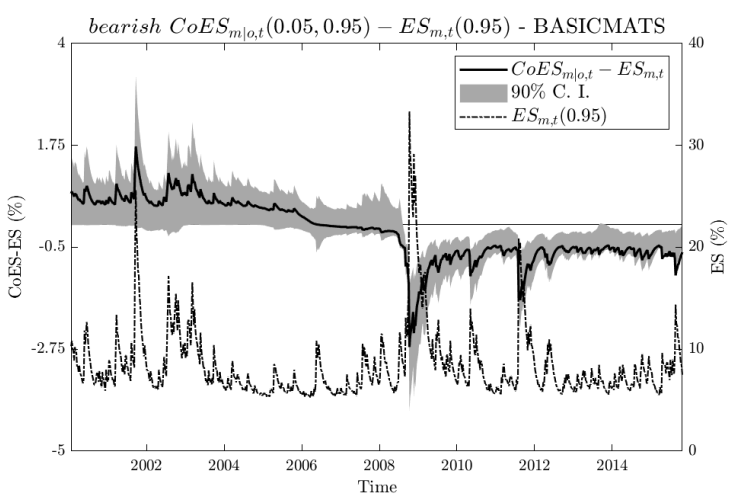

(c) Oil - BASIC MATS sector

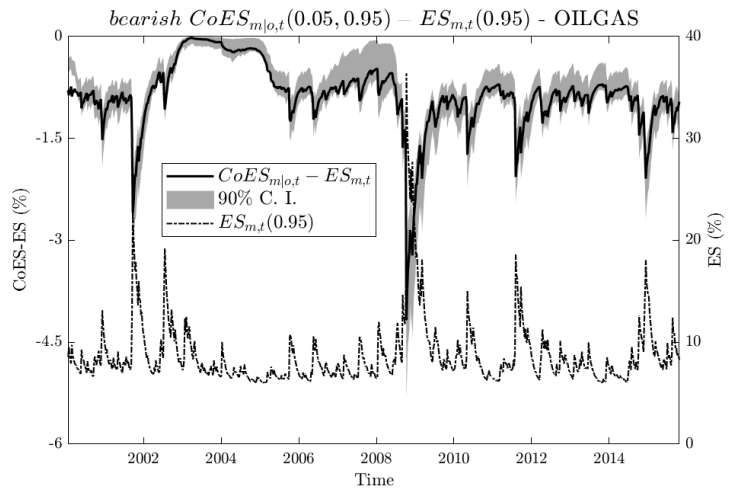

(b) Oil - OIL \& GAS sector

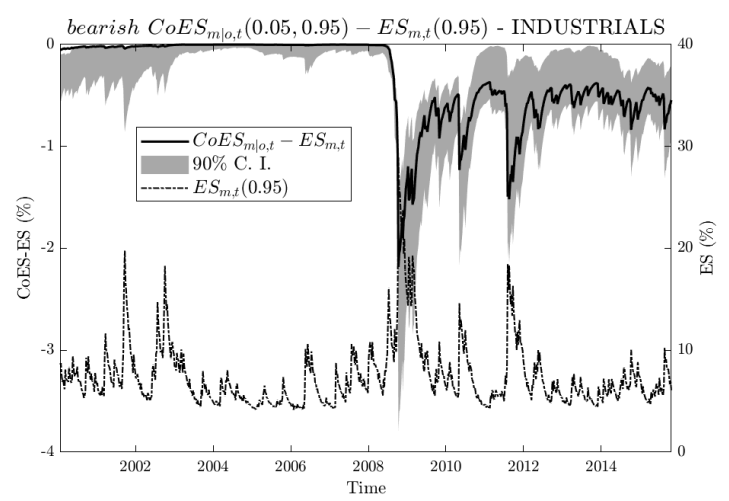

(d) Oil - INDUSTRIALS sector

Left axis shows the difference in percentage between the $\operatorname{CoES}_{m, t}(0.05,0.05)$ of the returns for a certain sector under a extreme downward movement in oil prices, i.e. below its 5-th quantile, and its unconditional $E S_{m, t}(0.05)$. Solid blue line shows this difference given the best copula mixture according to Table 6 . Grey area indicates the $90 \%$ confidence interval of the difference between $\operatorname{CoES}_{m \mid o, t}(0.05,0.95)$ and $E S_{m, t}(0.05)$ following a Monte Carlo technique explained in Appendix C. The right axes shows the value of the $E S_{m, t}(0.05)$ in percentage. The dash-dotted black line indicate the $E S$ level over time. 
Figure 19b: $\operatorname{CoES}_{m \mid o, t}(0.05,0.05)$ for a certain sector given a bearish scenario for oil prices

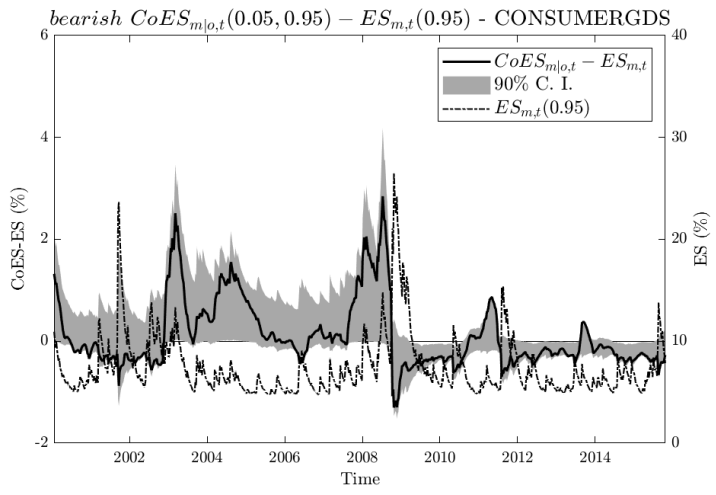

(e) Oil - CONSUMER GDS sector

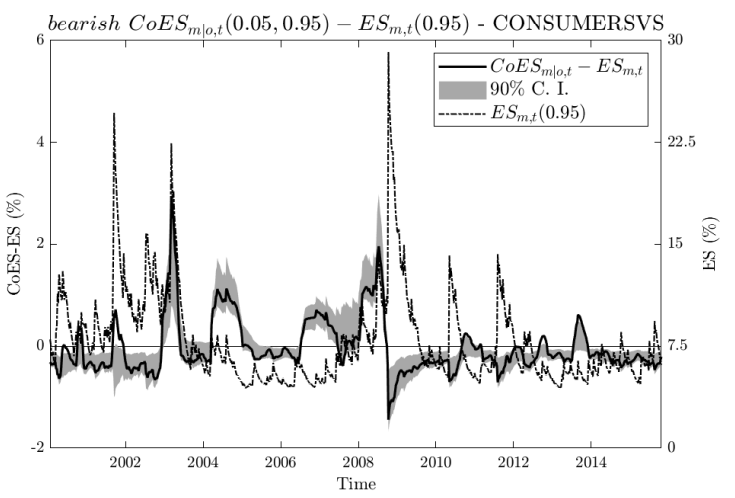

(g) Oil- CONSUMER SVS sector

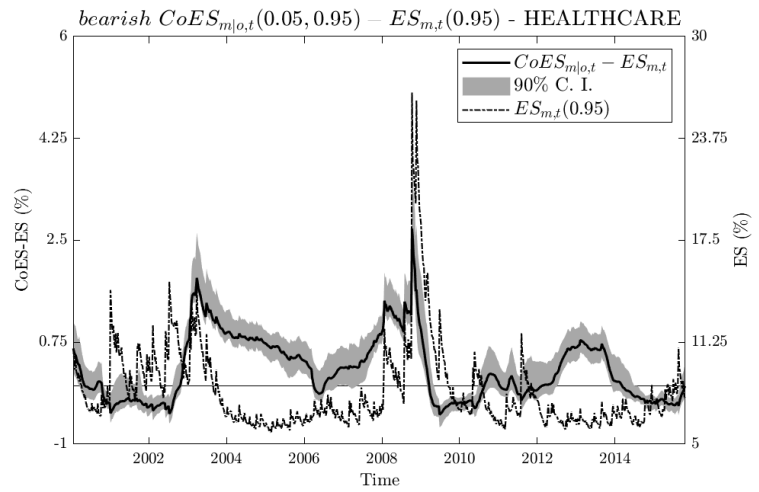

(f) Oil - HEALTH CARE sector

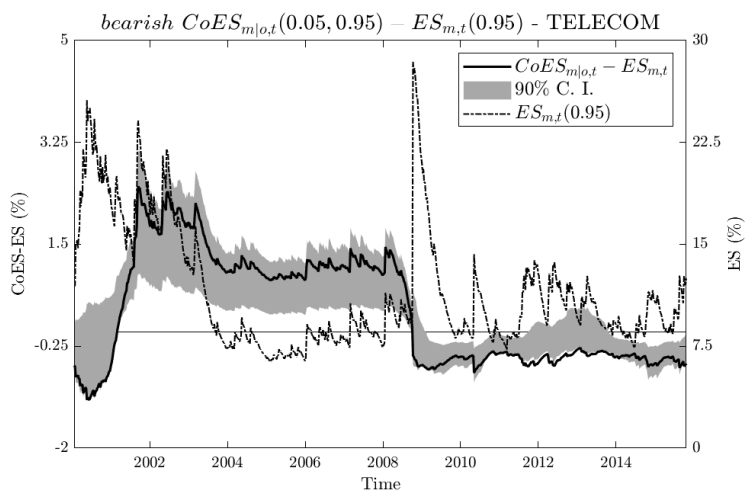

(h) Oil - TELECOM sector

Left axis shows the difference in percentage between the $\operatorname{CoES}_{m, t}(0.05,0.05)$ of the returns for a certain sector under a extreme downward movement in oil prices, i.e. below its 5-th quantile, and its unconditional $E S_{m, t}(0.05)$. Solid blue line shows this difference given the best copula mixture according to Table 6 . Grey area indicates the $90 \%$ confidence interval of the difference between $\operatorname{CoES}_{m \mid o, t}(0.05,0.05)$ and $E S_{m, t}(0.05)$ following a Monte Carlo technique explained in Appendix C. The right axes shows the value of the $E S_{m, t}(0.05)$ in percentage. The dash-dotted black line indicate the $E S$ level over time. 
Figure 19c: $\operatorname{CoES}_{m \mid o, t}(0.05,0.05)$ for a certain sector given a bearish scenario for oil prices

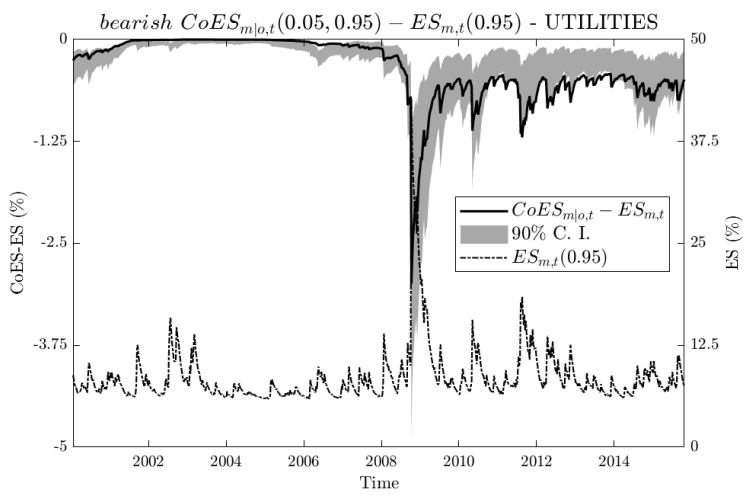

(i) Oil - UTILITIES sector

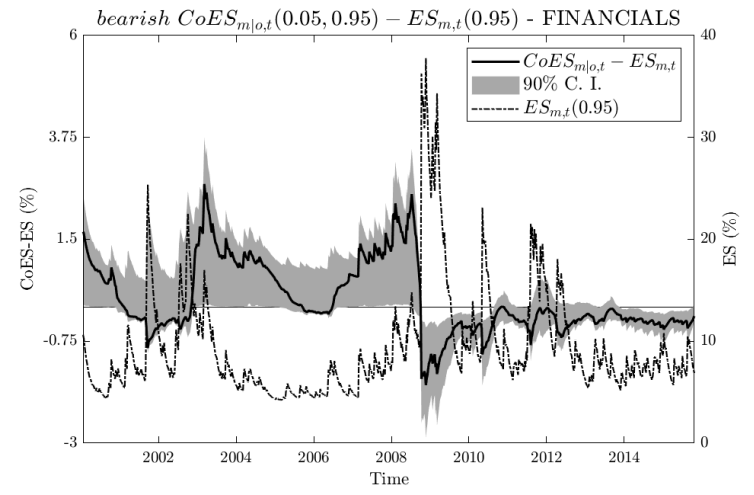

(j) Oil - FINANCIALS sector

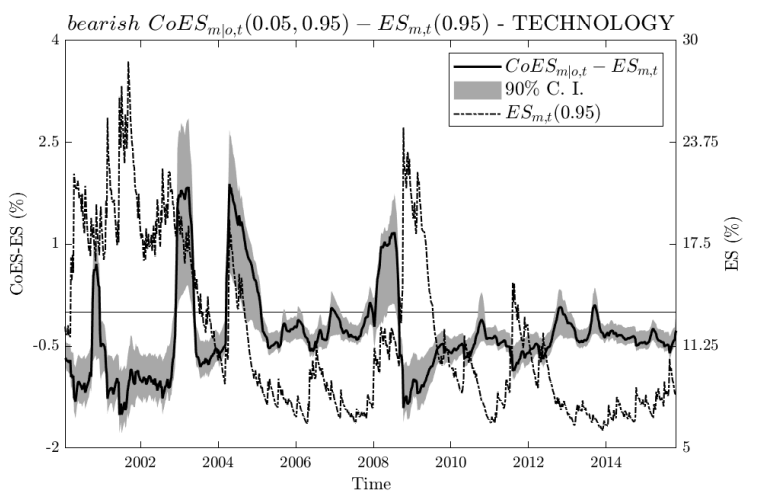

(k) Oil - TECHNOLOGY sector

Left axis shows the difference in percentage between the $\operatorname{CoES}_{m, t}(0.05,0.05)$ of the returns for a certain sector under a extreme downward movement in oil prices, i.e. below its 5-th quantile, and its unconditional $E S_{m, t}(0.05)$. Solid blue line shows this difference given the best copula mixture according to Table 6 . Grey area indicates the $90 \%$ confidence interval of the difference between $\operatorname{CoES}_{m \mid o, t}(0.05,0.05)$ and $E S_{m, t}(0.05)$ following a Monte Carlo technique explained in Appendix C. The right axes shows the value of the $E S_{m, t}(0.05)$ in percentage. The dash-dotted black line indicate the $E S$ level over time. 
Figure 20a: $\operatorname{CoES}_{m \mid o, t}(0.05,0.05)$ for a certain sector given a bullish scenario for oil prices

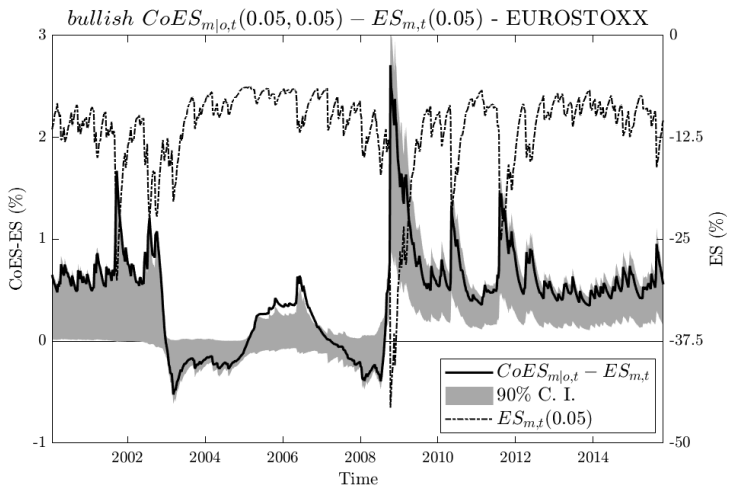

(a) Oil- EUROSTOXX index

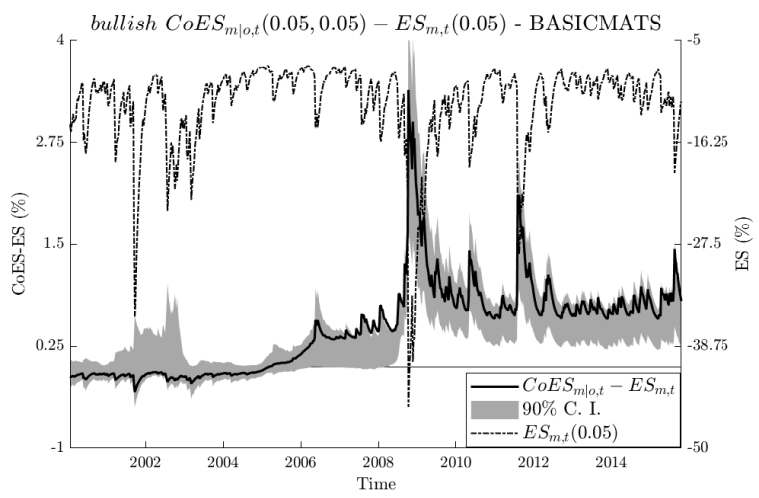

(c) Oil - BASIC MATS sector

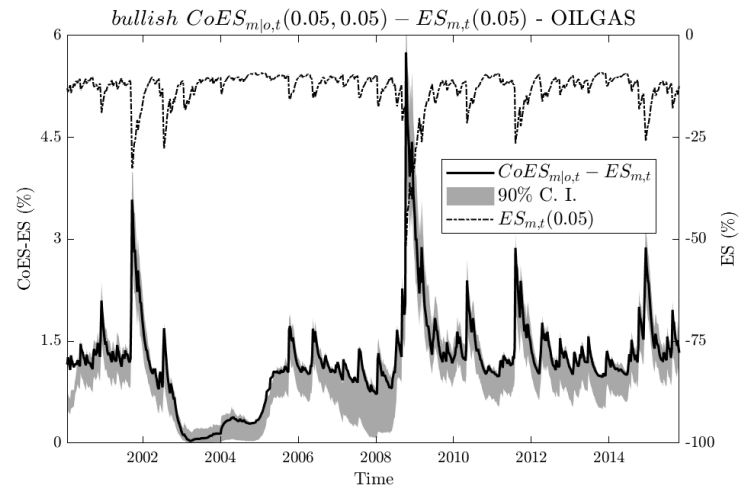

(b) Oil - OIL \& GAS sector

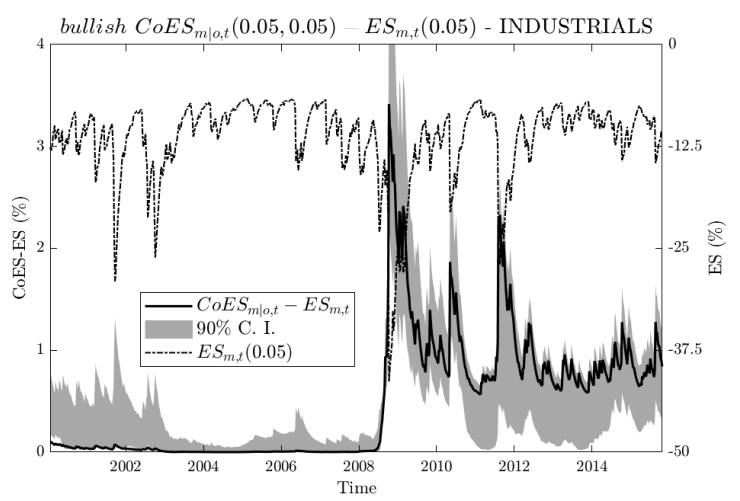

(d) Oil - INDUSTRIALS sector

Left axis shows the difference in percentage between the $\operatorname{CoES}_{m, t}(0.05,0.05)$ of the returns for a certain sector under a extreme upward movement in oil prices, i.e. above its 95 -th quantile, and its unconditional $E S_{m, t}(0.05)$. Solid blue line shows this difference given the best copula mixture according to Table 6 . Grey area indicates the $90 \%$ confidence interval of the difference between $\operatorname{CoES}_{m \mid o, t}(0.05,0.05)$ and $E S_{m, t}(0.05)$ following a Monte Carlo technique explained in Appendix C. The right axes shows the value of the $E S_{m, t}(0.05)$ in percentage. The dash-dotted black line indicate the $E S$ level over time. 
Figure 20b: $\operatorname{CoES} S_{m \mid o, t}(0.05,0.05)$ for a certain sector given a bullish scenario for oil prices

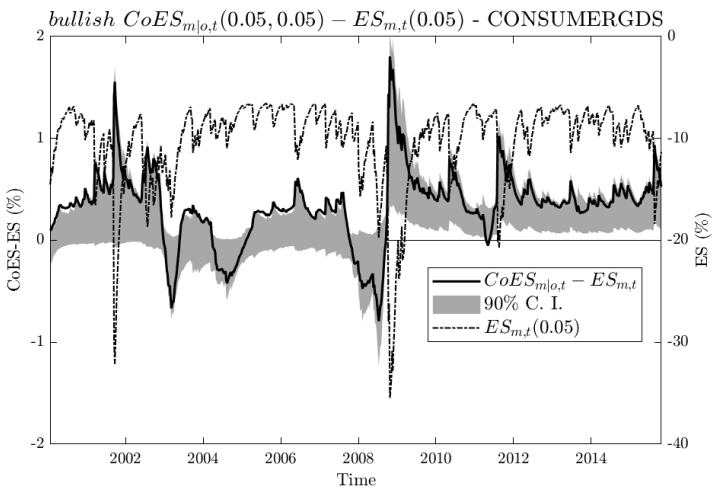

(e) Oil - CONSUMER GDS sector

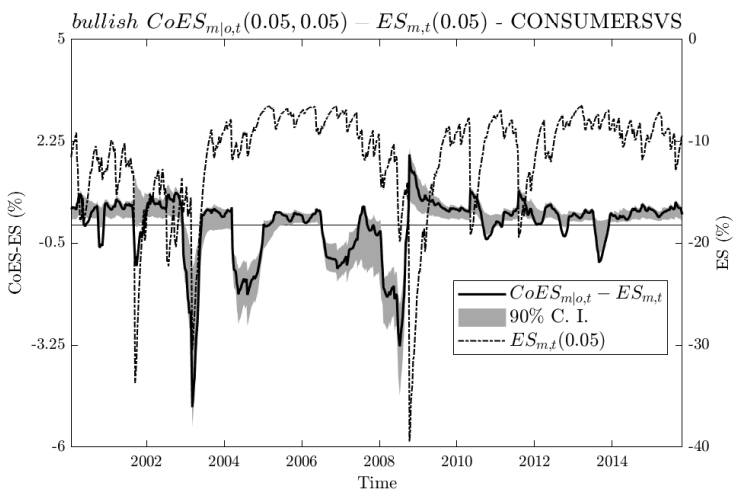

(g) Oil- CONSUMER SVS sector

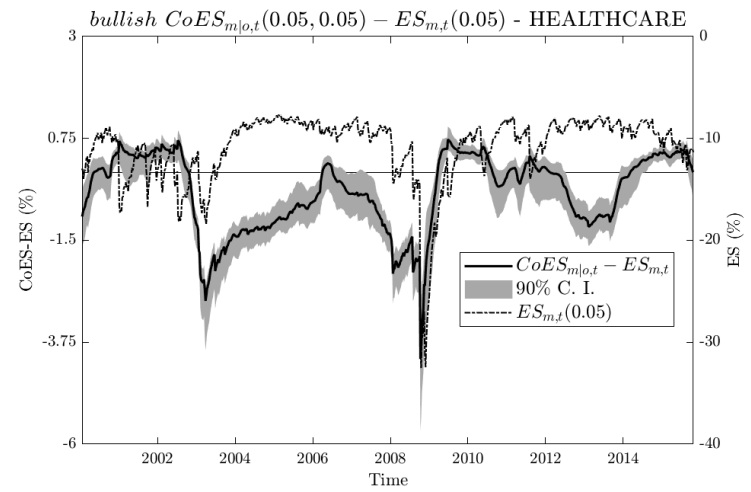

(f) Oil - HEALTH CARE sector

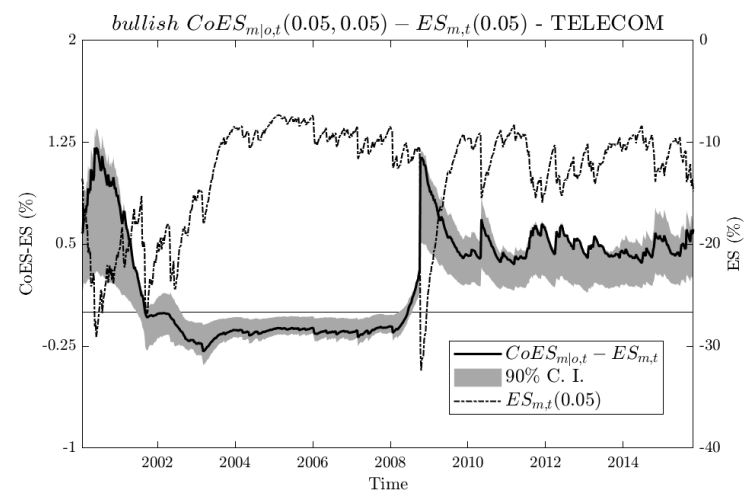

(h) Oil - TELECOM sector

Left axis shows the difference in percentage between the $\operatorname{CoES}_{m, t}(0.05,0.05)$ of the returns for a certain sector under a extreme upward movement in oil prices, i.e. above its 95 -th quantile, and its unconditional $E S_{m, t}(0.05)$. Solid blue line shows this difference given the best copula mixture according to Table 6.Grey area indicates the $90 \%$ confidence interval of the difference between $\operatorname{CoES}_{m \mid o, t}(0.05,0.05)$ and $E S_{m, t}(0.05)$ following a Monte Carlo technique explained in Appendix C. The right axes shows the value of the $E S_{m, t}(0.05)$ in percentage. The dash-dotted black line indicate the $E S$ level over time. 
Figure 20c: $\operatorname{CoES}_{m \mid o, t}(0.05,0.05)$ for a certain sector given a bullish scenario for oil prices

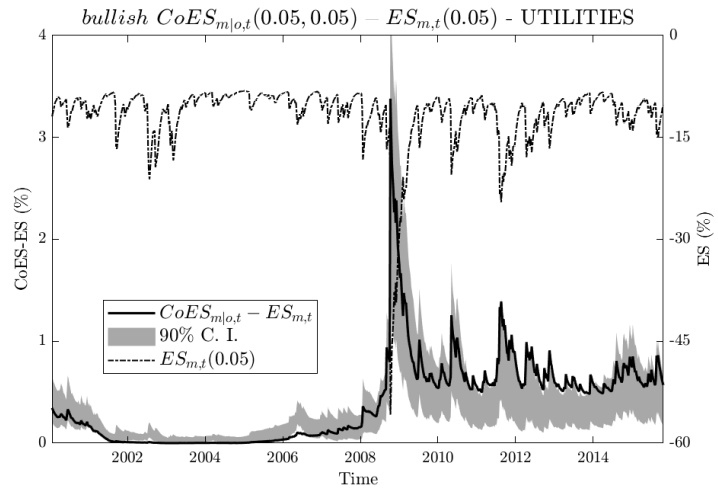

(i) Oil - UTILITIES sector

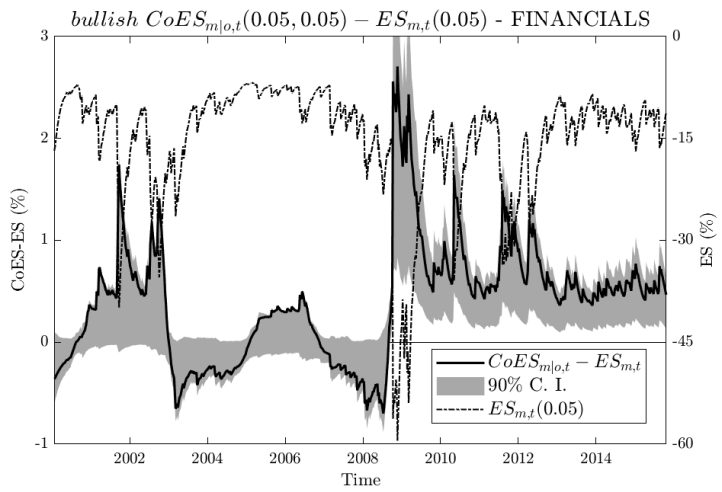

(j) Oil - FINANCIALS sector

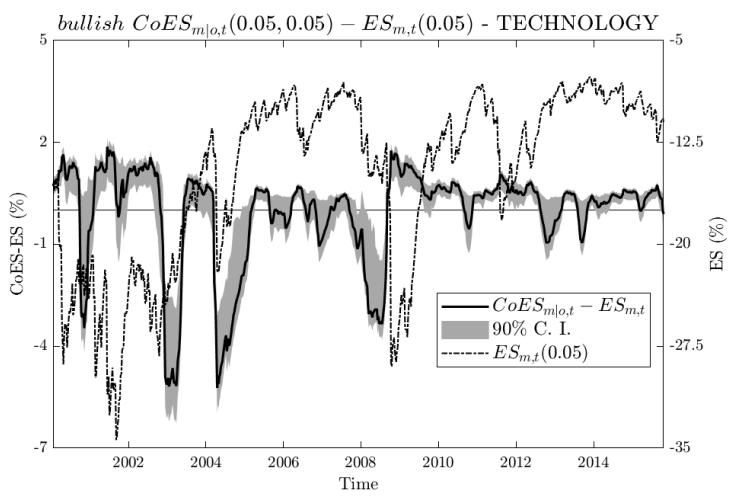

(k) Oil - TECHNOLOGY sector

Left axis shows the difference in percentage between the $\operatorname{CoES} S_{m, t}(0.05,0.05)$ of the returns for a certain sector under a extreme upward movement in oil prices, i.e. above its 95 -th quantile, and its unconditional $E S_{m, t}(0.05)$. Solid blue line shows this difference given the best copula mixture according to Table 6.Grey area indicates the $90 \%$ confidence interval of the difference between $\operatorname{CoES}_{m \mid o, t}(0.05,0.05)$ and $E S_{m, t}(0.05)$ following a Monte Carlo technique explained in Appendix C. The right axes shows the value of the $E S_{m, t}(0.05)$ in percentage. The dash-dotted black line indicate the $E S$ level over time. 
Figure 21a: $\operatorname{CoES}_{m \mid 0, t}(0.05,0.95)$ for a certain sector given a bearish scenario for oil prices

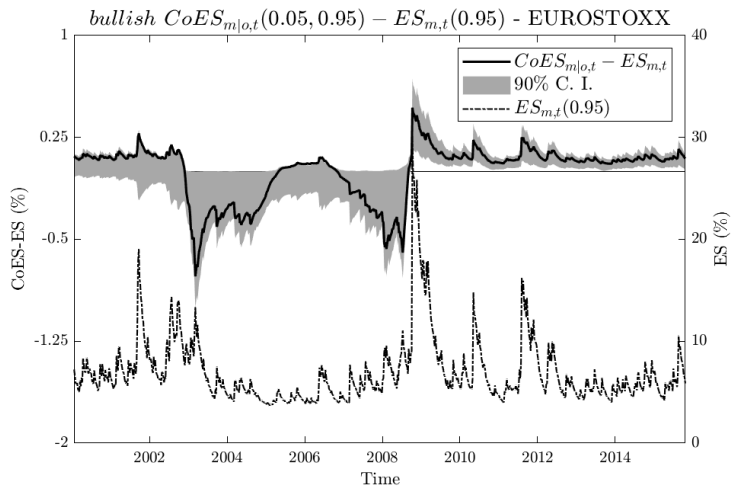

(a) Oil- EUROSTOXX index

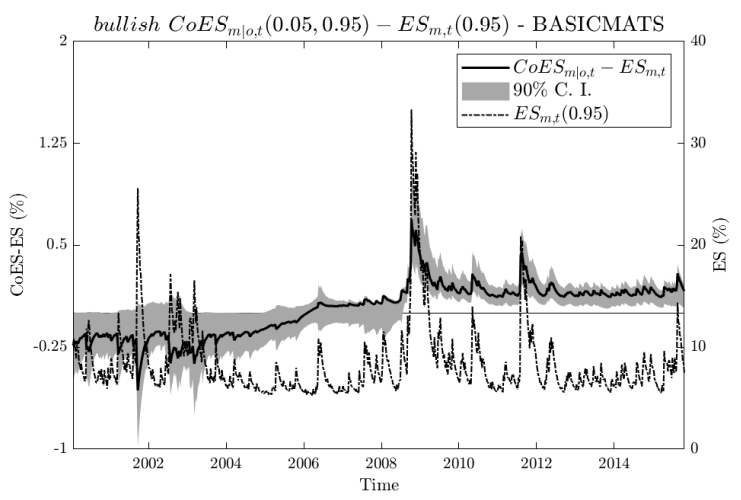

(c) Oil - BASIC MATS sector

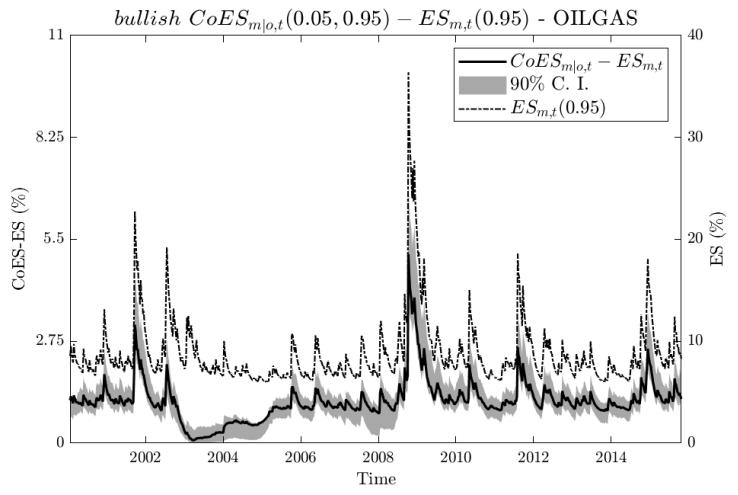

(b) Oil - OIL \& GAS sector

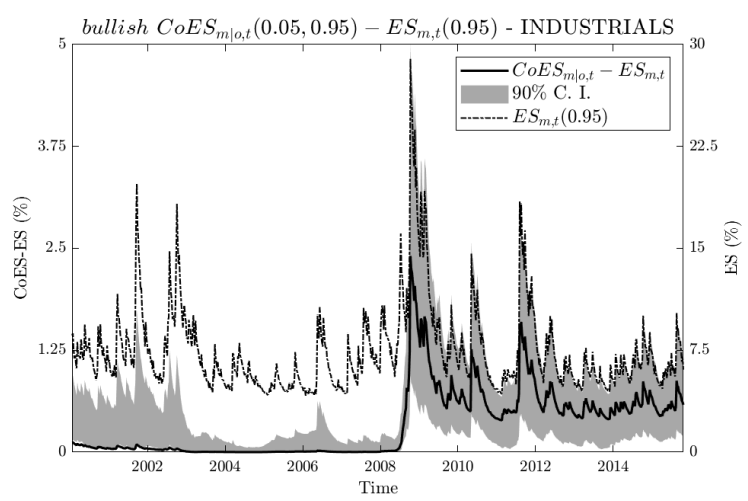

(d) Oil - INDUSTRIALS sector

Left axis shows the difference in percentage between the $\operatorname{CoES}_{m, t}(0.05,0.95)$ of the returns for a certain sector under a extreme downward movement in oil prices, i.e. below its 5-th quantile, and its unconditional $E S_{m, t}(0.95)$. Solid blue line shows this difference given the best copula mixture according to Table 6 . Grey area indicates the $90 \%$ confidence interval of the difference between $\operatorname{CoES}_{m \mid o, t}(0.05,0.95)$ and $E S_{m, t}(0.95)$ following a Monte Carlo technique explained in Appendix C. The right axes shows the value of the $E S_{m, t}(0.95)$ in percentage. The dash-dotted black line indicate the $E S$ level over time. 
Figure 21b: $\operatorname{CoES}_{m \mid 0, t}(0.05,0.95)$ for a certain sector given a bearish scenario for oil prices

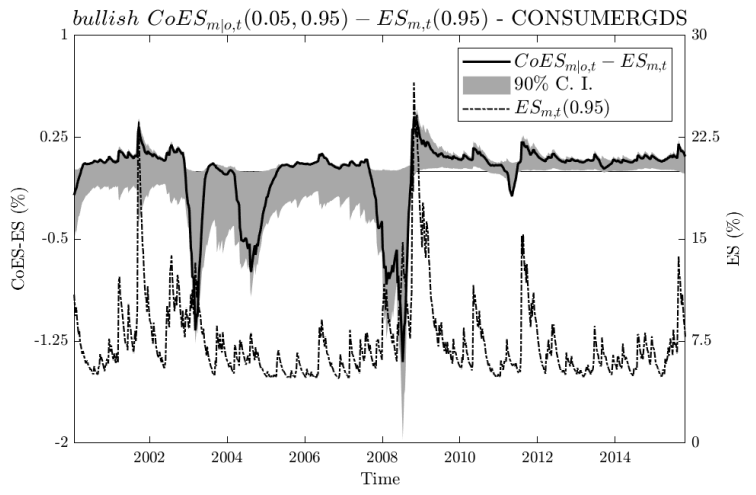

(e) Oil - CONSUMER GDS sector

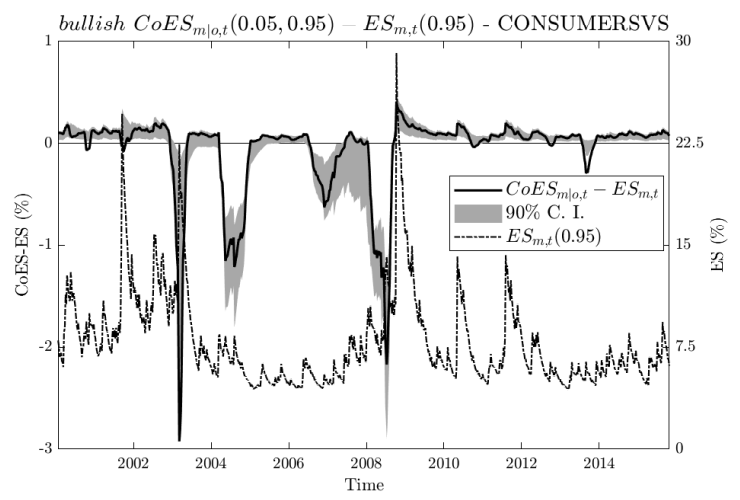

(g) Oil- CONSUMER SVS sector

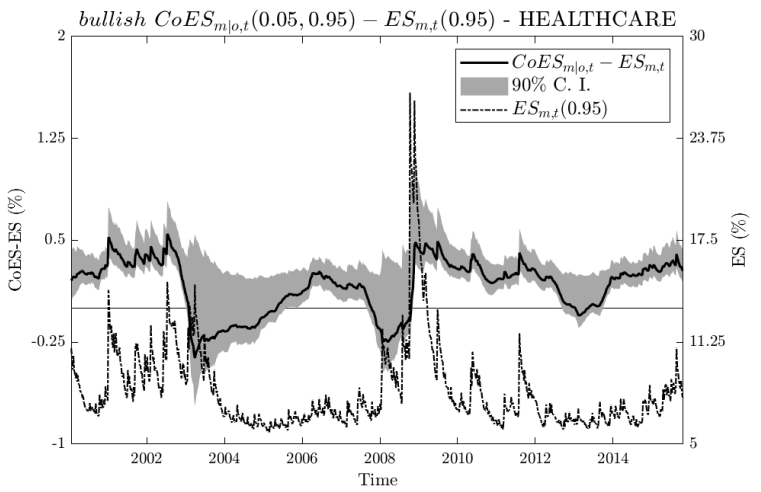

(f) Oil - HEALTH CARE sector

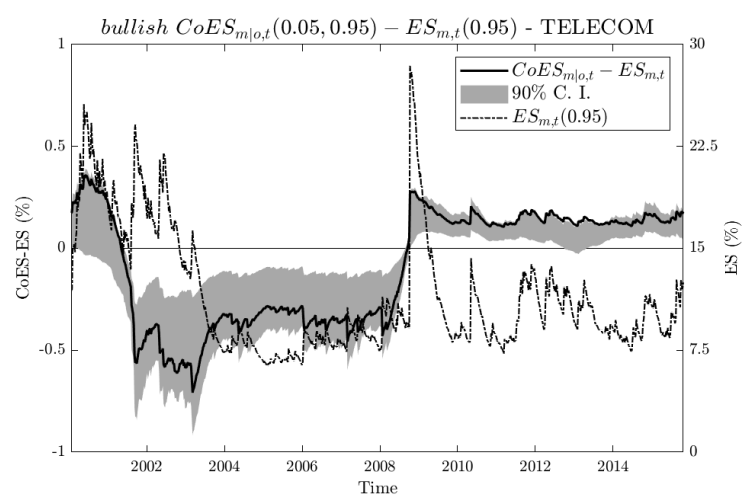

(h) Oil - TELECOM sector

Left axis shows the difference in percentage between the $\operatorname{CoES}_{m, t}(0.05,0.95)$ of the returns for a certain sector under a extreme downward movement in oil prices, i.e. below its 5-th quantile, and its unconditional $E S_{m, t}(0.95)$. Solid blue line shows this difference given the best copula mixture according to Table 6 . Grey area indicates the $90 \%$ confidence interval of the difference between $\operatorname{CoES}_{m \mid o, t}(0.05,0.95)$ and $E S_{m, t}(0.95)$ following a Monte Carlo technique explained in Appendix C. The right axes shows the value of the $E S_{m, t}(0.95)$ in percentage. The dash-dotted black line indicate the $E S$ level over time. 
Figure 21c: $\operatorname{CoES}_{m \mid o, t}(0.05,0.95)$ for a certain sector given a bearish scenario for oil prices

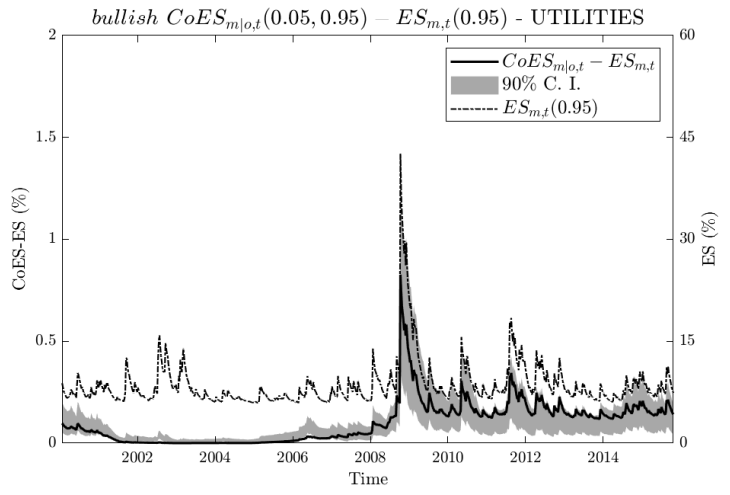

(i) Oil - UTILITIES sector

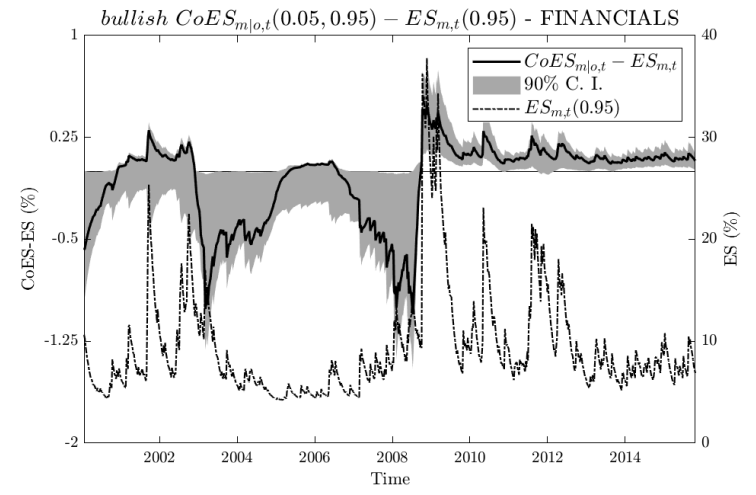

(j) Oil - FINANCIALS sector

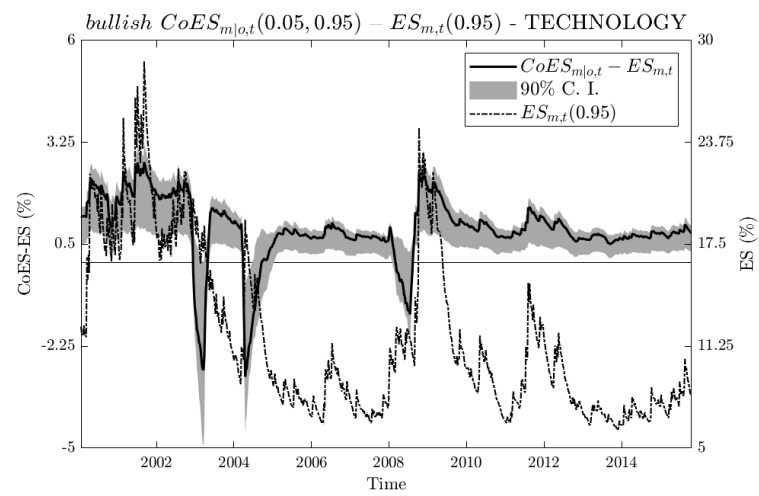

(k) Oil - TECHNOLOGY sector

Left axis shows the difference in percentage between the $\operatorname{CoES}_{m, t}(0.05,0.95)$ of the returns for a certain sector under a extreme downward movement in oil prices, i.e. below its 5-th quantile, and its unconditional $E S_{m, t}(0.95)$. Solid blue line shows this difference given the best copula mixture according to Table 6 . Grey area indicates the $90 \%$ confidence interval of the difference between $\operatorname{CoES}_{m \mid 0, t}(0.05,0.95)$ and $E S_{m, t}(0.95)$ following a Monte Carlo technique explained in Appendix C. The right axes shows the value of the $E S_{m, t}(0.95)$ in percentage. The dash-dotted black line indicate the $E S$ level over time. 


\section{References}

[1] Aas, K., C. Czado, A. Frigessi, and H. Bakken (2009). Pair-copula constructions of multiple dependence. Insurance Math. Econom. 44(2), 182-198.

[2] Abadie, A. (2002). Bootstrap tests for distributional treatment effects in instrumental variable models. J. Amer. Statist. Assoc. 97(457), 284-292.

[3] Acerbi, C. and D. Tasche (2002). On the coherence of expected shortfall. J. Bank. Financ. 26(7), 1487-1503.

[4] Adrian, T. and M. K. Brunnermeier (2016). CoVaR. Am. Econ. Rev. 106(7), 1705-1741.

[5] Aloui, C. and R. Jammazi (2009). The effects of crude oil shocks on stock market shifts behaviour: A regime switching approach. Energy Econ. 31(5), 789-799.

[6] Aloui, R., S. Hammoudeh, and D. K. Nguyen (2013). A time-varying copula approach to oil and stock market dependence: The case of transition economies. Energy Econ. 39, 208-221.

[7] Andreopoulos, S. (2009). Oil matters: Real input prices and U.S. unemployment revisited. B.E. J. Macroecon. 9(1), 31 pages.

[8] Ao, S.-I., H. K. Kim, and M. A. Amouzegar (2015). Transactions on Engineering Technologies. Springer, Dordrecht.

[9] Apergis, N. and S. M. Miller (2009). Do structural oil-market shocks affect stock prices? Energy Econ. 31(4), 569-575.

[10] Arouri, M., J. Jouini, and D. K. Nguyen (2011). Volatility spillovers between oil prices and stock sector returns: Implications for portfolio management. J. Int. Money Finance 30(7), 1387-1405.

[11] Arouri, M., J. Jouini, and D. K. Nguyen (2012). On the impacts of oil price fluctuations on European equity markets: Volatility spillover and hedging effectiveness. Energy Econ. 34(2), 611-617.

[12] Arouri, M. and D. K. Nguyen (2010). Oil prices, stock markets and portfolio investment: Evidence from sector analysis in Europe over the last decade. Energy Policy 38(8), 4528-4539.

[13] Aussenegg, W. and C. Cech (2011). Simple time-varying copula estimation. Available at https://ssrn.com/abstract=1313714.

[14] Balcilar, M., R. Gupta, and S. M. Miller (2015). Regime switching model of US crude oil and stock market prices: 1859 to 2013. Energy Econ. 49, 317-327.

[15] Bauwens, L., A. Preminger, and J. V. K. Rombouts (2010). Theory and inference for a Markov switching GARCH model. Econom. J. 13(2), 218-244.

[16] Bernal, O., J.-Y. Gnabo, and G. Guilmin (2014). Assessing the contribution of banks, insurance and other financial services to systemic risk. J. Bank. Finance 47, 270-287.

[17] Boyer, M. M. and D. Filion (2007). Common and fundamental factors in stock returns of Canadian oil and gas companies. Energy Econ. 29(3), 428-453.

[18] Brechmann, E. C. and U. Schepsmeier (2013). Modeling dependence with C- and D-vine copulas in R. J. Stat. Softw. 52(3), $1-25$.

[19] Cai, J. (1994). A Markov model of switching-regime ARCH. J. Bus. Econ. Stat. 12(3), 309-316.

[20] Cech, C. (2006). Copula-based top-down approaches in financial risk aggregation. Available at https://ssrn.com/abstract= 953888.

[21] Chen, N.-F., R. Roll, and S. A. Ross (1986). Economic forces and the stock market. J. Bus. 59(3), 383-403.

[22] Cherubini, U., F. Gobbi, and S. Mulinacci (2016). Convolution Copula Econometrics. Springer, Cham.

[23] Ciner, C. (2001). Energy shocks and financial markets: nonlinear linkages. Stud. Nonlinear Dynam. Econometrics 5(3), 11 pages.

[24] Clements, M. P. and H.-M. Krolzig (2002). Can oil shocks explain asymmetries in the US business cycle? Emp. Econ. 27(2), 185-204.

[25] Cologni, A. and M. Manera (2009). The asymmetric effects of oil shocks on output growth: A Markov-switching analysis for the G-7 countries. Econ. Model. 26(1), 1-29.

[26] Delle Chiaie, S., L. Ferrara, and D. Giannone (2017). Common factors of commodity prices. Available at https://ideas.repec. org/p/bfr/banfra/645.html.

[27] Demarta, S. and A. J. McNeil (2005). The t copula and related copulas. Int. Stat. Rev. 73(1), 111-129.

[28] Fernández Casillas, E., R. Pérez Sánchez, and J. Ruiz Andújar (2012). Análisis dinámico del impacto de los shocks en el precio del petróleo sobre el empleo por sectores productivos. Econ. Ind. 384, 85-98.

[29] Fischer, M. J. (2003). Tailoring copula-based multivariate generalized hyperbolic secant distributions to financial return data: an empirical investigation. Available at https://www.econstor.eu/handle/10419/29595.

[30] Genest, C. and L.-P. Rivest (1993). Statistical inference procedures for bivariate Archimedean copulas. J. Amer. Statist. Assoc. 88(423), 1034-1043.

[31] Georges, P., A.-G. Lamy, E. Nicolas, G. Quibel, and T. Roncalli (2001). Multivariate survival modelling: A unified approach with copulas. Available at https://ssrn.com/abstract=1032559.

[32] Girardi, G. and A. T. Ergün (2013). Systemic risk measurement: Multivariate GARCH estimation of CoVaR. J. Bank. Finance 37(8), 3169-3180.

[33] Haas, M., S. Mittnik, and M. S. Paolella (2004). A new approach to Markov-switching GARCH models. J. Financial Econom. 2(4), 493-530.

[34] Hamilton, J. D. (1994). Time Series Analysis. Princeton University Press. 
[35] Hamilton, J. D. and R. Susmel (1994). Autoregressive conditional heteroskedasticity and changes in regime. J. Econom. 64(12), 307-333.

[36] Hamilton, J. D. (1983). Oil and the macroeconomy since World War II. J. Political Econ. 91(2), 228-248.

[37] Hamilton, J. D. and G. Lin (1996). Stock market volatility and the business cycle. J. Appl. Econom. 11(5), 573-593.

[38] Hansen, B. E. (1994). Autoregressive conditional density estimation. Int. Econ. Rev. 35(3), 705-730.

[39] Holmes, M. and P. Wang (2003). Oil price shocks and the asymmetric adjustment of UK output: a Markov-switching approach. Int. Rev. Appl. Econ. 17(2), 181-192.

[40] Hooker, M. A. (1999). Oil and the macroeconomy revisited. Available at https://ssrn.com/abstract=186014.

[41] Huang, R. D., R. W. Masulis, and H. R. Stoll (1996). Energy shocks and financial markets. J. Futures Mark. 16(1), 1-27.

[42] Huang, W.-Q. and S. Uryasev (2018). The CoCVaR approach: systemic risk contribution measurement. J. Risk 20(4), 75-93.

[43] Hurvich, C. M. and C.-L. Tsai (1989). Regression and time series model selection in small samples. Biometrika 76(2), 297307.

[44] Jiang, C. (2012). Does tail dependence make a difference in the estimation of systemic risk? Available at https://www2.bc. edu/chuanliang-jiang/Job_Market_Paper.pdf.

[45] Joe, H. (1997). Multivariate Models and Multivariate Dependence Concepts. CRC Press, Boca Raton FL.

[46] Joe, H. and T. Hu (1996). Multivariate distributions from mixtures of max-infinitely divisible distributions. J. Multivar. Anal. 57(2), 240-265.

[47] Kim, C.-J. (1994). Dynamic linear models with Markov-switching. J. Econom. 60(1-2), 1-22.

[48] Lee, B.-J., C. W. Yang, and B.-N. Huang (2012). Oil price movements and stock markets revisited: A case of sector stock price indexes in the G-7 countries. Energy Econ. 34(5), 1284-1300.

[49] Luo, J. (2011). Stepwise Estimation of D-Vines with Arbitrary Specified Copula Pairs and EDA Tools. Diploma thesis, Technische Universität München, Germany. Available at https://mediatum.ub.tum.de/doc/1079291/1079291.pdf.

[50] Manner, H. and O. Reznikova (2012). A survey on time-varying copulas: Specification, simulations, and application. Econom. Rev. 31(6), 654-687.

[51] Mensi, W., S. Hammoudeh, S. J. H. Shahzad, and M. Shahbaz (2017). Modeling systemic risk and dependence structure between oil and stock markets using a variational mode decomposition-based copula method. J. Bank. Finance 75, 258279.

[52] Meyer, C. (2013). The bivariate normal copula. Commun. Stat. - Theory Methods 42(13), 2402-2422.

[53] Mork, K. A. (1989). Oil and the macroeconomy when prices go up and down: an extension of Hamilton's results. J. Political Econ. 97(3), 740-744.

[54] Moya-Martínez, P., R. Ferrer-Lapeña, and F. Escribano-Sotos (2014). Oil price risk in the Spanish stock market: An industry perspective. Econ. Model. 37, 280-290.

[55] Nandha, M. and R. Brooks (2009). Oil prices and transport sector returns: an international analysis. Rev. Quant. Finan. Acc. 33(4), 393-409.

[56] Nguyen, C. C. and M. I. Bhatti (2012). Copula model dependency between oil prices and stock markets: Evidence from China and Vietnam. J. Int. Finan. Markets, Inst. Money 22(4), 758-773.

[57] Nicoloutsopoulos, D. (2005). Parametric and Bayesian Non-parametric Estimation of Copulas. PhD thesis, University College London, U.K. Available at http://www.gatsby.ucl.ac.uk/ dilan/docs_mljc/dimitris.pdf.

[58] Ojea Ferreiro, J. (2018). Contagion spillovers between sovereign and financial European sector from a delta CoVaR approach. Available at https://ideas.repec.org/p/ucm/doicae/1812.html.

[59] Pappadà, R., F. Durante, and N. Torelli (2018). A graphical tool for copula selection based on tail dependence. In F. Mola, C. Conversano, and M. Vichi (Eds.), Classification,(Big) Data Analysis and Statistical Learning, pp. 211-218. Springer, Cham.

[60] Park, J. and R. A. Ratti (2008). Oil price shocks and stock markets in the U.S. and 13 European countries. Energy Econ. 30(5), 2587-2608.

[61] Patton, A. J. (2006). Modelling asymmetric exchange rate dependence. Int. Econ. Rev. 47(2), 527-556.

[62] Ramos, S. B. and H. Veiga (2013). Oil price asymmetric effects: Answering the puzzle in international stock markets. Energy Econ. 38, 136-145.

[63] Raymond, J. E. and R. W. Rich (1997). Oil and the macroeconomy: A Markov state-switching approach. J. Money Credit Bank. 29(2), 193-213.

[64] Reboredo, J. C. (2010). Nonlinear effects of oil shocks on stock returns: a Markov-switching approach. Appl. Econ. 42(29), 3735-3744.

[65] Reboredo, J. C. (2011). How do crude oil prices co-move?: A copula approach. Energy Econ. 33(5), 948-955.

[66] Reboredo, J. C. and A. Ugolini (2015a). A vine-copula conditional value-at-risk approach to systemic sovereign debt risk for the financial sector. N. Amer. J. Econ. Finance 32, 98-123.

[67] Reboredo, J. C. and A. Ugolini (2015b). Downside/upside price spillovers between precious metals: A vine copula approach. N. Amer. J. Econ. Finance 34, 84-102.

[68] Reboredo, J. C. and A. Ugolini (2016). Quantile dependence of oil price movements and stock returns. Energy Econ. 54, 33-49.

[69] Rodriguez, J. C. (2007). Measuring financial contagion: A copula approach. J. Empirical Finance 14(3), 401-423.

[70] Sadorsky, P. (2001). Risk factors in stock returns of Canadian oil and gas companies. Energy Econ. 23(1), 17-28. 
[71] Schepsmeier, U. (2010). Maximum Likelihood Estimation of C-Vine Pair-Copula Constructions based on Bivariate Copulas from Different Families. PhD thesis, Technische Universität München, Germany. Available at https://mediatum.ub.tum.de/ doc/1079296/file.pdf.

[72] Sklar, A. (1959). Fonctions de répartition à n dimensions et leurs marges. Publ. Inst. Statist. Univ. Paris 8, 229-231.

[73] Sukcharoen, K., T. Zohrabyan, D. Leatham, and X. Wu (2014). Interdependence of oil prices and stock market indices: A copula approach. Energy Econ. 44, 331-339.

[74] Venter, G. G. (2002). Tails of copulas. Proceedings of the Casualty Actuarial Society 89(170 \& 171), pp. 68-113.

[75] Wen, X., Y. Wei, and D. Huang (2012). Measuring contagion between energy market and stock market during financial crisis: A copula approach. Energy Econ. 34(5), 1435-1446.

[76] Zhang, M.-H. (2008). Modelling total tail dependence along diagonals. Insurance Math. Econom. 42(1), 73-80.

[77] Zhu, H., H. Huang, C. Peng, and Y. Yang (2016). Extreme dependence between crude oil and stock markets in Asia-Pacific regions: Evidence from quantile regression. Available at http://www.economics-ejournal.org/economics/discussionpapers/ 2016-46. 